\title{
On the possibility of using organic molecules in the characterization of subsurface processes
}

\author{
Dissertation \\ zur Erlangung des Doktorgrades \\ der Mathematisch-Naturwissenschaftlichen Fakultäten \\ der Georg-August-Universität zu Göttingen
}

vorgelegt von

Mario Schaffer

aus Dresden

Göttingen 2013 
D 7

Referent:

Prof. Dr. Martin Sauter

Georg-August-Universität Göttingen

Korreferenten:

Prof. Dr. Eckhard Worch

Technische Universität Dresden

Dr. Tobias Licha

Georg-August-Universität Göttingen

Tag der mündlichen Prüfung:

4. April 2013 


\section{Short Summary}

Nowadays, tracer tests represent an important part in the repertoire of hydro(geo)logical characterization techniques. For determining hydromechanical parameters of and flow properties within a reservoir or an aquifer, conservative tracer compounds are usually the applied chemicals of choice. This means that these compounds behave inert and, thus, interact only negligible during their residence time in the investigated geosystem. In contrast, the use of non-conservative organic molecules as tracers is a novel approach. Here, additional information on subsurface processes may be provided when the molecules interact in a known way with certain components of the considered system. However, the interpretation of the tracer behavior requires a sufficient a priori knowledge on processes and influence factors affecting the tracer transport. Since sorption is probably the most relevant physicochemical transport process for numerous organic solutes in the subsurface, the systematic investigation of sorption processes including their relation to molecular properties and boundary conditions was a main focus of the presented cummulative thesis. In addition, the derived implications on tracer transport were directly incorporated into the design of a new reactive reservoir tracer for geological storage of $\mathrm{CO}_{2}$.

In order to get a general overview on the sorption of organic compounds with different functionalities, the $\mathrm{pH}$-dependent transport of several ionizable pharmaceuticals (acids, bases, zwitter) was investigated by using sediment column experiments. The sorption coefficients were determined and compared with two correlation approaches. As a result, a strong $\mathrm{pH}$-dependence of sorption was found for all compounds with $\mathrm{p} K_{a}$ values in or near the studied $\mathrm{pH}$ range. However, an appropriate prediction of sorption was only feasible for neutral and anionic (acidic) compounds. In contrast, the sorption of cationic (bases) and zwitter-ionic compounds was stronger than expected indicating the occurrence of additional electrostatic sorption mechanisms, which are not considered in the conventional concepts. 
Consequently, cation exchange processes were expected to have a significant influence on the retardation of organic cations in the subsurface. The dominating role of cation exchange processes was demonstrated for two cationic beta-blockers in column experiments. Higher concentrations of inorganic cations in solution led to lower sorption of the organic cation due to increased competition for the negatively charged sorbent exchange sites. The contribution of non-hydrophobic interactions to the overall sorption was estimated with $>99 \%$. Due to the importance of cation exchange, more influence factors have to be considered for the successful prediction of the transport of organic cations in the subsurface.

As a first step towards the systematic consideration of further influence factors, the role of competing inorganic cations on the sorption of organic cations was studied in batch experiments. Sorption isotherms for the cationic beta-blocker metoprolol on sediment were obtained for varying background concentrations of competing inorganic ions. The obtained data showed that the influence of competing $\mathrm{Ca}^{2+}$ on the sorption of metoprolol is stronger than for $\mathrm{Na}^{+}$. The found correlation between the Freundlich sorption coefficient and the concentration of competing inorganic ions allows the prediction of metoprolol sorption within the investigated range of boundary conditions. Furthermore, the contribution of sorptive interactions to the organic carbon of the sediment was determined to be negligible. Therefore, the results improve the process understanding and help to improve predicting the subsurface transport of organic cations.

Eventually, the concept and the design of a new reactive tracer (KIS tracer) intended for the characterization of interfacial areas during injections of supercritical $\mathrm{CO}_{2}$ into deep saline aquifers is presented. Due to an interface-sensitive hydrolysis reaction with known kinetics the temporal study of the $\mathrm{CO}_{2}$ /brine interfacial area is feasible. Based on the findings from previous investigations, the conservative organic anion naphthalenesulfonate was selected as base structure for the ester synthesis (esterification) and, thus, also as hydrolysis product. Beside the definition of required tracer properties, first promising compounds were synthesized, tested in the laboratory, and evaluated with a newly developed macroscopic model. Furthermore, the numerical forward modeling of the tracer behavior is exemplarily described for several hypothetical functions of the interfacial area change. The first results are promising and provide first insight into the potential of KIS tracers. 


\section{Kurzfassung}

Tracertests stellen heute einen integralen Bestandteil im Repertoire der hydro(geo)logischen Charakterisierungstechniken dar. Insbesondere konservative Stoffe werden zur Bestimmung von hydraulischen Reservoir- und Aquiferparametern eingesetzt. Diese Stoffe verhalten sich weitestgehend inert und unterliegen somit nur vernachlässigbaren physikochemischen Wechselwirkungen während ihrer Verweilzeit im untersuchten Geosystem. Im Gegensatz dazu stellt der Einsatz nichtkonservativer organischer Stoffe als Tracer einen relativ neuen Ansatz dar, welcher das Potential birgt, zusätzliche Informationen zu ablaufenden Untergrundprozessen zu gewinnen, sofern die Wechselwirkungsarten und somit das Tracerverhalten bekannt sind. Folglich ist die genaue Kenntnis potentieller Transportprozesse und deren Abhängigkeiten eine unabdingbare Voraussetzung für eine erfolgreiche Interpretation dieser Tracer. In diesem Zusammenhang ist die Sorption an Festphasen für zahlreiche gelöste organische Verbindungen der wohl bedeutendste physikochemische Transportprozess. Aus diesem Grund ist die systematische Untersuchung von Sorptionsprozessen und deren Abhängigkeiten von den Moleküleigenschaften bzw. Randbedingungen ein Hauptbestandteil der hier vorgestellten, kumulativen Dissertationsschrift. Die aus den Sorptionsuntersuchungen abgeleiteten Schlussfolgerungen wurden in die Entwicklung eines neuen, reaktiven Reservoir-Tracers für die geologische Speicherung von $\mathrm{CO}_{2}$ mit einbezogen.

Um einen Überblick über das Sorptionsverhalten organischer Verbindungen mit unterschiedlichen Funktionalitäten zu gewinnen, wurde zunächst der pH-abhängige Stofftransport mehrerer dissoziierbarer Arzneimittelwirkstoffe (Säuren, Basen, Zwitter) mit Hilfe von Sedimentsäulenexperimenten untersucht. Hierzu wurden die Sorptionskoeffizienten bestimmt und mit den vorausberechneten Ergebnissen zweier Korrelationsansätze verglichen. Eine starke pH-Abhängigkeit zeigte die Sorption für alle Moleküle mit einem $\mathrm{p} K_{S}$-Wert im oder nahe des untersuchten $\mathrm{pH}$ Bereiches. Eine zufriedenstellende Vorhersage war nur für neutrale und anionsche 
(saure) Verbindungen möglich. Im Gegensatz dazu war die Sorption der kationischen (basischen) und zwitter-ionischen Verbindungen stärker als erwartet. Als Ursache dafür kann das Auftreten zusätzlicher, elektrostatischer Sorptionsmechanismen angesehen werden, welche in den konventionellen Korrelationsansätzen nicht berücksichtigt werden.

Somit konnte unter anderem erwartet werden, dass auch Kationenaustausch einen signifikanten Prozess für die Retardation organischer Kationen im Untergrund darstellt. Mit zwei kationischen Beta-Blockern durchgeführte Säulenversuche belegen die dominierende Rolle von Kationenaustauschprozessen. Steigende Konzentrationen anorganischer Kationen führen aufgrund der verstärkten Konkurrenz um die Austauscherplätze des Sorbens zu einer geringeren Sorption der organischen Kationen. Der Beitrag nicht-hydrophober Wechselwirkungen zur Gesamtsorption konnte mit $>99 \%$ abgeschätzt werden. Aufgrund der großen Bedeutung von Kationenaustauschprozessen sollten weitere Einflussfaktoren berücksichtigt werden, um den Transport organischer Kationen zuverlässig vorhersagen zu können.

Daher wurde anschließend der Einfluss konkurrierender anorganischer Kationen auf die Sorption organischer Kationen in Wasser/Sediment-Batchtests systematisch untersucht. Die bei verschiedenen Hintergrundkonzentrationen an anorganischen Kationen aufgenommenen Sorptionsisothermen des kationischen Beta-Blockers Metoprolol zeigten eine deutlich stärkere Beeinflussung der Sorption durch $\mathrm{Ca}^{2+}$ als durch $\mathrm{Na}^{+}$. Durch die gefundene Korrelation zwischen dem Freundlich-Koeffizienten und der Konzentration anorganischer Kationen wird eine Vorhersage der MetoprololSorption im Bereich der untersuchten Randbedingungen möglich. Zudem konnte der Beitrag sorptiver Wechselwirkungen zum organischen Kohlenstoff des Sediments als vernachlässigbar bestimmt werden. Insgesamt liefern die erzielten Ergebnisse einen weiteren wichtigen Beitrag zur Prozessbeschreibung der Sorption und helfen somit, die Vorhersage des Stofftransportes organischer Kationen im Untergrund zu verbessern.

Im letzten Teil der Arbeit werden das Konzept und die Entwicklung eines neuen, reaktiven Tracers (KIS-Tracer) zur Charakterisierung von Grenzflächen während Injektionen von überkritischem $\mathrm{CO}_{2}$ in tiefe salinare Aquifere beschrieben. Durch eine 
Hydrolysereaktion an der $\mathrm{CO}_{2} /$ Wasser-Grenzfläche mit bekannter Kinetik wird ein Zusammenhang zur zeitlichen Änderung der Grenzflächengröße geschaffen. Basierend auf den vorangegangenen Untersuchungen zur Sorption, wurde das konservative, organische Anion Naphthalinsulfonat als Basisstruktur für die Tracersynthese (Veresterung) und somit auch als gewünschtes Hydrolyseprodukt ausgewählt. Neben der Definition notwendiger Tracereigenschaften wurden bereits erste Verbindungen synthetisiert, im Labor getestet und mit einem neuentwickelten, makroskopischen Modell ausgewertet. Abschließend wurde das Tracerverhalten exemplarisch für verschiedene hypothetische Funktionen der zeitlichen Grenzflächenänderung numerisch modelliert. Die bisher erzielten Ergebnisse sind sehr vielversprechend und gewähren einen ersten Einblick in das Potential von KISTracern. 


\section{Danksagung}

Zuallererst möchte ich mich bei meinen beiden Betreuern Prof. Dr. Martin Sauter und Dr. Tobias Licha für die Bereitstellung des spannenden Forschungsthemas sowie die umfangreiche Unterstützung bei der Anfertigung meiner Arbeit bedanken. Mein besonderer Dank gilt dabei Dr. Tobias Licha, welcher mir während meiner gesamten Promotionszeit stets mit konstruktiver Kritik und wertvollen Ratschlägen zur Seite gestanden hat. Hervorzuheben sind die oft intensiv und teilweise kontrovers geführten, fachlichen Diskussionen, welche mich stets motivierten mich mit großer Freude noch tiefer in die Thematik einzuarbeiten und bestimmte Zusammenhänge auch aus einem anderen Blickwinkel zu betrachten. Vielen Dank für diese einzigartige und beileibe nicht selbstverständliche Betreuung. Ich möchte mich ebenfalls bei allen weiteren Mitgliedern der Prüfungskomission: Prof. Dr. Eckhard Worch, Prof. Dr. Hans Ruppert, Dr. Chicgoua Noubactep und Dr. Jürgen Niemeyer, bedanken. Prof. Dr. Eckhard Worch danke ich insbesondere für die Übernahme des Koreferates und die stets sehr anregenden Diskussionen während meiner Besuche in Dresden.

Des Weiteren danke ich allen Kollegen der Angewandten Geologie, vor allem aber meinen Bürokollegen Dr. Karsten Nödler, Dr. Martin Nottebohm und Enrico, welche mir immer für Diskussionen und Gespräche jeglicher Art zur Verfügung gestanden haben. Ich freue mich sehr darüber, dass sich aus der kollegialen Beziehung ein freundschaftliches Verhältnis entwickelt hat, welches - da bin ich mir sicher - auch in Zukunft erhalten bleiben wird. Anke von Gaza und Mechthild Rittmeier danke ich für die Messung unterschiedlichster Parameter sowie für die Unterstützung bei meinen praktischen Arbeiten im Labor. Dr. Krzysztof Idzik und Dr. Eike-Fabian Sachs danke ich für die Hilfestellungen bei der chemischen Synthese.

Meinen Ko-Autoren danke ich für die experimentelle Unterstützung, das Einbringen guter Ideen und konstruktiver Vorschläge, ohne die ich meine Arbeit nicht so reibungslos und effizient hätte fertig stellen können. An dieser Stelle möchte ich mich, zusätzlich zu den bereits genannten Kollegen, noch bei Dr. Hilmar Börnick für 
die unzähligen Diskussionen und Telefongespräche sowie bei Norman Boxberger und Anne Niedbala für die Durchführung zahlreicher Laborversuche bedanken. Friedrich Maier danke ich für die numerische Modellierung und die oft erkenntnisreichen Diskussionen physikalischer Sachverhalte.

Meiner lieben Freundin Yukey danke ich für ihre Fürsorge und hingebungsvolle Unterstützung während der vergangenen zweieinhalb Jahre. 감사합니다! 谢谢! 



\section{Table of Contents}

Page

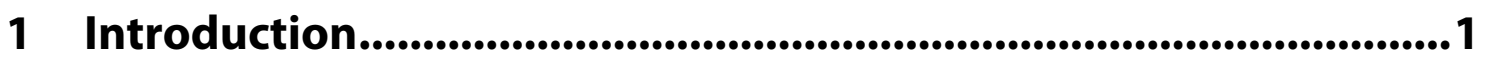

1.1 Motivation and background ..........................................................................1

1.1.1 Organic molecules in hydrogeological systems ............................................ 1

1.1.2 Organic molecules and their application as tracers in geosystems ........ 2

1.1.3 Subsurface processes affecting the fate of organic molecules ................... 4

1.2 Scope, objectives, and further outline of the thesis .................................7

1.3 References ......................................................................................................................10

2 Sorption influenced transport of ionizable pharmaceuticals onto a natural sandy aquifer sediment at different $\mathrm{pH}$................14

2.1 Introduction ......................................................................................................16

2.2 Theory and calculations ................................................................................17

2.3 Materials and methods..............................................................................19

2.3.1 Pharmaceuticals ........................................................................................................19

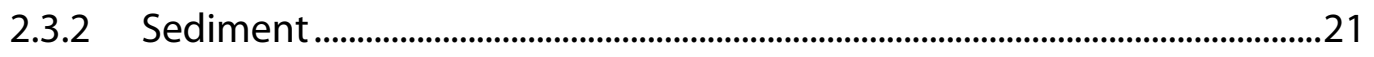

2.3.3 Water matrix ……………………………………………………………………...2

2.3.4 Column experiments ..........................................................................................2

2.4 Results and discussion............................................................................23

2.4.1 Acidic compounds..................................................................................................23

2.4.2 Neutral compounds ..........................................................................................2

2.4.3 Alkaline compounds ............................................................................................25

2.4.4 Zwitter-ionic compounds .....................................................................................26

2.5 Summary and conclusions ..........................................................................28

2.6 Acknowledgment...........................................................................................29

2.7 References ….............................................................................................................30 
3 Role of cation exchange processes on the sorption influenced transport of cationic beta-blockers in aquifer sediments .................................................................................33

3.1 Introduction ........................................................................................................35

3.2 Materials and methods..................................................................................37

3.2.1 Chemicals..............................................................................................................

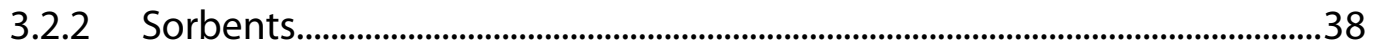

3.2.3 Model water .............................................................................................................

3.2.4 Column experiments ..............................................................................................39

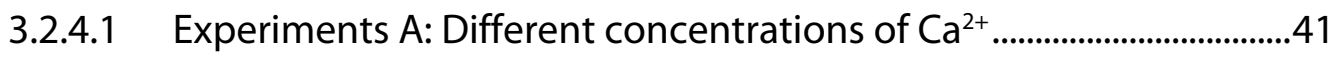

3.2.4.2 Experiments B: Desorption ............................................................................42

3.2.4.3 Experiments C: Different concentrations of atenolol ...........................42

3.2.4.4 Experiment D: Comparison with metoprolol.............................................42

3.2.4.5 Determination of sorption coefficients ......................................................43

3.2.5 Chemical analysis ....................................................................................................4

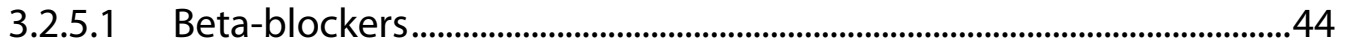

3.2.5.2 Analysis of inorganic cations .........................................................................4

3.2.5.3 Sediment analysis.........................................................................................45

3.3 Results and discussion................................................................................46

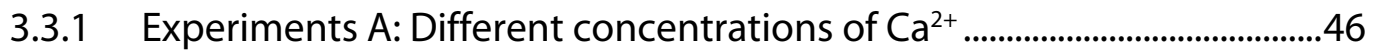

3.3.2 Experiments B: Desorption .....................................................................................48

3.3.3 Experiments C: Different concentrations of atenolol...................................49

3.3.4 Experiment D: Comparison with metoprolol ...................................................51

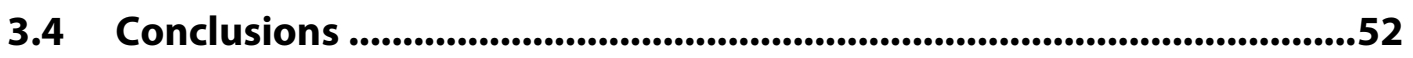

3.5 Acknowledgments .........................................................................5

3.6 References ....................................................................................................53

4 Influence of competing inorganic cations on the ion exchange equilibrium of the monovalent organic cation metoprolol on natural sediment.......................................................57 
4.1 Introduction ........................................................................................................55

4.2 Materials and methods.................................................................61

4.2.1 Chemicals ...............................................................................................................61

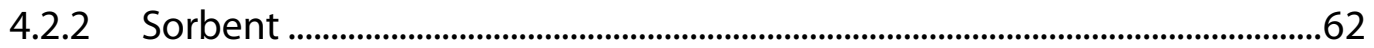

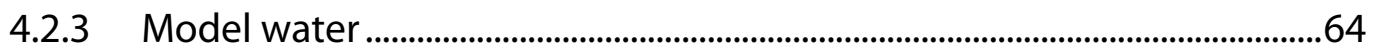

4.2.4 Batch-equilibrium experiments...................................................................65

4.2.5 Chemical analysis..........................................................................................65

4.2.5.1 Analysis of metoprolol and metoprolol acid...........................................65

4.2.5.2 Analysis of inorganic cations.......................................................................66

4.3 Results and discussion ............................................................................66

4.3.1 Role of organic matter ...................................................................................6

4.3.2 Influence of competing inorganic ions ..............................................................67

4.4 Summary and conclusions ...........................................................................70

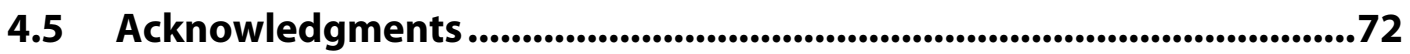

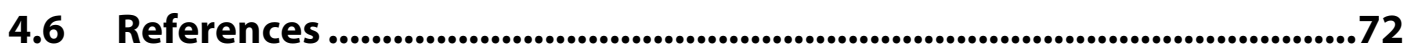

5 A new generation of tracers for the characterization of interfacial areas during supercritical carbon dioxide injections into deep saline aquifers: Kinetic interfacesensitive tracers (KIS tracer) ....................................................75

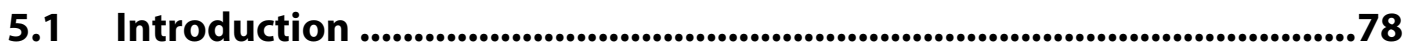

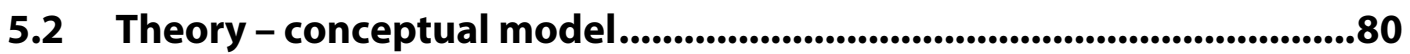

5.2.1 Application of KIS tracers during $\mathrm{CO}_{2}$ injections............................................80

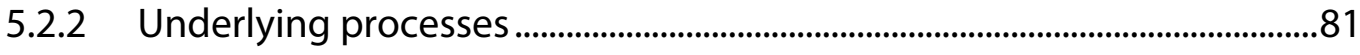

5.3 KIS tracer design .......................................................................................83

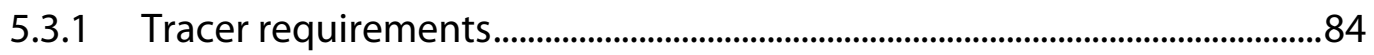

5.3.2 Tracer design / synthesis ..............................................................................85

5.4 Experiments and modeling .............................................................88

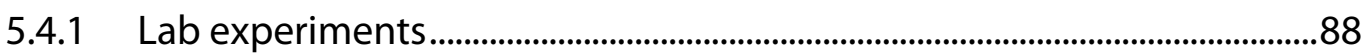

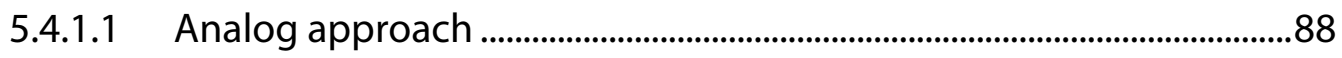

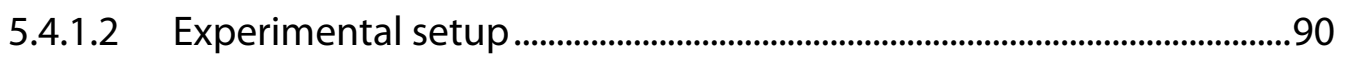


5.4.2 Numerical modeling ................................................................................................91

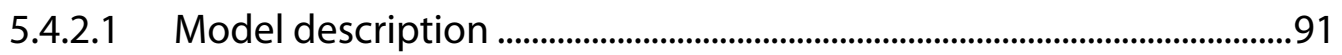

5.4.2.2 Relation between concentration curve and interfacial area size ....93

5.4.3 First results from static batch experiments......................................................94

5.5 Summary and conclusions ....................................................................96

5.6 Acknowledgment............................................................................98

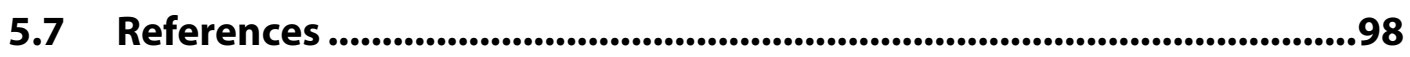

6 General conclusions and perspectives .................................. 102

6.1 Sorption of organic molecules onto aquifer materials ....................... 103

6.2 Development of reactive organic tracers for the characterization of $\mathrm{CO}_{2}$ plume spreading......................................................................... 105

Appendix A.$\ldots \ldots \ldots \ldots \ldots \ldots \ldots \ldots \ldots \ldots \ldots \ldots \ldots \ldots \ldots \ldots \ldots \ldots \ldots \ldots \ldots \ldots \ldots \ldots \ldots \ldots \ldots \ldots \ldots \ldots \ldots \ldots \ldots \ldots$

A1 Liquid chromatography ................................................................................................... X

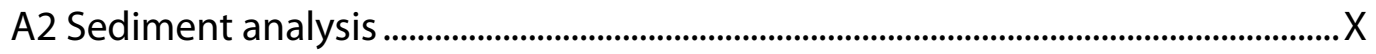

A3 Comparison of applied correlations ............................................................................ XI

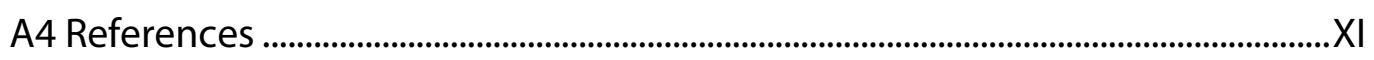

Appendix B............................................................................ XIII

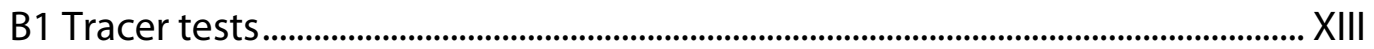

B2 Inverse modeling of the breakthrough curves ....................................................XIV

B3 Exemplary replicates of the experiments .............................................................. XV

Appendix C.......................................................................................XVI

C1 Sorption capacity of the different grain size fractions.........................................XVI

C2 Statistical analysis of the isotherms ................................................................XVII

C2.1 Reference Isotherm without competition.........................................................XVIII

C2.2 Isotherms for competition with $\mathrm{Na}^{+}$..................................................................... XIX

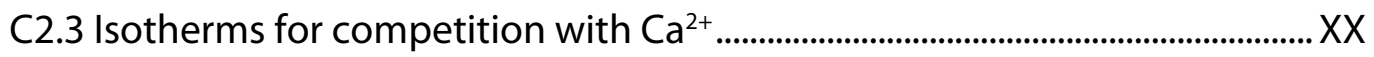

Appendix D .................................................................................... XXI 


\section{List of Figures}

Figures in the Text

Page

Fig. 2.1 Average from column experiments derived log $K_{o c}$ values (uniform columns) compared with estimated log $K_{o c}$ values (hatched columns) calculated with a modified log $K_{o w}-\log K_{o c}$ correlation after Sabljic et al. (1995) for all compounds at $\mathrm{pH}=4, \mathrm{pH}=6$, and $\mathrm{pH}=8$. Error bars indicate the range of experimentally derived $\log K_{o c}$ for at least three measurements, except for TRI at $\mathrm{pH}=8$.

Fig. 2.2 Experimental and modeled breakthrough curves for eight pharmaceuticals at $\mathrm{pH}=4, \mathrm{pH}=6$, and $\mathrm{pH}=8$ showing the $\mathrm{pH}$ dependence for different compounds and a wide spectrum of $\mathrm{p} K_{a}$. Concentrations $c$ of the breakthrough curves were normalized with the initial concentration $c_{0}$. Pore volumes were calculated by normalizing the experiment duration to the breakthrough time of the $\mathrm{Cl}^{-}$tracer.

Fig. 3.1 Experimental and modeled breakthrough curves (including tracer tests) of atenolol for sediment $\mathrm{S} 1$ with and without $\mathrm{CaCl}_{2}$ addition $\left(\mathrm{Ca}^{2+}\right.$ concentrations of 40 and $400 \mathrm{mg} \mathrm{L}^{-1}$ ). Concentrations $c$ of the breakthrough curves were normalized with the initial concentration $c_{0}$. Pore volumes were calculated by normalizing the experiment duration to the ideal breakthrough time of the $\mathrm{Cl}^{-}$tracer.

Fig. 3.2 Experimental and modeled breakthrough curves (including tracer tests) of atenolol for sediment S2 with and without $\mathrm{CaCl}_{2}$ addition $\left(\mathrm{Ca}^{2+}\right.$ concentrations of 40 and $400 \mathrm{mg} \mathrm{L}^{-1}$ ). Concentrations $c$ of the breakthrough curves were normalized with the initial concentration $c_{0}$. Pore volumes were calculated by normalizing the experiment duration to the ideal breakthrough time of the $\mathrm{Cl}^{-}$tracer.

Fig. 3.3 Experimental and modeled desorption curves of atenolol for sediments S1 and S2 with $\mathrm{CaCl}_{2}$ addition after 53 pore volumes $\left(\mathrm{Ca}^{2+}\right.$ concentrations of 40 and $\left.400 \mathrm{mg} \mathrm{L}^{-1}\right)$. Concentrations $c$ of desorption curves were normalized with the initial concentration $c_{0}$ of the previous breakthrough curves. Pore volumes were calculated by normalizing the experiment duration to the ideal breakthrough time of the $\mathrm{Cl}^{-}$tracer.

Fig. 3.4 Experimental and modeled breakthrough curves (including tracer tests) for different concentrations of atenolol (C1-C4) and metoprolol (D1, $\mathrm{Eq}=$ chemical equilibrium model, nonEq = chemical non-equilibrium model) in sediment S3 at constant ionic strength. Concentrations c of the breakthrough curves were normalized with the initial concentration $c_{0}$. Pore volumes were calculated by normalizing the experiment duration to the ideal breakthrough time of the $\mathrm{Cl}^{-}$tracer. 
Fig. 4.1 A-B: Freundlich sorption isotherms of metoprolol on sandy aquifer sediment from water with various $\mathrm{Na}^{+}$concentrations or $\mathrm{Na}^{+}$activities at $\mathrm{pH}=7.0 ; \mathrm{C}-\mathrm{D}$ : Freundlich sorption isotherms of metoprolol on sandy aquifer sediment from water with various $\mathrm{Ca}^{2+}$ concentrations or $\mathrm{Ca}^{2+}$ activities at $\mathrm{pH}=7.0$. Data points represent the average of batch triplicates. Error bars show the range of measured minimum and maximum values.

Fig. 4.2 A: Relation between the Freundlich coefficients $\log K_{F r}$ and the concentration of the competing ions $\mathrm{Na}^{+}$and $\mathrm{Ca}^{2+} ; \mathrm{B}$ : Relation between the Freundlich coefficients $\log K_{F r}$ and the activity of the competing ions $\mathrm{Na}^{+}$and $\mathrm{Ca}^{2+}$

Fig. 5.1 Injection well: Injection and spreading of $\mathrm{scCO}_{2}$ together with dissolved KIS tracer. Monitoring well: Measurement of KIS tracer reaction products in the brine.

Fig. 5.2 Schematic representation of all involved processes at the $\mathrm{scCO}_{2} /$ water interface during KIS tracer application.

Fig. 5.3 Synthesis of phenyl naphthalene-2-sulfonate from naphthalene-2sulfonyl chloride and phenol.

Fig. 5.4 Hydrolysis reaction of phenyl naphthalene-2-sulfonate with water and the fluorescent properties of the reagent and the reaction products.

Fig. 5.5 Sketch of the numerical model domain: The yellow dot at $20 \mathrm{~mm}$ height represents the observation point where the fluorescence signal is measured. Red boundaries are no flow boundaries. On the upper green boundary the flux $q$ is defined, where the reaction products flow into the water.

Fig. 5.6 Comparison of measured concentration curves for the hydrolysis reaction products of phenyl acetate (PhAc) and phenyl naphthalene-2sulfonate (2-NSAPh).

Fig. 5.7 Comparison of different modeled scenarios: Concentration curves are modeled based on different functions for $A(t)$. For the model calibration (red line) the constant $A$ from the experiment was used. 
Figures in the Appendix

Fig. A1 Average from column experiments derived log $K_{o c}$ values (grey columns) compared with estimated log $K_{o c}$ values calculated with the modified $\log K_{o w}-\log K_{o c}$ correlation after Sabljic et al. (1995) (green columns) and the correlations of Franco et al. (2008) (orange columns) for all compounds at $\mathrm{pH}=4, \mathrm{pH}=6$, and $\mathrm{pH}=8$. The correlation from Franco et al. (2008) could not be applied for the zwitter-ionic cetirizine............XI

Fig. B1 Replicate of experiment A1 .............................................................................................. XV

Fig. B2 Replicate of experiment C4 ..............................................................................................XV

Fig. B3 Replicate of experiment D1 ..............................................................................................XV

Fig. 1 left: Mean cumulative particle size distribution of the sediment; right: Distribution of sorbed metoprolol on the different particle size fractions at neutral $\mathrm{pH}$ and a temperature of $20 \pm 1{ }^{\circ} \mathrm{C}$. Results are presented in terms of averages of data from the duplicate batches. The error bars reported in the figure have been calculated by considering the difference between batch results.

Fig. C2 Reference isotherm for metoprolol $\left(\mathrm{R}^{2}=0.9962\right)$................................................XVIII

Fig. C3 Isotherm of metoprolol at $0.37 \mathrm{mmol} \mathrm{L}^{-1} \mathrm{Na}^{+}\left(\mathrm{R}^{2}=0.9989\right)$................................. XIX

Fig. C4 Isotherm of metoprolol at $3.7 \mathrm{mmol} \mathrm{L}^{-1} \mathrm{Na}^{+}\left(\mathrm{R}^{2}=0.9994\right)$................................... XIX

Fig. C5 Isotherm of metoprolol at $37.0 \mathrm{mmol} \mathrm{L}^{-1} \mathrm{Na}^{+}\left(\mathrm{R}^{2}=0.9986\right)$................................ XIX

Fig. C6 Isotherm of metoprolol at $0.37 \mathrm{mmol} \mathrm{L}^{-1} \mathrm{Ca}^{2+}\left(\mathrm{R}^{2}=0.9990\right)$.................................XX

Fig. C7 Isotherm of metoprolol at $3.7 \mathrm{mmol} \mathrm{L}^{-1} \mathrm{Ca}^{2+}\left(\mathrm{R}^{2}=0.9970\right)$.................................... XX

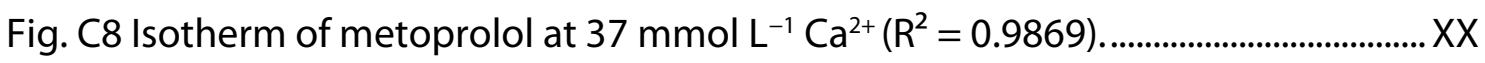




\section{List of Tables}

Tables in the Text

Page

Table 1.1 Compilation of tracers used in hydrological geosciences...................................... 3

Table 2.1 Chemical properties, structures and speciation of the sorbates.......................20

Table 2.2 Physicochemical properties of the used sorbent and column

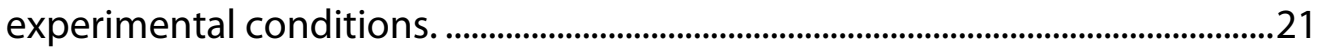

Table 3.1 Chemical properties and structures of the sorbates.

Table 3.2 Physicochemical properties of the used sediments and column experimental conditions.

Table 3.3 Concentrations of beta-blockers and inorganic main cations for each experiment.

Table 3.4 Distribution coefficients and calculated relative proportion of cation exchange.

Table 4.1 Physicochemical properties of the sorbate and sorbent. .62

Table 4.2 Freundlich regression parameters of all batch experiment series. .64

Table 5.1 Properties of synthesized KIS tracer compounds, phenyl acetate and their respective reaction products.

Table 5.2 Comparison of physical and chemical properties between $\mathrm{scCO}_{2}$ with $n$-octane as analog compound.

\section{Tables in the Appendix}

Table B1 Column experimental conditions and modeled parameters of the tracer tests.

Table B2 CXTFIT modeled parameters and fit quality for all column experiments..... XIV 


\section{Chapter 1}

\section{Introduction}

\subsection{Motivation and background}

\subsubsection{Organic molecules in hydrogeological systems}

To date, more than 69 million inorganic and organic substances have been registered at the Chemical Abstract Service (CAS, 2012). More than 40 million of these substances can be assigned to the class of organic compounds. The vast number of known and the theoretically unlimited number of not yet described organic molecules merely implies the existing large variety of different structures, properties, and thus, conceivable applications.

In aquatic environments two main groups of dissolved organic compounds are found: (1) compounds originating from biomass and/or metabolic processes (e.g., all kinds of organic matter: hydrocarbons, humic substances, etc.) representing the background level of natural substances and (2) compounds from anthropogenic origin (e.g., industrial chemicals, pesticides, pharmaceuticals, etc.).

The latter have been detected in virtually all surface and subsurface water bodies during the last decades (Daughton and Ternes, 1998; Halling-Sørensen, 1998; Heberer, 2002; Kolpin et al., 2002; Schwarzenbach et al., 2006). On the one hand, certain threshold concentrations of these compounds might have adverse effects in terms of water quality, since specific (eco)toxicological risks from single compounds or mixtures are often unknown (DeLorenzo et al., 2001; Schwarzenbach et al., 2006). Therefore, the occurrence, environmental behavior, and risk assessment of these chemicals including their respective transformation products are typical research topics in environmental sciences. 
On the other hand, the deliberate introduction of selected compounds with desired properties from the huge pool of available organic compounds into aquifers holds the immense potential to gain insight into the properties of hydro(geo)logical systems and the therein occurring processes. Chemical substances that are intentionally applied for investigating certain elements of aquifer systems are termed as (hydrogeological) tracers and are described in more detail in the following chapter.

\subsubsection{Organic molecules and their application as tracers in geosystems}

The application of various organic molecules as tracers has been proven as a useful instrument in the characterization of groundwater systems. In this work, a tracer is defined as a chemical compound that is intentionally introduced into a hydrogeological system (e.g., aquifer or georeservoir) having a temporally and spatially well-known input function. Due to the relation of the input function (e.g., Dirac pulse, step or continuous input) with the observed system response function (breakthrough curve) quantitative and system-specific information can be gained (Käss, 2004).

In Table 1.1 an impression of the wide spectrum of tracers including their possible applications, processes, and required properties is given. Depending on their physicochemical and chemical behavior, respectively, tracers can principally be differentiated in conservative and non-conservative tracers (Goldscheider et al., 2008). Conservative tracers are considered as physically and chemically inert (ideal tracers) to the greatest possible extent. Classically, they are applied for tracking connectivities and flow paths; analyzing travel times, groundwater drift, and flow velocities; determining recharge and discharge as well as for estimating hydromechanical aquifer properties (e.g., dispersivity, porosity) (Flury and Wai, 2003). In contrast, non-conservative tracers underlie physicochemical processes or chemical reactions during their transport. Therefore, they may provide unique information on physicochemical aquifer properties and the water chemistry (Ptak et al., 2004; Divine and McDonnell, 2005; Luhmann et al., 2012). 
Table 1.1 Compilation of tracers used in hydrological geosciences.

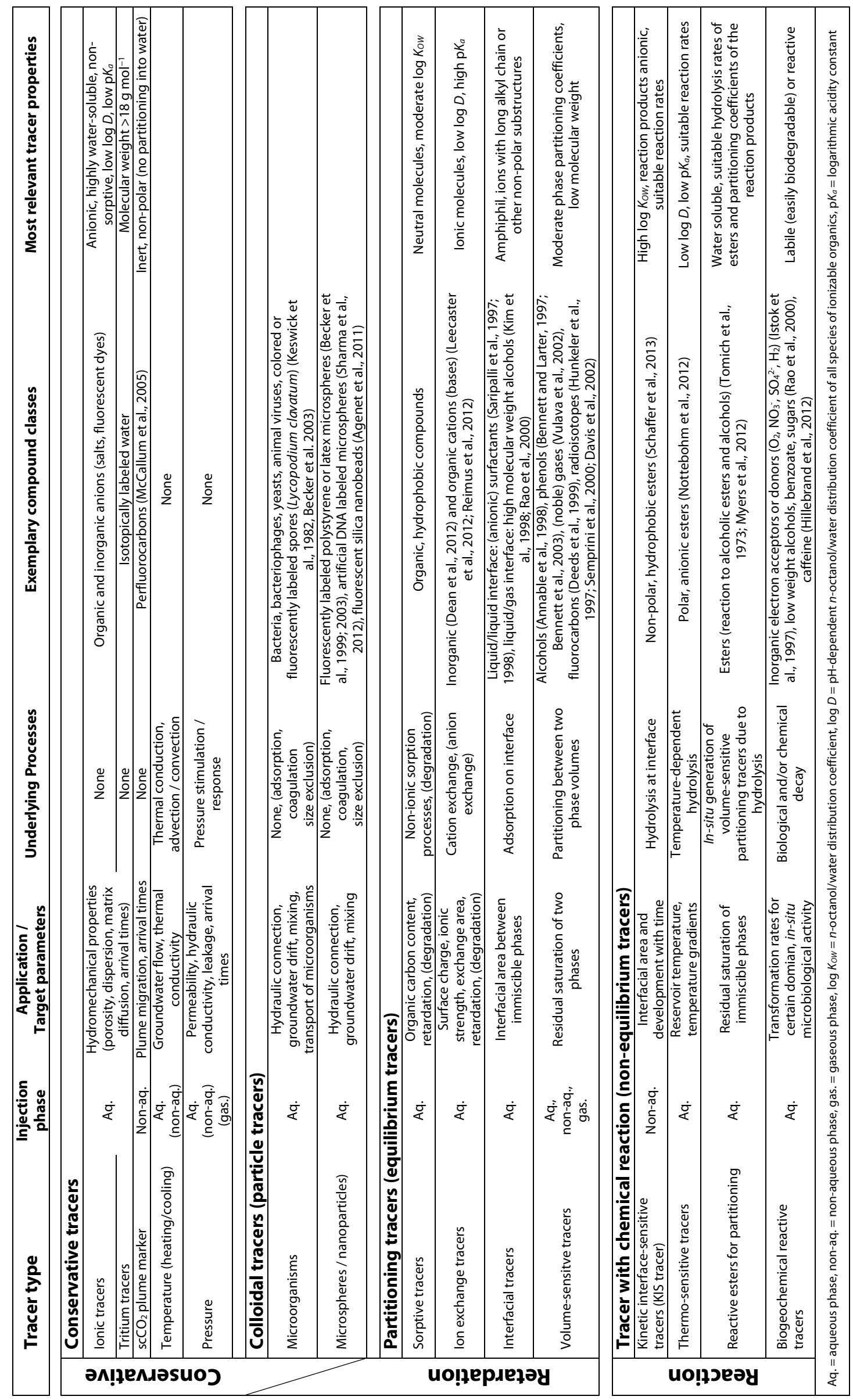


In general, extensive knowledge on the reactive or non-reactive behavior of any applied tracer is the indispensable prerequisite for the successful qualitative and quantitative interpretation of tracer tests. However, basically all molecules are influenced to some degree by physical, chemical or biological processes. This means that fully ideal tracers do not really exist. Even tracers, which are supposed to behave conservatively, may interact to some extent with aquifer materials or with the water chemistry during their transport in the subsurface. Hence, for several commonly selected fluorescent dyes, for instance, sorption (Smart and Laidlaw, 1977; Kasnavia et al., 1999; Geyer et al., 2007), biodegradation (Benischke et al., 2007; Goldscheider et al., 2008) and precipitation (Geyer et al., 2007; Licha et al., 2013) were reported. These limitations may be detected and mitigated by conducting multi-tracer tests with different "potentially conservative" compounds and comparing their breakthrough curves. For non-conservative tracers, which are intended to interact in a designated way within the aquifer, this approach is usually not feasible and the exact knowledge on (potential) processes is even more essential in order to avoid misinterpretations. However, the actual occurring compound-specific processes and their dependences are often unknown and cannot yet be predicted.

In order to overcome these limitations, the thorough study of the relative role of all involved processes and their influence factors affecting the tracer transport is necessary. The possibility, extent and nature of appearing processes are strongly connected to the molecule structures and thus its molecular properties. If this interplay is exactly understood, organic molecules can be a powerful tool for the purposeful and explicit characterization of subsurface processes, too. As a consequence, the additional use of non-conservative tracers to commonly applied conservative tracers has the potential to significantly increase the informative value of tracer tests.

\subsubsection{Subsurface processes affecting the fate of organic molecules}

Prior to discussing specific processes affecting the fate of solutes in the subsurface, the term subsurface process has to be defined. Here, subsurface processes include all phenomena/effects leading to spatial and/or temporal concentration changes of a considered solute in the subsurface. The term transport processes is often used 
equivalently in the literature (Adam et al., 2000) and can be mathematically described based on the principle of mass conservation for a considered substance by means of the advection-dispersion model including source terms. This yields to the following equation for the general three-dimensional case:

$$
\begin{aligned}
& \text { (1) (2) (3) (4) } \\
& \frac{\partial c}{\partial t}=-\bar{v} \cdot \vec{\nabla} c+\vec{\nabla}\left(D_{\text {Disp. }} \vec{\nabla} c\right)+\vec{\nabla}\left(D_{\text {Diff. }} \vec{\nabla} c\right)+\frac{\partial q}{\partial t} \quad \text { with }
\end{aligned}
$$

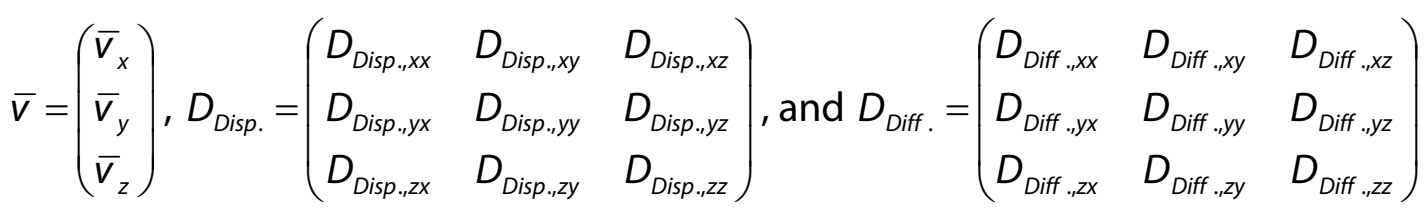

where $c$ is the solute concentration, $t$ is time, $\bar{v}$ is the mean pore water velocity, $D_{\text {Disp. }}$ is the hydromechanic dispersion tensor, $D_{\text {Diff. }}$ is the pore diffusion tensor, and $q$ is the concentration in co-existing phases (e.g., solids or immiscible liquid phases).

As a consequence, subsurface processes can be generally divided into two categories: (1) system/fluid-specific and (2) compound-specific processes. The former includes all hydromechanical mass flux processes in Eq. (1.1). Advection and hydromechanical dispersion ( $1^{\text {st }}$ and $2^{\text {nd }}$ term) belong clearly to this group. Despite the fact that diffusion ( $3^{\text {rd }}$ term) is also a pure physical process, it cannot be fully attributed to the first category, since molecular and, thus, diffusion coefficients depend on the size and the weight of a molecule, respectively (Worch, 1993). Usually, these hydrodynamical processes can be investigated with tracer compounds showing a (almost ideal) conservative behavior. In conclusion, physically driven transport processes are well understood, can be measured, and sufficiently described by means of mathematical equations.

The latter comprises all processes, which lead to a chemical or physicochemical alteration of the respective solutes during their subsurface transport ( $4^{\text {th }}$ term). The source/sink term can be split further according to the relevant processes. This considers typical processes, such as dissolution or precipitation according to the solubility product; chemical reactions with other solutes or with mineral surfaces; chemical and microbial degradation as well as sorption. Therefore, the explicit description/formulation of these processes summarized in the fourth term of Eq. (1.1) is much more challenging. 
The systematic study of sorption processes and their relevance for hydrogeological systems is a main focus of the presented thesis. Adsorption is a surface process and can be defined as a net enrichment of chemical species from a fluid phase on the surface of a liquid or a solid (Sposito, 1998; Worch, 2012). In this work, the terms adsorption and (geo)sorption are used interchangeably, because the distinction between absorption and adsorption is not always obvious in heterogeneous natural systems. This is especially true for complex geosorbents, such as organic matter in aquifer materials (Worch, 2012). Depending on the nature of a sorption process in the subsurface, hydrophobic (non-polar) interactions with the sorbent organic matter (SOM) and electrostatic (polar) interactions with minerals, oxides, and SOM surfaces can be distinguished. Hydrophobic sorption results from an decrease in entropy by the sorption of solutes on hydrophobic surfaces and can be explained by the occurrence of unspecific van-der-Waals interactions (dipole and/or induced-dipole interactions). As a consequence, the more hydrophobic the solute the higher is its affinity to migrate from the (polar) aqueous phase to the (non-polar) solid phases. This sorption process is often described as partitioning process of solutes between water and SOM. The additional use of general or compound class-specific correlations based on the $n$-octanol-water distribution coefficient log $K_{o w}$ (e.g., Karickhoff et al., 1979; Sabljic et al., 1995) or the water solubility (Razzaque and Grathwohl, 2008) as polarity measures commonly allows a sufficient prediction for the sorption behavior (partitioning coefficients) of neutral organic compounds.

For charged species of organic molecules the situation is much more complex, since electrostatic interactions additionally to hydrophobic interactions must be expected. Depending on the degree of dissociation and protonation of solutes with ionizable functional groups (bases, acids, zwitter-ionics, amphoteres), respectively, several sorption mechanisms and, thus, transport properties for each species come into question. The probably most relevant electrostatic sorption mechanisms are ion exchange, surface complexation, hydrogen bonding, ligand exchange, cation bridging, and charge-transfer or electron donor-acceptor mechanisms (Senesi, 1992; Tolls, 2001; Cunningham et al., 2004; Kah and Brown, 2007; Worch, 2012). The adequate mathematical description of these (partially overlapping) interactions is more complicated than for hydrophobic interactions, since the role and extent of these sorption mechanisms are affected to a greater extent by the ambient 
groundwater chemistry (e.g., $\mathrm{pH}$, ionic strength, etc.) and sorbent properties (e.g., surface area, surface charges, etc.). Furthermore, the existence and the type of relationship between the observed sorption and these influencing factors are often unknown. Therefore, the subsurface behavior of ionizable compounds can normally not be reliably predicted and requires extensive further research.

\subsection{Scope, objectives, and further outline of the thesis}

Due to the large number of organic compounds associated with different functionalities and molecular properties, the study of their individual interactions within the subsurface bears the potential to gain specific information about the underlying processes. For this purpose, the systematic investigation and description of existing relations between molecule properties and occurring processes is vital to understand the behavior of organic compounds in the subsurface. Vice versa, if the behavior of an organic molecule in the subsurface is known, conclusions on the existence and role of involved processes affecting the molecule's fate can be drawn. Thus, sufficient knowledge on processes is the prerequisite to interpret tracer data and to get valuable implications for the development and selection of new tracer substances.

However, a complete evaluation of all conceivable processes and organic molecules is obviously impossible within a single study. The presented work, therefore, can be considered as the successful and consequent continuation of current research. It claims to contribute to an overall understanding of the transport behavior of organic molecules in the subsurface by relating subsurface processes, especially sorption processes, with their molecule properties. Eventually, the gained understanding is used for supporting the development of new, chemically reactive tracers for process studies.

In the beginning, ionizable organic molecules with different chemical character (different functional groups and physicochemical properties) were investigated with respect to their transport and sorption behavior. Consecutively, the most relevant sorption processes of cationic compounds were identified and studied separately. Furthermore, a new tracer class for the sequestration of $\mathrm{CO}_{2}$ into deep saline aquifers 
is proposed and first results gained from controlled laboratory experiments are presented. For the tracer development the previous findings on sorption of charged organics were taken into account. A more detailed outline is presented in the following.

Chapter 2 presents the screening of the $\mathrm{pH}$-dependent transport behavior of eight frequently prescribed human pharmaceuticals in sediment column experiments. The selected pharmaceuticals bear different ionizable functional groups, which can be protonated or deprotonated depending on the water $\mathrm{pH}$. Therefore, the investigation included neutral, anionic, cationic, and zwitter-ionic molecules. Thus, differences in their transport behavior were expected. The experimentally obtained sorption coefficients were compared with predicted values derived from two different regressions (log $K_{o w}-\log K_{o c}$ correlations) considering the sorbate speciation in solution. Beside the detection of a significant $\mathrm{pH}$-dependence on sorption for all charged compounds, a strong retardation was measured for several substances despite their high polarity. The measured data confirmed a good match for the prediction of sorption only for acidic and neutral compounds. Cationic compounds retarded much stronger than expected, which was attributed to additional ionic interactions (e.g., cation exchange processes), which are not considered in the applied correlations.

Chapter 3 deals with the identification of the relevant sorption processes of organic cations by conducting column experiments using the beta-blockers atenolol and metoprolol as example compounds. The sorption behavior of these compounds onto different sediments and under varying background concentrations of inorganic cations was compared. Due to decreasing sorption of the beta-blockers with increasing concentrations of inorganic cations, cation exchange could be identified as the dominating sorption process whereby the contribution of hydrophobic interactions to the overall sorption was determined to be negligible. Thus, meaningful predictions of organic cation sorption with commonly applied models like $\log K_{o w}-\log K_{o c}$ correlations are not possible and new, more complex approaches considering further boundary conditions are unavoidable.

In Chapter $\mathbf{4}$ the identified cation exchange processes of organic cations are studied systematically in order to improve the quantitative process description. For this 
purpose, the influence of competing $\mathrm{Na}^{+}$and $\mathrm{Ca}^{2+}$ cations on the sorption process of the monovalent organic cation metoprolol onto a natural sediment was investigated by determining Freundlich sorption isotherms for different electrolyte and metoprolol concentrations. The similar isotherm non-linearity indicates that the relevant sorption mechanisms did not change over several orders of magnitude. Freundlich sorption coefficients were correlated with the concentration of the competing inorganic ions allowing the prediction of metoprolol sorption at different electrolyte concentrations. Eventually, the presented work represents a first stepping stone for a general and systematic understanding of occurring sorption processes for organic cations. The results will contribute to the development of predictive models for the subsurface transport of organic cations.

In Chapter $\mathbf{5}$ the concept and the development of a new reactive tracer type for the characterization of interfacial areas between water and supercritical $\mathrm{CO}_{2}$ during $\mathrm{CO}_{2}$ injections into deep saline aquifers is presented (KIS tracer). Starting from the definition of tracer requirements, an exemplary methodology for a suitable target molecular design is described and first promising ester compounds were synthesized. The gained experience on sorption and transport of charged organic molecules (especially organic anions) from the previous investigations were considered for the selection of suitable compound structures during the molecular design. The interface behavior of the novel compounds was tested in analog laboratory experiments and evaluated with a macroscopic numerical model. Based on the experimentally determined interface mass flux for the combined phase transfer and subsequent reaction, several interface expansion scenarios were predicted by forward modeling.

Chapter 6 summarizes the conclusions with respect to the focus of the thesis and gives an outlook for future research activities.

In Appendix A additional information regarding Chapter 2 is presented.

In Appendix B additional information regarding Chapter 3 is presented.

In Appendix C additional information regarding Chapter 4 is presented. 
In Appendix D a complete list of journal articles, conference contributions, and miscellaneous publications authored or co-authored by me and related to the presented work are listed.

Since this thesis is a cumulative dissertation including published journal articles, cited literature is listed separately at the end of each chapter.

\subsection{References}

Adam, C., Gläßer, W., Hölting, B., 2000. Hydrogeologisches Wörterbuch, Enke/Georg Thieme Verlag, Stuttgart/New York.

Agenet, N., Moradi-Tehrani, N., Tillement, O., 2011. Fluorescent nanobeads: a new generation of easily detectable water tracers. In: Proceedings of the International Petroleum Technology Conference, Bangkok, Thailand, IPTC-15312.

Annable, M.D., Rao, P.S.C., Hatfield, K., Graham, W.D., Wood, A.L., Enfield, C.G., 1998. Partitioning tracers for measuring residual NAPL: field-scale test results. Journal of Environmental Engineering 124 (6), 498-503.

Becker, M.W., Reimus, P.W., Vilks, P., 1999. Transport and attenuation of carboxylate-modified latex microspheres in fractured rock laboratory and field tracer tests. Ground Water 37 (3), 387-395.

Becker, M.W., Metge, D.W., Collins, S.A., Shapiro, A.M., Harvey, R.W., 2003. Bacterial transport experiments in fractured crystalline bedrock. Ground Water 41 (5), 682-689.

Benischke, R., Goldscheider, N., Smart, C., 2007. Tracer techniques, in: Goldscheider, N., Drew, D. (Eds.), Methods in karst hydrogeology. Taylor \& Francis, London, pp. 147-170.

Bennett, B., Larter, S.R., 1997. Partition behaviour of alkylphenols in crude oil/brine systems under subsurface conditions. Geochimica et Cosmochimica Acta 61 (20), 4393-4402.

Bennett, B., Aplin, A.C., Larter, S.R., 2003. Measurement of partition coefficients of phenol and cresols in gas-charged crude oil/water systems. Organic Geochemistry 34 (12), 1581-1590.

CAS, 2012. CAS REGISTRY database counter, http://www.cas.org/content/chemical-substances. Accessed $7^{\text {th }}$ December 2012.

Cunningham, V.L., Constable, D.J.C., Hannah, R.E., 2004. Environmental risk assessment of paroxetine. Environmental Science and Technology 38 (12), 3351-3359.

Daughton, C.G., Ternes, T.A., 1999. Pharmaceuticals and personal care products in the environment: agents of subtle change? Environmental Health Perspectives 107 (Suppl 6), 907-938.

Davis, B.M., Istok, J.D., Semprini, L., 2002. Push-pull partitioning tracer tests using radon-222 to quantify non-aqueous phase liquid contamination. Journal of Contaminant Hydrology 58 (1-2), 129-146.

Dean, C., Reimus, P., Newell, D., 2012. Evaluation of a cation exchanging tracer to interrogate fracture surface area in EGS systems. In: Proceedings of the $37^{\text {th }}$ Workshop on Geothermal Reservoir Engineering, Stanford, USA, SGP-TR-194. 
Deeds, N.E., McKinney, D.C., Pope, G.A., 1999. Vadose zone characterization at a contaminated field site using partitioning interwell tracer technology. Environmental Science and Technology 33 (16), 2745-2751.

DeLorenzo, M.E.,Scott, G.I., Ross, P.E., 2001. Toxicity of pesticides to aquatic microorganisms: A review. Environmental Toxicology and Chemistry 20 (1), 84-98.

Divine, C.E., McDonnell, J.J., 2005. The future of applied tracers in hydrogeology. Hydrogeology Journal 13 (1), 255-258.

Flury, M., Wai, N.N., 2003. Dyes as tracers for vadose zone hydrology. Reviews of Geophysics 41 (1), 1002.

Geyer, T., Birk, S., Licha, T., Liedl, R., Sauter, M., 2007. Multitracer test approach to characterize reactive transport in karst aquifers. Ground Water 45 (1), 36-45.

Goldscheider, N., Meiman, J., Pronk, M., Smart, C., 2008. Tracer tests in karst hydrogeology and speleology. International Journal of Speleology 37 (1), 27-40.

Halling-Sørensen, B., Nors Nielsen, S., Lanzky, P.F., Ingerslev, F., Holten Lützhøft, H.C., Jørgensen, S.C., 1998. Occurrence, fate and effects of pharmaceutical substances in the environment - a review. Chemosphere 36 (2), 357-393.

Heberer, T., 2002. Occurrence, fate, and removal of pharmaceutical residues in the aquatic environment: a review of recent research data. Toxicology Letters 131 (1-2), 5-17.

Hillebrand, O., Nödler, K., Licha, T., Sauter, M., Geyer, T., 2012. Identification of the attenuation potential of a karst aquifer by an artificial dualtracer experiment with caffeine. Water Research 46 (16), 5381-5388.

Hunkeler, D., Hoehn, E., Höhener, P., Zeyer, J., 1997. ${ }^{222} \mathrm{Rn}$ as a partitioning tracer to detect diesel fuel contamination in aquifers: laboratory study and field observations. Environmental Science and Technology 31 (11), 3180-3187.

Istok, J.D., Humphrey, M.D., Schroth, M.R., Hyman, M.R., O’Reilly, K.T., 1997. Single-well, "push-pull" test for in situ determination of microbial activities. Ground Water 35 (4), 619-631.

Kah, M., Brown, C.D., 2007. Prediction of the adsorption of ionizable pesticides in soils. Journal of Agricultural and Food Chemistry 55 (6), 2312-2322.

Karickhoff, S., Brown, D.S., Scott, T.A., 1979. Sorption of hydrophobic pollutants on natural sediments. Water Research 13 (3), 241-248.

Kasnavia, T., Vu, D., Sabatini, D.A., 1999. Fluorescent dye and media properties affecting sorption and tracer selection. Ground Water 37 (3), 376-381.

Käss, W., 2004. Lehrbuch der Hydrogeologie, vol. 9, Lehrbuch Geohydrologische Markierungstechnik, $2^{\text {nd }}$ ed. Borntraeger, Berlin/Stuttgart.

Keswick, B.H., Wang, D.-S., Gerba, C.P., 1982. The use of microorganisms as ground-water tracers: a review. Ground Water 20 (2), 142-149.

Kim, H., Annable, M.D., Rao, P.S.C., 1998. Influence of air-water interfacial adsorption and gas-phase partitioning on the transport of organic chemicals in unsaturated porous media. Environmental Science and Technology 32 (9), 1253-1259.

Kolpin, D.W., Furlong, E.T., Meyer, M.T., Thurman, E.M., Zaugg, S.D., Barber, L.B., Buxton, H.T., 2002. Pharmaceuticals, hormones, and other organic wastewater contaminants in U.S. streams, 19992000: a national reconnaissance. Environmental Science and Technology 36 (6), 1202-1211. 
Leecaster, K., Ayling, B., Moffitt, G., Rose, P., 2012. Use of safranin T as a reactive tracer for geothermal reservoir characterization. In: Proceedings of the $37^{\text {th }}$ Workshop on Geothermal Reservoir Engineering, Stanford, USA, SGP-TR-194.

Licha, T., Niedbala, A., Bozau, E., Geyer, T., 2013. An assessment of selected properties of the fluorescent tracer, Tinopal CBS-X related to conservative behavior, and suggested improvements. Journal of Hydrology 484, 38-44.

Luhmann, A.J., Covington, M.D., Alexander, S.C., Chai, S.Y., Schwartz, B.F., Grotena, J.T., Alexander Jr., E.C., 2012. Comparing conservative and nonconservative tracers in karst and using them to estimate flow path geometry. Journal of Hydrology 448-449, 201-211.

McCallum, S.D., Riestenberg, D.E., Cole, D.R., Freifeld, B.M., Trautz, R.C., Hovorka, S.D., Phelps, T.J., 2005. Monitoring geologically sequestered $\mathrm{CO}_{2}$ during the Frio Brine pilot test using perfluorocarbon tracers. In: Proceedings of the $4^{\text {th }}$ Annual Conference on Carbon Capture and Sequestration, Alexandria, USA.

Myers, M., Stalker, L., Ross, A., Dyt, C., Ho, K.-B., 2012. Method for the determination of residual carbon dioxide saturation using reactive ester tracers. Applied Geochemistry 27 (10), 2148-2156.

Nottebohm, M., Licha, T., Sauter, M., 2012. Tracer design for tracking thermal fronts in geothermal reservoirs. Geothermics 43, 37-44.

Ptak, T., Piepenbrink, M., Martac, E. 2004. Tracer tests for the investigation of heterogeneous porous media and stochastic modelling of flow and transport - a review of some recent developments. Journal of Hydrology 294 (1-3), 122-163.

Rao, P.S.C., Annable, M.D., Kim, H., 2000. NAPL source zone characterization and remediation technology performance assessment: recent developments and applications of tracer techniques. Journal of Contaminant Hydrology 45 (1-2), 63-78.

Razzaque, M., Grathwohl, P., 2008. Predicting organic carbon-water partitioning of hydrophobic organic chemicals in soils and sediments based on water solubility. Water Research 42 (14), 3775-3780.

Reimus, P., Williams, M., Vermeul, V., Rose, P., Leecaster, K., Ayling, B., Sanjuan, R., Ames, M., Dean, C., Benoit, D., 2012. Use of tracers to interrogate surface area in single-well tracer tests in EGS Systems. In: Proceedings of the $37^{\text {th }}$ Workshop on Geothermal Reservoir Engineering, Stanford, USA, SGP-TR-194.

Sabljic, A., Guesten, H., Verhaar, H., Hermens, J., 1995. QSAR modelling of soil sorption. Improvements and systematics of log $K_{O c}$ vs. log Kow correlations. Chemosphere 31 (11-12), 4489-4514.

Saripalli, K.P., Kim, H., Rao, P.S.C., Annable, M.D., 1997. Measurement of specific fluid-fluid interfacial areas of immiscible fluids in porous media. Environmental Science and Technology 31 (3), $932-$ 936.

Saripalli, K.P., Rao, P.S.C., Annable, M.D., 1998. Determination of specific NAPL-water interfacial areas of residual NAPLs in porous media using the interfacial tracers technique. Journal of Contaminant Hydrology 30 (3-4), 375-391.

Schaffer, M., Maier, F., Licha, T., Sauter, M., 2013. A new generation of tracers for the characterization of interfacial areas during supercritical carbon dioxide injections into deep saline aquifers: Kinetic interface-sensitive tracers (KIS tracer). International Journal of Greenhouse Gas Control 14, 200208. 
Schwarzenbach, R.P., Escher, B.I., Fenner, K., Hofstetter, T.B., Johnson, C.A., von Gunten, U., Wehrli, B., 2006. The challenge of micropollutants in aquatic systems. Science 313 (5790), 1072-1077.

Semprini, L., Hopkins, O.S., Tasker, B.R., 2000. Laboratory, field and modeling studies of radon-222 as a natural tracer for monitoring NAPL contamination. Transport in Porous Media 38 (1-2), 223-240.

Senesi, N., 2001. Binding mechanisms of pesticides to soil humic substances. Science of The Total Environment 123-124, 63-76.

Sharma, A.N., Luo, D., Walter, M.T., 2012. Hydrological tracers using nanobiotechnology: proof of concept. Environmental Science and Technology 46 (16), 8928-8936.

Smart, P.L., Laidlaw, I.M.S., 1977. An evaluation of some fluorescent dyes for water tracing. Water Resources Research 13 (1), 15-33.

Sposito, G., 1998, Bodenchemie, Ferdinand-Enke-Verlag, Stuttgart.

Tolls, J., 2001. Sorption of veterinary pharmaceuticals in soils: a review. Environmental Science and Technology 35 (17), 3397-3406.

Tomich, J.F., Dalton Jr., R.L., Deans, H.A., Rice, U., Shallenberger, L.K., 1973. Single-well tracer method to measure residual oil saturation. Journal of Petroleum Technology 25 (2), 211-218.

Vulava, V.M., Perry, E.B., Romanek, C.S., Seaman, J.C., 2002. Dissolved gases as partitioning tracers for determination of hydrogeological parameters. Environmental Science and Technology 36 (2), 254-262.

Worch, E., 1993. Eine neue Gleichung zur Berechnung von Diffusionskoeffizienten gelöster Stoffe. Vom Wasser 81, 289-297.

Worch, E., 2012. Adsorption technology in water treatment. Fundamentals, processes, and modeling, De Gruyter, Berlin/Boston. 


\section{Chapter 2}

\section{Sorption influenced transport of ionizable pharmaceuticals onto a natural sandy aquifer sediment at different $\mathrm{pH}$}

Mario Schaffer ${ }^{1, *}$, Norman Boxberger ${ }^{2}$, Hilmar Börnick², Tobias Licha', Eckhard Worch ${ }^{2}$

\section{Citation:}

Schaffer, M., Boxberger, N., Börnick, H., Licha, T., Worch, E., 2012. Sorption influenced transport of ionizable pharmaceuticals onto a natural sandy aquifer sediment at different $\mathrm{pH}$. Chemosphere 87 (5), 513-520.

\footnotetext{
${ }^{1}$ Geoscience Centre, Dept. Applied Geology, University of Göttingen, Goldschmidtstr. 3, 37077 Göttingen, Germany

${ }^{2}$ Institute of Water Chemistry, Dresden University of Technology, 01062 Dresden, Germany

* Corresponding author
} 


\section{Abstract}

The $\mathrm{pH}$-dependent transport of eight selected ionizable pharmaceuticals was investigated by using saturated column experiments. Seventy-eight different breakthrough curves on a natural sandy aquifer material were produced and compared for three different $\mathrm{pH}$ levels at otherwise constant conditions. The experimentally obtained $K_{o c}$ data were compared with calculated $K_{o c}$ values derived from two different $\log K_{o w}-\log K_{o c}$ correlation approaches. A significant $\mathrm{pH}$ dependence on sorption was observed for all compounds with $\mathrm{p} K_{a}$ in the considered $\mathrm{pH}$ range. Strong retardation was measured for several compounds despite their hydrophilic character. Besides an overall underestimation of $K_{o c}$, the comparison between calculated and measured values only yields meaningful results for the acidic and neutral compounds. Basic compounds retarded much stronger than expected, particularly at low pH when their cationic species dominated. This is caused by additional ionic interactions, such as cation exchange processes, which are insufficiently considered in the applied $K_{o c}$ correlations 


\subsection{Introduction}

In the past decades the occurrence of numerous polar anthropogenic trace compounds, particularly residues from pharmaceuticals and their metabolites, were detected in the aquatic environment (Halling-Sørensen et al., 1998; Daughton and Ternes, 1999; Heberer, 2002). These hydrophilic and poorly degradable organics are able to survive wastewater treatment (Stumpf et al., 1999; Lindqvist et al., 2005; Reemtsma et al., 2006) and enter into the water cycle (Ternes, 1998; Heberer, 2002; Nödler et al., 2010; Nödler et al., 2011). The ubiquitous occurrence of pharmaceuticals is caused by their high consumption, e.g. for the anticonvulsant and mood stabilizing drug carbamazepine a worldwide annual consumption of 1,000 tons was estimated (Zhang et al., 2008).

The interface between water and natural solids (e.g., sediments in aquifers, river bank filtration, and soil aquifer treatment sites) plays an important role in the elimination of these compounds from the aqueous phase. In particular, the occurrence of sorption and degradation processes at the solid/water interfaces are known to be main attenuation processes (Katayama et al., 2010). Numerous environmentally relevant pharmaceuticals contain one or more dissociable functional groups (acidic/basic). Therefore, these compounds are in dissociation equilibrium and ionic depending on the $\mathrm{pH}$. Particularly for compounds with logarithmic acid dissociation constants $\mathrm{pK}_{a}$ in the typical groundwater $\mathrm{pH}$ range $(\mathrm{pH}=5-8)$, a highly $\mathrm{pH}$ dependent sorption behavior can be expected (Kah and Brown, 2007; Franco and Trapp, 2008; Franco et al. 2009).

Different authors demonstrated a strong $\mathrm{pH}$-dependence for the sorption of several ionizable compounds, e.g. Figueroa et al. (2004) for tetracycline, Vasudevan et al. (2009) for ciprofloxacin, and ter Laak et al. (2006) for three further antibiotics. In most cases, however, the experiments are limited to batch experiments under equilibrium conditions. Flow-through experiments with focus on $\mathrm{pH}$ under more realistic flow and sediment packing conditions are rarely available. Based on column experiments, a strong $\mathrm{pH}$-dependence on the transport was shown, e.g. for nalidixic acid on aquifer sand by Lorphensri et al. (2007) and for 32 organic acids on soil organic matter by Tülp et al. (2009). 
The objective of the presented study was the screening of $\mathrm{pH}$ effects on the sorption of further frequently used ionizable pharmaceuticals under dynamic conditions. For this purpose, ten column experiments with eight selected pharmaceuticals in natural sandy aquifer sediment were conducted and the resulting 78 breakthrough curves were compared. All physical and hydromechanical parameters were kept constant, only the $\mathrm{pH}$ was varied. The subsequent evaluation of the obtained breakthrough curves allows the determination and comparison of retardation factors and sorption coefficients $K_{o c}$ at different $\mathrm{pH}$ values. Additionally, the sediment was characterized to assess the influence of $\mathrm{pH}$ on the sorbent. As a result, the most important occurring processes and dependencies could be identified and compared, such as the role of speciation and the characteristics of the sediment. Additionally, the validity of two different $K_{o c}$ correlation approaches for the investigated compounds was studied. Furthermore, these results provide the basis for an improved understanding of sediment/water interactions and a more precise prognostic modeling of the sorption of ionizable compounds in further research.

\subsection{Theory and calculations}

The sorption influenced transport of medium to non-polar organic pollutants through porous media is often adequately predicted by means of compound (class) specific or unspecific $\log K_{o w}-\log K_{o c}$ correlations (Chiou et al., 1979; Karickhoff, 1981; Sabljic et al., 1995). Kow is the compound specific $n$-octanol/water distribution coefficient as polarity indicator and can be received for every compound of interest from literature data. $K_{o c}$ is the organic carbon normalized sorption coefficient and the practically applied parameter from these correlations in the retardation concept. The solid/water distribution coefficient $K_{d}$ for the considered compound is normalized to the fraction of organic carbon $f_{O C}$ in the solid phase yielding $K_{O C}$ :

$K_{O C}=\frac{K_{d}}{f_{O C}}$

If the distribution coefficient $K_{d}$, the bulk density $\rho$, and the effective porosity $n_{e}$ are known, the retardation factor $R$ can be calculated under the assumption of a linear sorption isotherm with: 


$$
R=1+\frac{\rho}{n_{e}} \cdot K_{d}
$$

As a consequence, significant retardation for non-polar compounds with high log $K_{\text {ow }}$ and hence also high $\log K_{o c}$ can be expected in the subsurface. For ionizable compounds an extended concept considering the $\mathrm{pH}$-dependent speciation of the sorbates within the water phase was applied. Here, the $\mathrm{pH}$-dependent $n$-octanol/water distribution coefficient $\log D$ was introduced into the correlation instead of log Kow:

$\log K_{\text {OC }}=A \cdot \log D+B$

In this work, $A$ and $B$ are empirical parameters for non-hydrophobic compounds with values of 0.52 and 1.02 (Sabljic et al., 1995), respectively. The corresponding $\log D$ for alkaline or acidic compounds can be calculated from log $K_{\text {ow }}$ and the acidity constant $\mathrm{p} K_{a}$ for every $\mathrm{pH}$ level (Scherrer and Howard, 1977):

$$
\begin{aligned}
& \log D_{\text {acid }}=\log K_{\text {ow }}+\log \left(\frac{1}{1+10^{p H-p K_{a}}}\right) \\
& \log D_{\text {base }}=\log K_{\text {ow }}+\log \left(\frac{1}{1+10^{p K_{a}-p H}}\right)
\end{aligned}
$$

Thus, the concentration for the anionic species of acids relative to its conjugate neutral species increases with increasing $\mathrm{pH}$. Simultaneously, $\log D$ decreases resulting in lower log $K_{o c}$ and thus $R$. In contrast, bases become cationic due to the increasing protonation at decreasing $\mathrm{pH}$ values. Additionally, two recent non-linear $K_{O C}$ regressions for organic acids and bases were used (Franco and Trapp, 2008):

$$
\begin{aligned}
& \log K_{O C \text { (acid) }}=\log \left(\frac{10^{0.54 \cdot \log K_{o W}+1.11}}{1+10^{p H-0.6-p K_{a}}}+\frac{10^{0.11 \cdot \log K_{o W}+1.54}}{1+10^{p K_{a}-p H+0.6}}\right) \\
& \log K_{\text {OC (base) }}=\log \left(\frac{10^{0.37 \cdot \log K_{O W}+1.70}}{1+10^{p K_{a}-p H}}+\frac{10^{p K_{a}^{0.55} \cdot f}}{1+10^{p H-p K_{a}}}\right) \text { with } f_{p H=7}=\frac{D_{\text {base }}+D_{\text {acid }}}{1+D_{\text {base }}+D_{\text {acid }}}
\end{aligned}
$$

The parameter $f$ expresses a diffusion limiting factor. For calculating the $\mathrm{pH}$ dependent $K_{o c}$ values for bases with Eq. (2.7) Franco and Trapp's (2008) suggestion was adopted to use the variable sediment $\mathrm{pH}$ instead of the fixed, optimal regression $\mathrm{pH}_{\mathrm{opt}}=4.5$. However, Franco et al. (2009) showed that the implementation of $\mathrm{pH}$ into 
these regressions is only expedient for acids to predict the $\mathrm{pH}$ effect on sorption. The $K_{o c}$ of zwitter-ionic compounds can not be calculated.

The application of the modified empirical $K_{o c}$ correlation in Eq. (2.3) has its limitations. These limitations apply particularly to compounds having several functional groups (e.g., zwitter-ions) with more than one $\mathrm{p} K_{a}$. Furthermore, the general transferability of the $K_{o c}$ concept to ionizable compounds is questionable as only non-polar interactions and partitioning to the sediment total organic carbon content TOC are considered (Sabljic, 1989). Nevertheless, a strong correlation between $\log K_{O c}$ and $\log K_{o w}$ was found for cationic bases in an earlier study (Franco and Trapp, 2008). Consequently, this must lead to an underestimation of $K_{o c}$ and $K_{d}$ for ionizable organic compounds (Tolls, 2001; Cunningham et al., 2004; Kah and Brown, 2007) when additional processes are involved such as ion exchange, cation bridging, surface complexation, and hydrogen bonding. These additional processes and their relative importance depend on the nature of the sorbent (sediment) (Nicholls and Evans, 1991; Tolls, 2001; Kwon and Armbrust, 2008; Figueroa-Diva et al., 2010). As such, additional properties of the sediment other than TOC have to be considered. These are specific surface area, $\mathrm{pH}$, cation exchange capacity (CEC), charge properties and the mineral composition of the sediment.

\subsection{Materials and methods}

\subsubsection{Pharmaceuticals}

For the column studies eight human pharmaceuticals ( 3 bases, 4 acids, 1 zwitter) with a wide range of $\mathrm{p} K_{a}$ values were selected (Table 2.1). Therefore, the presence of differently charged species (cation, anion, zwitter-ion) in the experiments is guaranteed and the investigation of $\mathrm{pH}$ effects becomes feasible. The investigated compounds included the beta blocker atenolol, the tranquilizer diazepam, the nonsteroidal anti-inflammatory drug naproxen, and the anticonvulsant phenobarbital from Fagron (Barsbüttel, Germany); the anticonsulvants carbamazepine and primidone from Sigma-Aldrich (Steinheim, Germany); the antihistamine cetirizine from KSK-Pharma (Berghausen, Germany); and the antibiotic trimethoprim from Fluka (Neu-Ulm, Germany). All compounds had a purity $>98 \%$. Compound 
concentrations from the experiments were determined using high pressure liquid chromatography and UV detection (details see Appendix A1).

Table 2.1 Chemical properties, structures and speciation of the sorbates.

\begin{tabular}{|c|c|c|c|c|c|c|}
\hline \multirow{2}{*}{$\begin{array}{c}\text { Compound } \\
\text { Detect. wavelength } \lambda\end{array}$} & \multirow{2}{*}{ Structure } & \multirow{2}{*}{$\begin{array}{c}\mathrm{p} K_{a}^{\mathrm{a}} \\
\text { (Character })\end{array}$} & \multirow{2}{*}{$\log K_{o w}{ }^{a}$} & \multicolumn{3}{|c|}{ Species $^{\mathrm{d}}$ at pH $=$} \\
\hline & & & & 4 & 6 & 8 \\
\hline $\begin{array}{c}\text { Atenolol } \\
\lambda=227 \mathrm{~nm}\end{array}$ & & $\begin{array}{l}9.2 \pm 0.4^{*} \\
\text { (B) }\end{array}$ & $0.1 \pm 0.28$ & + & + &,+ 0 \\
\hline $\begin{array}{c}\text { Carbamazepine } \\
\lambda=232 \mathrm{~nm}\end{array}$ & & $\begin{array}{c}-0.49 \pm 0.2^{*} \\
\text { (B) }\end{array}$ & $2.67 \pm 0.38$ & 0 & 0 & 0 \\
\hline $\begin{array}{c}\text { Cetirizine } \\
\lambda=232 \mathrm{~nm}\end{array}$ & & $\begin{array}{c}2.2^{b} \\
2.9^{b} \\
8.0^{b} \\
(A / B)\end{array}$ & $1.62 \pm 0.63$ &,$++/-$ & $+/-$ & $+/-,-$ \\
\hline $\begin{array}{l}\text { Diazepam } \\
\lambda=232 \mathrm{~nm}\end{array}$ & & $\begin{array}{l}3.4 \pm 0.1^{*} \\
\text { (B) }\end{array}$ & $2.96 \pm 0.55$ &,+ 0 & 0 & 0 \\
\hline $\begin{array}{l}\text { Naproxen } \\
\lambda=215 \mathrm{~nm}\end{array}$ & & $\begin{array}{c}4.8 \pm 0.3 \\
(\mathrm{~A})\end{array}$ & $3.0 \pm 0.24$ & $0,-$ & - & - \\
\hline $\begin{array}{c}\text { Phenobarbital } \\
\lambda=243 \mathrm{~nm}\end{array}$ & & $\begin{array}{l}7.6 \pm 0.1 \\
(\mathrm{~A})\end{array}$ & $0.53 \pm 0.26$ & 0 & 0 & - \\
\hline $\begin{array}{l}\text { Primidone } \\
\lambda=215 \mathrm{~nm}\end{array}$ & & $\begin{array}{l}12.3 \pm 0.4 \\
\text { (A) }\end{array}$ & $0.4 \pm 0.52$ & 0 & 0 & 0 \\
\hline $\begin{array}{c}\text { Trimethoprim } \\
\lambda=225 \mathrm{~nm}\end{array}$ & & $\begin{array}{l}7.2 \pm 0.1^{*} \\
\text { (B) }\end{array}$ & $0.79 \pm 0.38$ & + & + &,+ 0 \\
\hline
\end{tabular}

a SciFinder Scholar 2007 predicted values, calculated using Advanced Chemistry Development (ACD/Labs) Software V11.02 (1994-2011 ACD/Labs), unless otherwise noted; all log Kow values refer to the neutral species.

${ }^{b}$ van Balen et al., 2001.

'Character of ionizable functional group: (A) acidic, (B) basic, (A/B) acidic and basic functional groups (zwitter).

${ }^{d}$ Charge of the occurring relevant species at certain $\mathrm{pH}$ according to their $\mathrm{p} K_{a}:(0)$ neutral, $(+)$ cation, $(-)$ anion, $(+/-)$ zwitter.

* All $\mathrm{p} K_{a}$ values given for bases refer to $\mathrm{p} K_{a}$ values for the conjugate acid (protonated species). 


\subsubsection{Sediment}

A fluvial river bed sediment from a former tributary of the Elbe River close to the city of Torgau, Germany was used for the experiments. The grain size fractions of clay $(0.7 \%,<2 \mu \mathrm{m})$ and silt $(3.5 \%,<63 \mu \mathrm{m})$ of this coarse medium sand $(>95 \%, 63-$ 2,000 $\mu \mathrm{m}$ ) are very low (Amiri et al., 2005). Before column packing, the sediment was sieved and the homogenized fraction $<2 \mathrm{~mm}$ was used. The clay and silt fraction $<63 \mu \mathrm{m}$ consists mainly of quartz (10\%) and the layered silicate minerals mica (muscovite, illite, biotite, 35\%), kaolinite (40\%), and chlorite ( $<5 \%)$. Quartz, muscovite, illite, and chlorite minerals possess points of zero charge (PZC) lower than 4 and provide therefore negatively charged surfaces over the entire considered $\mathrm{pH}$ range. Mainly due to carboxylic groups $\left(\mathrm{p} K_{a}=4-5\right)$, the solid organic matter also represents an important source for variable negative charges. As a consequence, sorption and exchange of cations is possible at even lower $\mathrm{pH}$ levels. Measured sediment properties are listed in Table 2.2 and further information on sediment characterization methods are available in Appendix A2.

Table 2.2 Physicochemical properties of the used sorbent and column experimental conditions.

\begin{tabular}{|c|c|c|c|}
\hline \multicolumn{2}{|c|}{ Sorbent and bulk properties } & \multicolumn{2}{|c|}{ Column conditions for all runs } \\
\hline BET $\left[\mathrm{m}^{2} \mathrm{~g}^{-1}\right]$ & 1.9 & $L[\mathrm{~cm}]$ & 25 \\
\hline $\mathrm{pH}\left(\mathrm{CaCl}_{2}\right)[-]$ & 5.85 & $A\left[\mathrm{~cm}^{2}\right]$ & 9.2 \\
\hline $\mathrm{pH}\left(\mathrm{H}_{2} \mathrm{O}\right)[-]$ & 6.20 & $Q\left[\mathrm{~cm}^{3} \mathrm{~min}^{-1}\right]$ & 0.82 \\
\hline$\rho_{b}\left[\mathrm{~g} \mathrm{~cm}^{-3}\right]$ & $1.78 \pm 0.03$ & $v_{f}\left[\mathrm{~m} \mathrm{~d}^{-1}\right]$ & 1.28 \\
\hline$\rho_{s}\left[\mathrm{~g} \mathrm{~cm}^{-3}\right]$ & 2.65 & $v_{w}\left[\mathrm{~m} \mathrm{~d}^{-1}\right]$ & 3.77 \\
\hline$n_{e}[-]$ & $0.340 \pm 0.02$ & $c_{0}\left[\mu \mathrm{g} \mathrm{L}^{-1}\right]$ & 500 \\
\hline$f_{O C}\left[\mathrm{mg} \mathrm{g}^{-1}\right]$ & $2.33(0.23 \%)$ & & \\
\hline $\mathrm{CEC}_{\mathrm{pH}=8.1}\left[\mathrm{cmol}_{\mathrm{c}} \mathrm{kg}^{-1}\right]$ & 1.36 & & \\
\hline $\mathrm{CEC}_{\mathrm{pH}=6.2}\left[\mathrm{cmol}_{\mathrm{c}} \mathrm{kg}^{-1}\right]$ & 0.74 & & \\
\hline
\end{tabular}

BET $=$ specific surface area, $\rho_{b}=$ bulk density, $\rho_{s}=$ solid density, $n_{e}=$ effective porosity, $f_{O c}=$ fraction of organic carbon, $\mathrm{CEC}=$ cation exchange capacity at certain $\mathrm{pH}, L=$ column length, $A=$ cross-sectional area of column, $Q=$ flow,$v_{f}=$ filter velocity,$v_{w}=$ porewater velocity,$c_{0}=$ initial concentration 


\subsubsection{Water matrix}

Elbe river water, sampled in Dresden, Germany was filtered (cellulose nitrate, $<0.45 \mu \mathrm{m})$ to remove all suspended or colloidal substances and used for the experiments. The dissolved organic carbon DOC ranged between 4.6 and $7.5 \mathrm{mg} \mathrm{L}^{-1}$. Natural $\mathrm{pH}$ of the river water was around 7.5 and was adjusted with $\mathrm{NaOH}$ or $\mathrm{HCl}$ to the $\mathrm{pH}$ levels of 4,6 , and 8 . The stability of $\mathrm{pH}$ was controlled over time at the inflow and outflow of the columns. After one week equilibration time, a mixture of the eight pharmaceuticals was added to the reservoir. Due to initial concentrations of $c_{0}=500 \mu \mathrm{g} \mathrm{L}^{-1}$ the investigation and direct measurement without concentration steps prior to chemical analysis was possible.

\subsubsection{Column experiments}

Stainless steel columns with dimensions of $250 \times 34 \mathrm{~mm}$ were used for the experiments. Hydromechanical properties of the columns were kept constant for every single experiment and did not change over time (Table 2.2). The bulk parameter $n_{e}$ was calculated from the breakthrough curves of a conservative $\mathrm{Cl}^{-}$ tracer $(\mathrm{NaCl})$ before and after the experiments. In order to guarantee saturated conditions the water was pumped in up-flow direction. All column experiments were carried out at a constant temperature of $10^{\circ} \mathrm{C}$.

During the experiments the columns were purged with water, containing the pharmaceutical mixture, and the breakthrough behavior of each pharmaceutical was measured over time. The samples were taken with respect to the required temporal resolution. All experiments were verified by repeating each experiment at least three times, except for trimethoprim at $\mathrm{pH}=8$ which was not repeated. The breakthrough curves and the hydraulic and sediment parameters of all experiments at the same $\mathrm{pH}$ level were averaged before modeling to reduce statistical uncertainties caused by sediment heterogeneities. The evaluation of the obtained experimental breakthrough curves was achieved by an iterative parameter-fitting procedure based on the one-dimensional, analytical solution of the advection-dispersion-equation under equilibrium conditions. In addition, two sink terms for sorption and degradation processes are implemented (Van Genuchten, 1982; Wexler, 1992). The 
optimization parameters of this model are $R$, the effective dispersivity $a_{\text {eff, }}$ and a firstorder kinetic degradation rate. Possible effects caused by sorption kinetics are included in $a_{\text {eff }}$ already (Rahman et al., 2003; Worch, 2004).

Initially, $K_{d}$ was derived in Eq. (2.2) from the modeled $R$ of the breakthrough curves. Afterwards, $K_{o c}$ was calculated by the use of Eq. (2.1). These experimental $K_{o c}$ values were compared with calculated values on the basis of the correlation in Eq. (2.3) by the use of $\log K_{\text {ow }}$ from literature and with Eq. (2.4) and Eq. (2.5) calculated $\log D$, respectively. Additionally the experimental results were compared with the correlation results obtained from Eq. (2.6) and (2.7) (Franco and Trapp, 2008).

\subsection{Results and discussion}

All $K_{O C}$ values derived from the column experiments are given in Figure 2.1 and the corresponding breakthrough curves are shown in Figure 2.2. The comparison of measured with correlated data after Franco and Trapp (2008) is given in Figure A1 (see Appendix A).

\subsubsection{Acidic compounds}

Two acidic compounds (naproxen, phenobarbital) with their anionic species occurring in the investigated $\mathrm{pH}$ range were investigated. A general low retardation was measured for phenobarbital. $R$ ranges between 1.6 at $\mathrm{pH}=4$ and 1.1 at $\mathrm{pH}=8$. The appearing weak $\mathrm{pH}$-dependence is caused by a hydroxyl group due to a lactamlactim tautomerization in the barbituric substructure. This group leads to the resulting $\mathrm{p} K_{a}$ and becomes deprotonated with increasing $\mathrm{pH}$. The increasing anionic character makes the molecule more polar, thus resulting in a decrease in retardation. The comparison of the measured and calculated $K_{o c}$ values shows moderate differences. At this point, it is obvious that the relative error of the measured $K_{o c}$ is considerable at small $R$ around 1 (see Eq. 2.2).

A higher retardation and $\mathrm{pH}$-dependence was observed for naproxen. $R$ decreases from 7.7 at $\mathrm{pH}=4$ to 1.4 at $\mathrm{pH}=8$. The increasing deprotonation of the carboxyl group with increasing $\mathrm{pH}$ changes the molecule to the hydrophilic anionic form. 
Except at $\mathrm{pH}=8$, where the $\log D$ seems underestimated, accordance between experimental and calculated $K_{o c}$ was found. In general, the two investigated acidic compounds seem to confirm the expected transport behavior received from the modified Koc concept as well as from the regression of Franco and Trapp (2008).

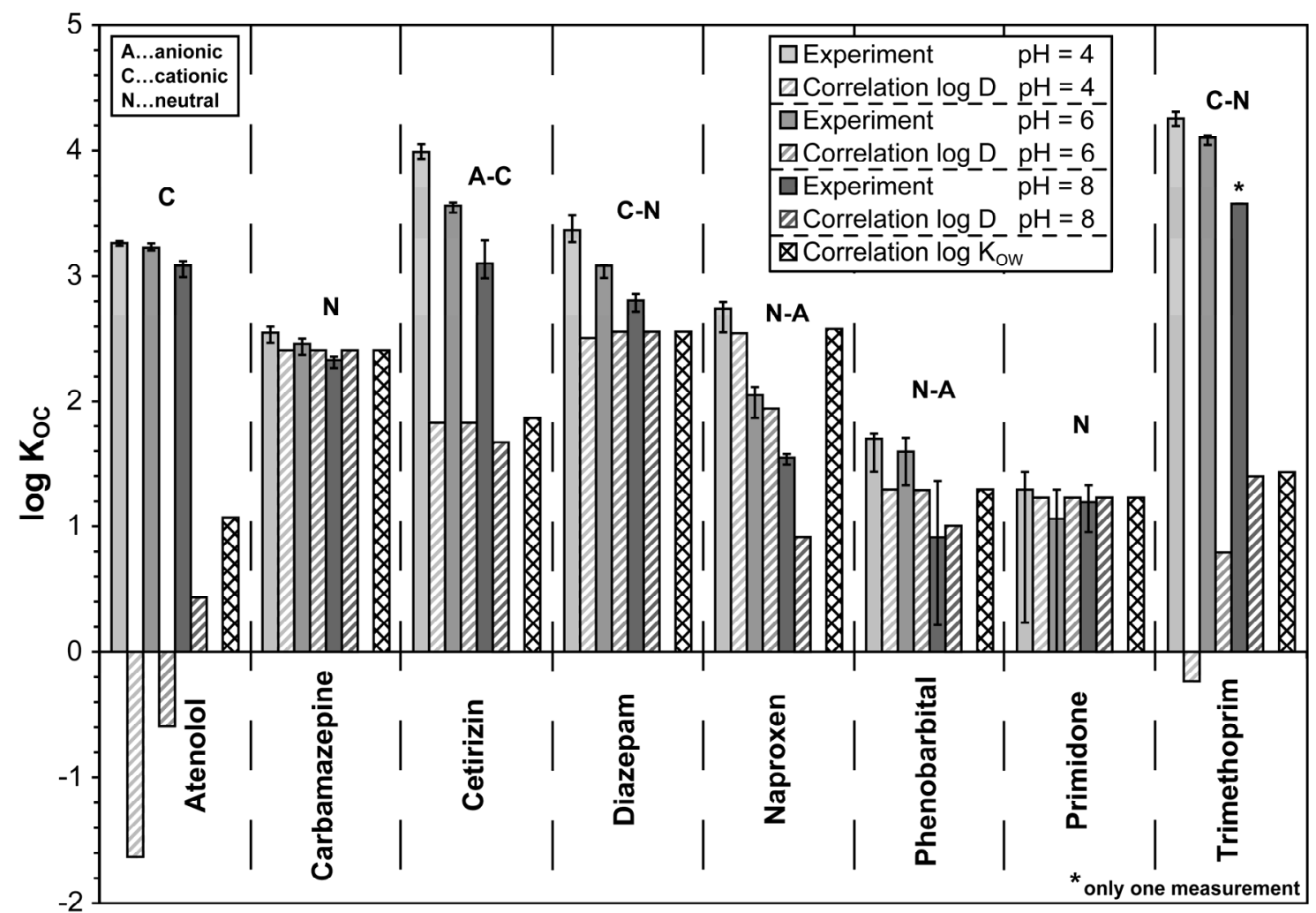

Fig. 2.1 Average from column experiments derived log $K_{o c}$ values (uniform columns) compared with estimated $\log K_{o c}$ values (hatched columns) calculated with a modified log $K_{o w}$ log $K_{o c}$ correlation after Sabljic et al. (1995) for all compounds at $\mathrm{pH}=4, \mathrm{pH}=6$, and $\mathrm{pH}=8$. Error bars indicate the range of experimentally derived $\log K_{o c}$ for at least three measurements, except for TRI at $\mathrm{pH}=8$.

\subsubsection{Neutral compounds}

The validity of the $K_{o c}$ concept together with no $\mathrm{pH}$-dependence of the retardation was expected for the two neutral compounds primidone and carbamazepine because of their $\mathrm{p} K_{a}$ values being far beyond the investigated $\mathrm{pH}$ range.

Primidone has shown low retardation as well as its main metabolite phenobarbital. For all considered $\mathrm{pH}$ levels, $\mathrm{R}$ remains around 1.2. No dependence from $\mathrm{pH}$ could be detected. A theoretically possible deprotonation of the hydroxyl group due to a 
lactam-lactim tautomerization cannot occur at the experimental $\mathrm{pH}$ values. So, the molecule stays in its neutral form and is very mobile because of its low log Kow.

According to the higher $\log K_{\text {ow }}, R$ between 5.3 at $\mathrm{pH}=4$ and 3.6 at $\mathrm{pH}=8$ were found for carbamazepine. Because of its very low $\mathrm{p} K_{a}$, only the neutral form of carbamazepine is the clearly dominating species at all investigated $\mathrm{pH}$ levels. Despite this, a weak $\mathrm{pH}$-dependence was registered. The weak decrease in retardation for carbamazepine with increasing $\mathrm{pH}$ originates from the significantly higher log Kow compared to primidone. The probability for hydrophobic interactions with the sediment decreases with rising $\mathrm{pH}$ due to the increasing deprotonation of the functional groups (mainly carboxyl and hydroxyl groups) on the sediment organic matter with increasing $\mathrm{pH}$. As these interactions dominate the sorption process for carbamazepine (Scheytt et al., 2005) and other neutral compounds with higher log Kow their retardation decreases, too. In contrast, the influence of the $\mathrm{pH}$ dependent sediment charge on the sorption of the very polar compound primidone seems to be negligible. As expected, the two applied correlations gave similar and acceptable results for neutral compounds.

\subsubsection{Alkaline compounds}

Strongest retardations and therefore highest $\log K_{o c}$ values were observed for the cationic compounds atenolol, diazepam, and trimethoprim. In contrast to organic acids, the nitrogen bearing functional groups in these compounds are protonated and thus ionic below their $\mathrm{p} K_{a}$. An increase of $\mathrm{pH}$ leads to a shift of the dissociation equilibrium in favor of the neutral species. Hence, the hydrophobicity and $\log D$ values increase with rising $\mathrm{pH}$. However, the $\mathrm{pH}$-dependent retardation of the compounds investigated in this study shows an inverted image. $R$ decreased from 23.3 to 15.8 for atenolol, from 29.4 to 8.8 for diazepam and from 219.6 to 47.0 for trimethoprim with increasing $\mathrm{pH}$ from 4 to 8. Despite of the non-protonated, neutral species becoming the dominating species the retardation decreases with increasing $\mathrm{pH}$. Therefore, the modified $K_{o c}$ concept fails to predict the sorption behavior of these alkaline substances. Even worse, the implementation of $\log D$ intended to correct for neutral/charged species distribution further enhances the differences between estimated and measured log $K_{o c}$ data. Much better results were obtained by 
using the specific correlation for bases from Franco and Trapp (2008). In contrast to the modified $K_{o c}$ concept, at least the trend of decreasing sorption with increasing $\mathrm{pH}$ could be reproduced. Nevertheless, absolute $K_{o c}$ values are still underestimated.

An additional sorption process has to be responsible for the increasing sorption of the cationic species. The existence and dominating role of cation exchange processes on the retardation was earlier reported for the beta-blocker atenolol (Yamamoto et al., 2009) as well as for the antibiotic trimethoprim (Bekçi et al., 2006; Qtaitat, 2004). This is plausible since the composition of the sediment (TOC, minerals) gives evidence for the presence of negatively charged surfaces at all here investigated $\mathrm{pH}$ levels (see Chapter 2.3.2). Also, Figueroa et al. (2004), Carmosini and Lee (2009), and Vasudevan et al. (2009) could highlight the importance of cation exchange processes for the cationic species of tetracycline antibiotics and the fluoroquinoline ciprofloxacin on negatively charged surfaces. Therefore, the shown similar behavior is likely for the further investigated basic compound diazepam. Atenolol at $\mathrm{pH}=8$ is the only substance which was noticeably biodegraded (to $80 \%$ of $c_{0}$ ) during the experiments (Fig. 2.2).

\subsubsection{Zwitter-ionic compounds}

The zwitter-ionic character of cetirizine in the considered $\mathrm{pH}$ range is caused by two basic reacting tertiary amine groups with $\mathrm{p} K_{a}$ of 2.2 and 8.0, respectively and one acidic carboxyl group with $\mathrm{p} K_{a}$ of 2.9. At $\mathrm{pH}$ values close to 4 and 8, cetirizine occurs as a monovalent cation and a monovalent anion, respectively. The $\log D$ value changes minimally between $\mathrm{pH}=4$ and $\mathrm{pH}=8$ (van Balen et al., 2001) and only a weak $\mathrm{pH}$-dependence may be expected. But in contrast to this presumption, a strong $\mathrm{pH}$-influence associated with a much higher retardation was observed. The reason for such behavior might be explained by a combination of the above-mentioned effects. At low pH the cationic species with positive partial charges are dominating. Therefore, the affinity to negative charged sediment surfaces is high and the molecules are able to sorb due to cation exchange. With increasing $\mathrm{pH}$ the positive charges of cetirizine becomes weaker because of an increased deprotonation. As a result, the sorption due to cation exchange is reduced and the retardation factors decrease drastically from 130 at $\mathrm{pH} 4$ to 16 at $\mathrm{pH} 8$. 
Alkaline compounds

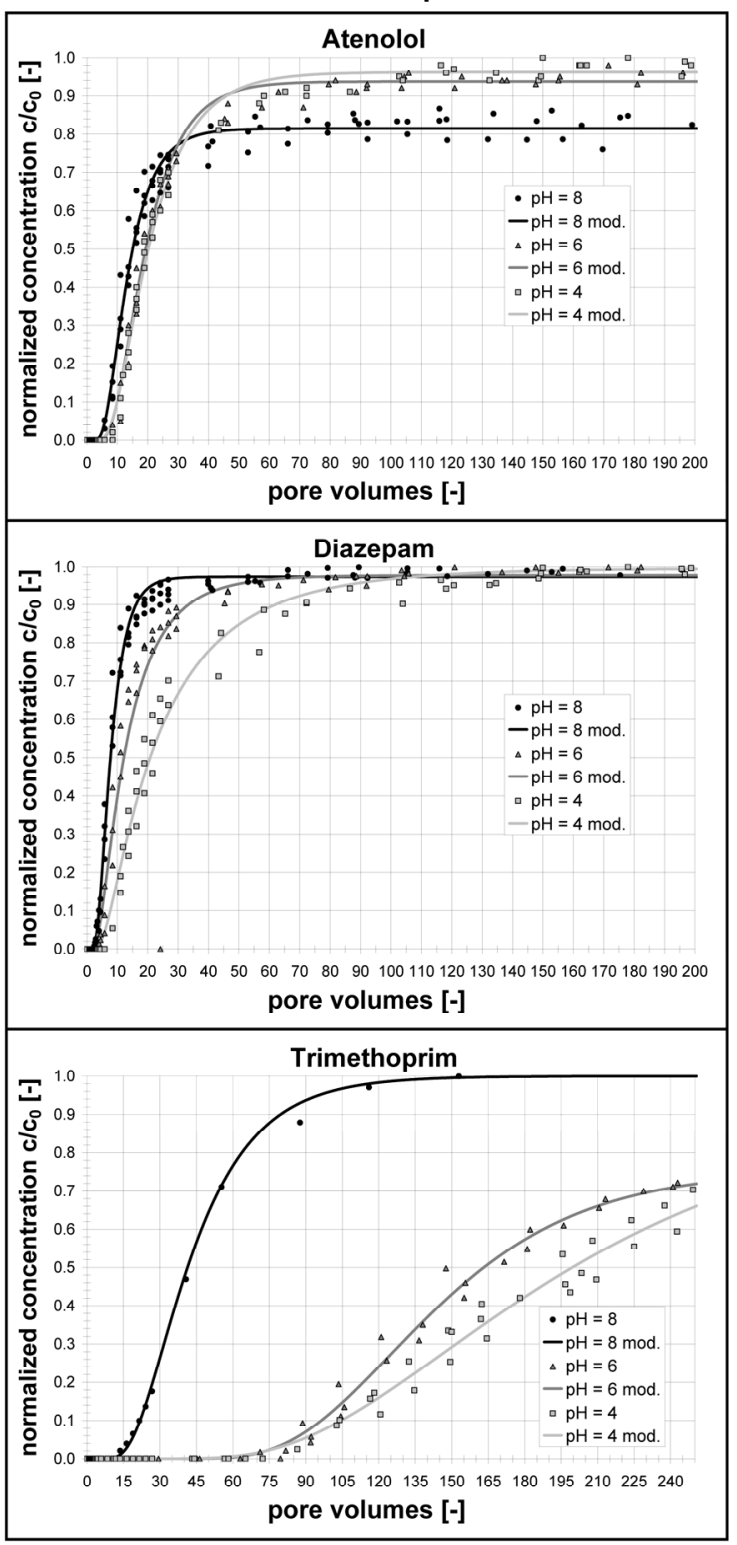

Zwitter-ionic compounds

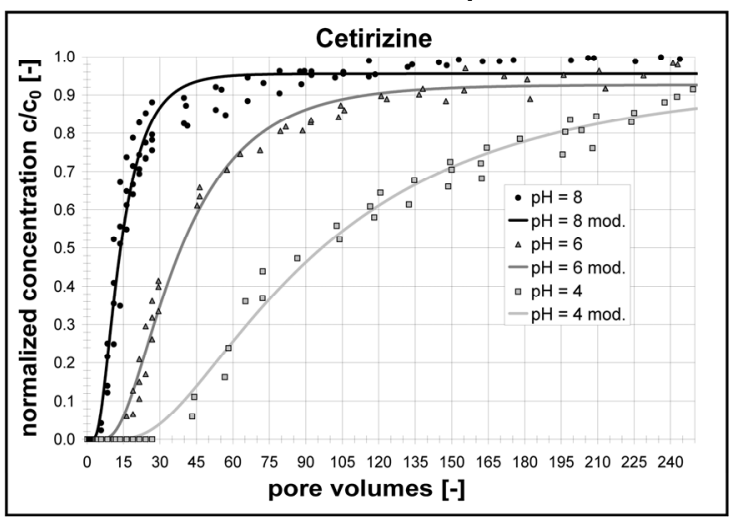

Acidic compounds

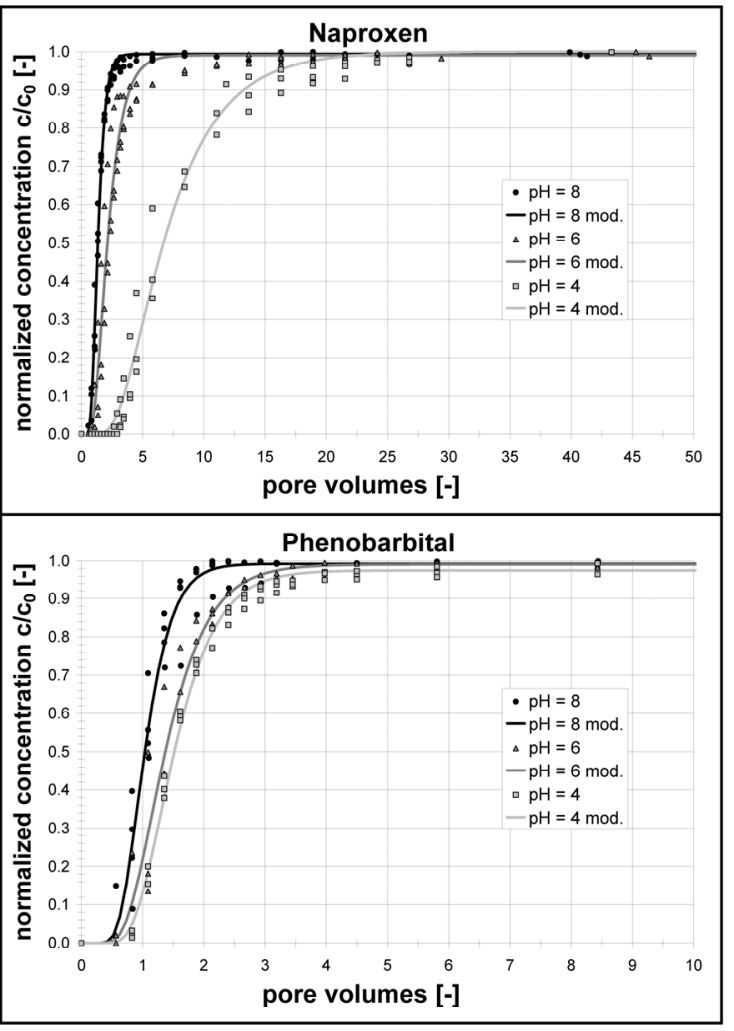

Neutral compounds

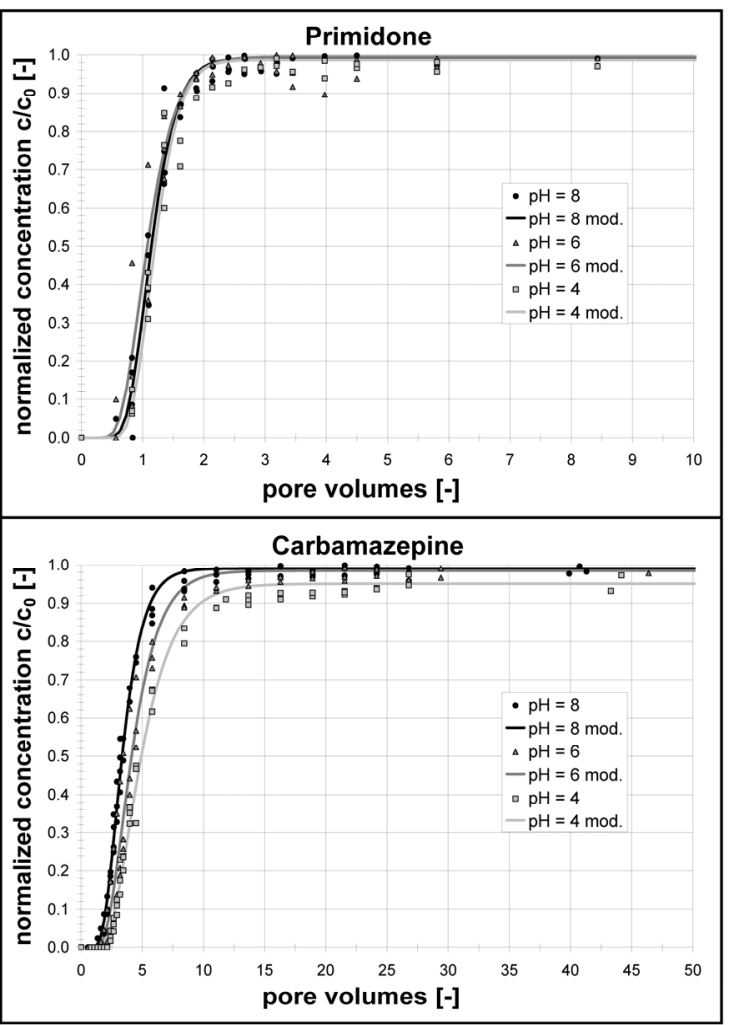

Fig. 2.2 Experimental and modeled breakthrough curves for eight pharmaceuticals at $\mathrm{pH}=4$, $\mathrm{pH}=6$, and $\mathrm{pH}=8$ showing the $\mathrm{pH}$-dependence for different compounds and a wide spectrum of $\mathrm{pK}_{a}$. Concentrations $\mathrm{c}$ of the breakthrough curves were normalized with the initial concentration $c_{0}$. Pore volumes were calculated by normalizing the experiment duration to the breakthrough time of the $\mathrm{Cl}^{-}$tracer. 


\subsection{Summary and conclusions}

As expected, a strong $\mathrm{pH}$-dependence of the transport behavior was observed for the majority of the investigated compounds. When analyzed outside the considered $\mathrm{pH}$ range $\left(\mathrm{p} K_{a}>9\right.$ or $\left.\mathrm{p} K_{a}<3\right)$ the compounds atenolol, carbamazepine, and primidone, with very high and low $\mathrm{p} K_{a}$ values, respectively, occur mainly as one species. Therefore, no or only a weak dependence from $\mathrm{pH}$ was registered. Retardations of all compounds were significant, except for primidone and phenobarbital. Despite of the low sediment TOC, $R$ ranged between 3 and 248 .

According to the literature (Tolls, 2001; Kah and Brown, 2007; Lorphensri et al., 2007; Yamamoto et al., 2009; Figueroa-Diva et al., 2010) it was established that the prediction of mobility applying $\log K_{o w}-\log K_{O C}$ correlations has considerable limitations for ionizable compounds. Large differences and an overall underestimation between measured and calculated $K_{o c}$ values were obtained for the majority of the applied substances. Only for the neutral compounds carbamazepine and primidone the $K_{o c}$ concept gave confident results.

The weak pH-dependence of the neutral compound carbamazepine was explained with a decrease of non-polar interactions with increasing $\mathrm{pH}$ due to the deprotonation of the functional groups on the sediment TOC. The implementation of $\log D$ instead of $\log K_{o w}$ into the calculation of $\log K_{o c}$ or the use of the correlation after Franco and Trapp (2008) enhances the prediction particularly for the acidic, partially anionic compounds naproxen and phenobarbital.

In contrast, the organic bases atenolol, trimethoprim and the zwitter-ion cetirizine with partially positive charges have shown much higher retardations than calculated from log $K_{o w}$ and have therefore the most substantial differences to the predicted $K_{o c}$ values. The integration of $\log D$ amplifies these differences. The reason is that in the $\log D$ concept only the speciation in solution is considered and additional occurring polar interactions to the sorbent are neglected. Particularly, the dominating role of cation exchange processes as a sorption process on negatively charged surfaces must be considered, even for sediments with very low CEC. Therefore, a general strong retardation of organic cations can be expected in non-tropic, permanently charged sediments and soils with higher $\mathrm{pH}$, such as the used sediment, as they usually have negative net surface charges (Sollins et al., 1988). Due to the preferable 
results achieved from Franco and Trapp (2008) it is more reliable to predict the sorption of organic bases with this regression. Nevertheless, considerable differences to the measured data still exist.

Moreover, it can be concluded that the $\mathrm{pH}$-dependent speciation has a bigger influence on the cation sorption than the $\mathrm{pH}$ induced charge variation of the sediment. Furthermore, the development and dynamics of sediment surface charges due to chemical processes are essential for estimating the transport behavior. As ion exchange and other polar interactions are possible sorption processes for the ionic species, further boundary conditions should be considered, like competition with other ions, interactions to dissolved organic matter, and specific sorption mechanisms.

The investigation has shown that the $\mathrm{pH}$ has a significant influence on the retardation of ionizable organic compounds. As a consequence, it can be noted that already small changes in the $\mathrm{pH}$ will have a big influence on the mobility of ionizable organic compounds. Hence, changes of $\mathrm{pH}$ caused by variations in, e.g. land use or climatic conditions might have considerable effects on the transport and retardation of organic pollutants. For this purpose, it is also essential to know that dominating sorption mechanisms can change from hydrophobic to ionic interactions and vice versa in dependence of the $\mathrm{pH}$ and sediment types. Simple prognostic models based on hydrophobic interactions like the $K_{o c}$ concept are not able to consider these effects. The more complex model approach of Franco and Trapp (2008) gives better but still unconvincing results and shows the limitations of empirical correlations. Therefore, new mechanistic, process-based approaches, considering further relevant boundary conditions, are necessary.

\subsection{Acknowledgment}

The presented study was funded by the European Commission (contract number 518118-1, GABARDINE, "Groundwater Artificial Recharge Based on Alternative Sources of Water: Advanced Integrated Technologies and Management"). 


\subsection{References}

Amiri, F., Börnick, H., Worch, E., 2005. Sorption of phenols onto sandy aquifer material: the effect of dissolved organic matter (DOM). Water Research 39 (5), 933-941.

Bekçi, Z., Seki, Y., Yurdakoç, M.K., 2006. Equilibrium studies for trimethoprim adsorption on montmorillonite KSF. Journal of Hazardous Materials 133 (1-3), 233-242.

Carmosini, N., Lee, L.S., 2009. Ciprofloxacin sorption by dissolved organic carbon from reference and bio-waste materials. Chemosphere 77 (6), 813-820.

Chiou, C.T., Peters, L.J., Freed, V.H., 1979. A Physical concept of soil-water equilibria for nonionic organic compounds. Science 206 (4420), 831-832.

Cunningham, V.L., Constable, D.J.C., Hannah, R.E., 2004. Environmental risk assessment of paroxetine. Environmental Science and Technology 38 (12), 3351-3359.

Daughton, C.G., Ternes, T.A., 1999. Pharmaceuticals and personal care products in the environment: Agents of subtle change? Environmental Health Perspectives 107 (Suppl 6), 907-938.

Figueroa, R.A., Leonard, A., MacKay, A.A., 2004. Modeling tetracycline antibiotic sorption to clays. Environmental Science and Technology 38 (2), 476-483.

Figueroa-Diva, R.A., Vasudevan, D., MacKay, A.A., 2010. Trends in soil sorption coefficients within common antimicrobial families. Chemosphere 79 (8), 786-793.

Franco, A., Trapp, S., 2008. Estimation of the soil-water partition coefficient normalized to organic carbon for ionizable organic chemicals. Environmental Toxicology and Chemistry 27 (10), 19952004.

Franco, A., Fu, W., Trapp, S., 2009. Influence of soil pH on the sorption of ionisable chemicals: modelling advances. Environmental Toxicology and Chemistry 28 (3), 458-464.

Halling-Sørensen, B., Nors Nielsen, S., Lanzky, P.F., Ingerslev, F., Holten Lützhøft, H.C., Jørgensen, S.C., 1998. Occurrence, fate and effects of pharmaceutical substances in the environment - a review. Chemosphere 36 (2), 357-393.

Heberer, T., 2002. Occurrence, fate, and removal of pharmaceutical residues in the aquatic environment: a review of recent research data. Toxicology Letters 131 (1-2), 5-17.

Kah, M., Brown, C.D., 2007. Prediction of the adsorption of ionizable pesticides in soils. Journal of Agricultural and Food Chemistry 55 (6), 2312-2322.

Karickhoff, S.W., 1981. Semi-empirical estimation of sorption of hydrophobic pollutants on natural sediments and soils. Chemosphere 10 (8), 833-846.

Katayama, A., Bhula, R., Burns, G.R., Carazo, E., Felsot, A., Hamilton, D., Harris, C., Kim, Y.-H., Kleter, G., Koerdel, W., Linders, J., Peijnenburg, J.G.M.W., Sabljic, A., Stephenson, R.G., Racke, D.K., Rubin, B., Tanaka, K., Unsworth, J., Wauchope, R.D., 2010. Bioavailability of xenobiotics in the soil environment. Reviews of Environmental Contamination and Toxicology 203, 1-86.

Kwon, J.-W., Armbrust, K.L., 2008. Aqueous solubility, n-octanol-water partition coefficient, and sorption of five selective serotonin reuptake inhibitors to sediments and soils. Bulletin of Environmental Contamination and Toxicology 81 (2), 128-135.

Lindqvist, N., Tuhkanen, T., Kronberg, L., 2005. Occurrence of acidic pharmaceuticals in raw and treated sewages and in receiving waters. Water Research 39 (11), 2219-2228. 
Lorphensri, O., Sabatini, D.A., Kibbey, T.C.G., Osathaphan, K., Saiwan, C., 2007. Sorption and transport of acetaminophen, 17a-ethynyl estradiol, nalidixic acid with low organic content aquifer sand. Water Research 41 (10), 2180-2188.

Nicholls, P.H., Evans, A.A., 1991. Sorption of lonizable organic compounds by field soils. Part 2: Cations, bases and zwitterions. Pesticide Science 33 (3), 331-345.

Nödler, K., Licha, T., Bester, K., Sauter, M., 2010. Development of a multi-residue analytical method, based on liquid chromatography-tandem mass spectrometry, for the simultaneous determination of 46 micro-contaminants in aqueous samples. Journal of Chromatography $A$ $1217(42), 6511-6521$.

Nödler, K., Licha, T., Fischer, S., Wagner, B., Sauter, M., 2011. A case study on the correlation of microcontaminants and potassium in the Leine River (Germany). Applied Geochemistry 26 (12), 21722180 .

Qtaitat, M.A., 2004. Study of the interaction of trimethoprim-montmorillonite by infrared spectroscopy. Spectrochimica Acta Part A: Molecular and Biomolecular Spectroscopy 60 (3), 673678.

Rahman, M., Amiri, F., Worch, E., 2003. Application of mass transfer model for describing nonequilibrium transport of HOCs through natural geosorbents. Water Research 37 (19), 46734684.

Reemtsma, T., Weiss, S., Mueller, J., Petrovic, M., Gonzalez, S., Barcelo, D., Ventura, F., Knepper, T.P., 2006. Polar pollutants entry into the water cycle by muncipal wastewater: A European perspective. Environmental Science and Technology 40 (17), 5451-5458.

Sabljic, A., 1989. Quantitative modelling of soil sorption for xenobiotic chemicals. Environmental Health Perspectives 83, 179-190.

Sabljic, A., Guesten, H., Verhaar, H., Hermens, J., 1995. QSAR modelling of soil sorption. Improvements and systematics of log $K_{O C}$ vs. log $K_{o w}$ correlations. Chemosphere 31 (11-12), 4489-4514.

Scherrer, R.A., Howard, S.M., 1977. Use of distribution coefficients in quantitative structure-activity relationships. Journal of Medicinal Chemistry 20 (1), 53-58.

Scheytt, T., Mersmann, P., Lindstädt, R., Heberer, T., 2005. Determination of sorption coefficients of pharmaceutically active substances carbamazepine, diclofenac, and ibuprofen, in sandy sediments. Chemosphere 60 (2), 245-253.

Sollins, P., Robertson, G.P., Uehara, G., 1988. Nutrient mobility in variable- and permanent-charge soils. Biogeochemistry 6 (3), 181-199.

Stumpf, M., Ternes, T.A., Wilken, R.-D., Rodrigues, S.V., Baumann, W., 1999. Polar drug residues in sewage and natural waters in the state of Rio de Janeiro, Brazil. Science of The Total Environment $225(1-2), 135-141$.

ter Laak, T.L., Gebbink, W.A., Tolls, J., 2006. The effect of pH and ionic strength on the sorption of sulfachloropyridazine, tylosin, and oxytetracycline to soil. Environmental Toxicology and Chemistry 25 (4), 904-911.

Ternes, T.A., 1998. Occurrence of drugs in german sewage treatment plants and rivers. Water Research 32 (11), 3245-3260.

Tolls, J., 2001. Sorption of veterinary pharmaceuticals in soils: a review. Environmental Science and Technology 35 (17), 3397-3406. 
Tülp, H.C., Fenner, K., Schwarzenbach, R.P., Goss, K.-U., 2009. pH-dependent sorption of acidic organic chemicals to soil organic matter. Environmental Science and Technology 43 (24). 9189-9195.

van Balen, G.P., Caron, G., Ermondi, G., Pagliara, A., Grandi, T., Bouchard, G., Fruttero, R., Carrupt, P.-A, Testa, B., 2001. Lipophilicity behaviour of the zwitterionic antihistamine cetirizine in phosphatidylcholine liposomes/water Systems. Pharmaceutical Research 18 (5), 694-701.

Van Genuchten, M.T., Alves, W.J., 1982. Analytical solutions of the one-dimensional convectivedispersive solute transport equation. U.S. Department of Agriculture, Technical Bulletin 1661.

Vasudevan, D., Bruland, G.L., Torrance, B.S., Upchurch, V.G., MacKay, A.A., 2009. pH-dependent ciprofloxacin sorption to soils: Interaction mechanisms and soil factors influencing sorption. Geoderma 151 (3-4), 68-76.

Wexler, E.J, 1992. Analytical solutions for one-, two-, and three-dimensional solute transport in groundwater systems with uniform flow. Techniques of Water Resources Investigations of the United States Geological Survey, Chapter B-7, Book 3, Applications of Hydraulics.

Worch, E., 2004. Modelling the solute transport under nonequilibrium conditions on the basis of mass transfer equations. Journal of Contaminant Hydrology 68 (1-2), 97-120.

Yamamoto, H., Nakamura, Y., Moriguchi, S., Nakamura, Y., Honda, Y., Tamura, I., Hirata, Y., Hayashi, A., Sekizawa, J., 2009. Persistence and partitioning of eight selected pharmaceuticals in the aquatic environment: Laboratory photolysis, biodegradation, and sorption experiments. Water Research 43 (2), 351-362.

Zhang, Y.J., Geissen, S.U., Gal, C., 2008. Carbamazepine and diclofenac: removal in wastewater treatment plants and occurrence in water bodies. Chemosphere 73 (8), 1151-1161. 


\section{Chapter 3}

\section{Role of cation exchange processes on the sorption}

\section{influenced transport of cationic beta-blockers in aquifer sediments}

Mario Schaffer ${ }^{1, *}$, Hilmar Börnick², Karsten Nödler ${ }^{1}$, Tobias Licha1, Eckhard Worch $^{2}$

Citation:

Schaffer, M., Börnick, H., Nödler, K., Licha, T., Worch, E., 2012. Role of cation exchange processes on the sorption influenced transport of cationic $\beta$-blockers in aquifer sediments. Water Research 46 (17), 5472-5482.

\footnotetext{
${ }^{1}$ Geoscience Centre, Dept. Applied Geology, University of Göttingen, Goldschmidtstr. 3, 37077 Göttingen, Germany

${ }^{2}$ Institute of Water Chemistry, Dresden University of Technology, 01062 Dresden, Germany

* Corresponding author
} 


\section{Abstract}

The influence of cation exchange processes on the transport behavior of the cationic beta-blockers atenolol and metoprolol was investigated by applying saturated laboratory column experiments. Breakthrough curves using natural sediments under different competitive conditions were generated and resulting sorption coefficients were compared. For the cationic species of atenolol (at $\mathrm{pH}=8$ ), the existence and dominating role of cation exchange processes were demonstrated by varying calcium concentrations. No effect of atenolol concentration on its retardation was observed within a wide concentration range. The breakthrough curve comparison of atenolol and the more hydrophobic metoprolol under constant conditions showed a significantly stronger retardation for metoprolol than for atenolol. However, additional non-polar interactions cannot explain the observed differences as they are determined to be negligible for both compounds. Due to the dominating role of cation exchange processes for the cationic species on overall sorption, a simple prediction of beta-blocker transport in the subsurface by using $K_{o c}$ values derived from log $K_{o w}-\log K_{o c}$ correlations is not feasible.

\section{Graphical abstract}

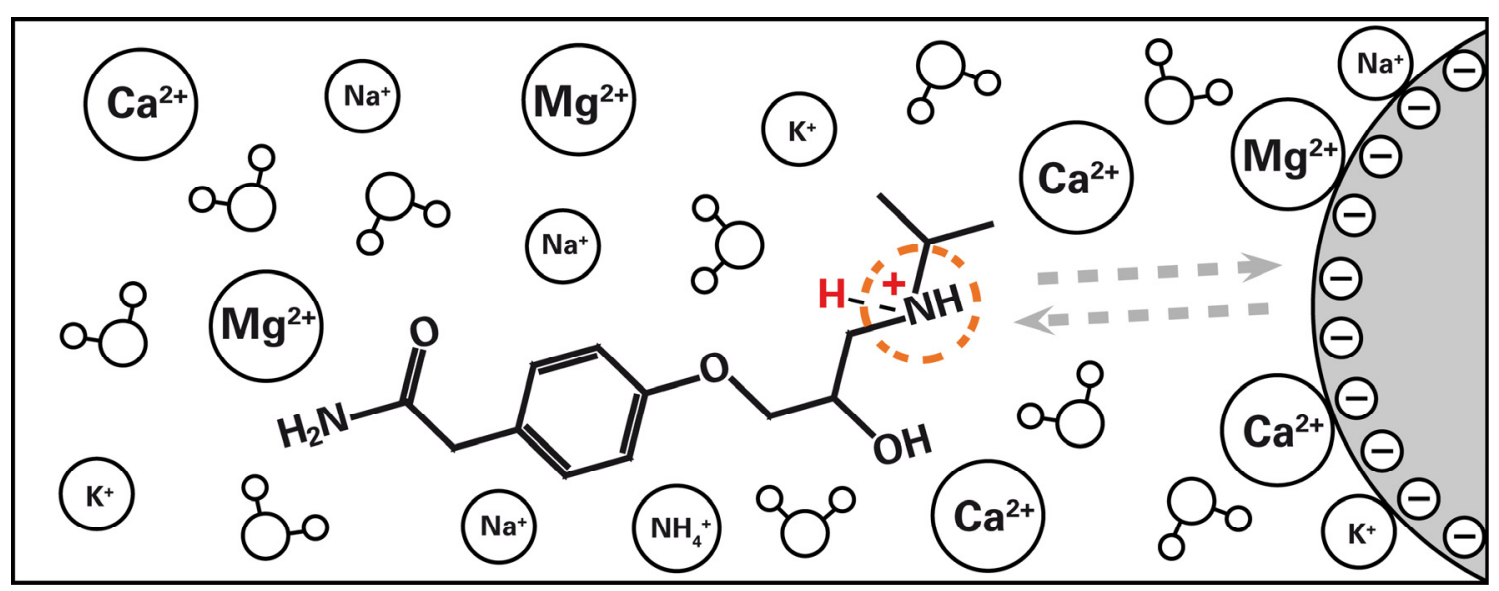




\subsection{Introduction}

During the last decades numerous pharmaceuticals and their metabolites have been detected in different parts of the water cycle (Ternes, 1998; Halling-Sørensen et al., 1998; Daughton and Ternes, 1999; Heberer, 2002). Frequently consumed betablockers (e.g., metoprolol, atenolol, sotalol, and propranolol) cannot be completely eliminated by conventional wastewater treatment (Ternes, 1998; Maurer et al., 2007). Therefore, these compounds are commonly detected in surface water and even in groundwater samples (Ternes, 1998; Sacher et al., 2001; Heberer, 2002; Cleuvers, 2005; Nödler et al., 2011).

The knowledge of interactions of these compounds with geosorbents in aquifers or during riverbank filtration and soil aquifer treatment is essential to assess their fate in the environment. Besides the chemical and biological degradation processes, sorption on environmental surfaces is the major transport influencing process for numerous anthropogenic trace compounds (Katayama et al., 2010).

Typically, beta-blockers are weak organic bases with acidity constants $p K_{a}>9$ for $\beta_{1^{-}}$ selective blockers ( $\mathrm{p} K_{a}$ of the conjugate acid). Therefore, at typical groundwater $\mathrm{pH}$ conditions $(\mathrm{pH}=4-8)$ the molecules are protonated and the cationic species clearly dominate. For charged species, the classical $K_{o c}$ concept for predicting the retardation in the subsurface by means of $\log K_{o w}-\log K_{o c}$ correlations (Chiou et al., 1979; Karickhoff, 1981; Sabljic et al., 1995) is usually not feasible (Tolls, 2001; Kah and Brown 2007; Schaffer et al., 2012). The very recent studies from Hyland et al. (2012) and Schaffer et al. (2012) highlight the limitations of the $K_{o c}$ concept and the need of a mechanistic understanding to predict the sorption behavior of charged compounds, since the specific mechanisms of the observed sorption are still unclear and electrostatic interactions are not yet quantitatively predictable.

Particularly for cationic organic compounds, the calculated distribution coefficients $K_{d}$ solely derived from organic carbon normalized sorption coefficients $K_{o c}$ are generally underestimated. This is because additional sorption processes (e.g., ion exchange, cation bridging, surface complexation, ligand exchange, hydrogen bonding) and $\mathrm{pH}$ effects (speciation, variable surface charges) are not sufficiently considered in this concept (Tolls, 2001; Cunningham et al., 2004; Kah and Brown, 2007; Schaffer et al., 2012). 
Previous studies covering the groundwater pH range (Zachara et al., 1986; Figueroa et al., 2004; ter Laak et al., 2006; Franco and Trapp, 2008; Franco et al., 2009) showed above the mineral's point of zero charge in general an increased sorption for organic bases with decreasing $\mathrm{pH}$. This means the higher the positively charged fraction of these molecules, the more important sorption becomes. Therefore, several authors came to the conclusion that sorption of the cationic species (particularly cation exchange) must be a significant sorption mechanism for a variety of organic bases in the cationic form (Zachara et al., 1986; Brownawell et al., 1990; Nicholls and Evans, 1991; Li et al., 2001; Bi et al., 2006; Carmosini and Lee, 2009). Fábrega et al. (1998, 2001) proposed two diagnostic modeling approaches based on numerically optimized sorption coefficients to describe competitive cation exchange for aromatic amines. In the case of beta-blockers, the occurrence of relevant cation exchange processes was also to be expected in sorption studies by Yamamoto et al. (2009), Ramil et al. (2010), and Schaffer et al. (2012).

Despite this state of knowledge, virtually all available studies dealing with the sorption of beta-blockers were carried out under fixed hydrochemical boundary conditions. The capability of cation exchange and its dependence on further influence factors (e.g., effects of $\mathrm{pH}$, ionic strength and ionic composition) are often not systematically considered in the determined sorption coefficients (Yamamoto et al., 2005; Kibbey et al., 2007; Maurer et al., 2007; Barron et al., 2009; Ramil et al., 2010, Stevens-Garmon et al., 2011, Hyland et al., 2012). Furthermore, these studies are generally limited to batch experiments, which do not allow an explicit separation of sorption and degradation processes for easily degradable compounds like atenolol.

Therefore, this study focuses on the evaluation of the importance of cation exchange processes for the worldwide highly consumed beta-blockers atenolol and metoprolol. In total, three different sediments were studied using saturated column experiments. These novel experiments were conducted under different competitive conditions with respect to $\mathrm{Ca}^{2+}$ concentrations. The influence of competing $\mathrm{Ca}^{2+}$ on beta-blocker retardation was determined by comparing resulting distribution coefficients. Additionally, desorption behavior is reported. Furthermore, the generally expected non-transferability of results from column experiments conducted with high concentrations to experiments using environmentally relevant 
concentrations was examined. These experiments are believed to make a valuable contribution to this current discussion. Finally, the comparison of two structural related compounds allows assessing the relevance of possible additional hydrophobic interactions on the transport of beta-blockers.

\subsection{Materials and methods}

\subsubsection{Chemicals}

Atenolol from Fagron (Barsbüttel, Germany) and metoprolol (tartrate salt) from Sigma-Aldrich (Steinheim, Germany) were used in the experiments. Their purity was $>99 \%$. For the HPLC-MS/MS analysis the analytical standard atenolol- $D_{7}$ from Sigma Aldrich (Steinheim, Germany) was used as internal standard. Atenolol acid was purchased from LGC Promochem (Wesel, Germany).

Atenolol and metoprolol are structurally related, featuring a basic reacting secondary amine group (Table 3.1). The sole difference between both compounds is that atenolol bears a more hydrophilic carboxamide group instead of a methoxy group. Hence, the neutral species of atenolol has a significantly lower $n$-octanol/water distribution coefficient $\log K_{\text {ow }}$ than the neutral species of metoprolol.

Table 3.1 Chemical properties and structures of the sorbates.

\begin{tabular}{|c|c|c|c|c|c|}
\hline Compound & Structure & $\mathbf{p} K_{a}^{a, b}$ & $\log K_{o w^{a, c}}$ & $\log K_{o w^{+a, d}}$ & $\log D_{\mathrm{pH}=8.0} \mathrm{e}^{\mathrm{e}}$ \\
\hline Atenolol & & 9.54 & 0.22 & $<-2.0$ & -1.2 \\
\hline Metoprolol & & 9.63 & 1.95 & -1.10 & 0.09 \\
\hline
\end{tabular}

a Caron et al. (1999).

${ }^{\mathrm{b}} \mathrm{All} \mathrm{p} K_{a}$ values refer to $\mathrm{p} K_{a}$ values for the conjugate acid (protonated species).

c All log Kow values refer to the neutral species.

${ }^{\mathrm{d}}$ All $\log \mathrm{Kow}^{+}$values refer to the cationic species.

e All $\log D$ values refer to the neutral and cationic species at $\mathrm{pH}=8$. SciFinder Scholar 2007 predicted values, calculated using Advanced Chemistry Development (ACD/Labs) Software V11.02 (1994-2012 ACD/Labs). 


\subsubsection{Sorbents}

Three fluvial riverbed sediments were used for the experiments. Sediment S1 was sampled in $1 \mathrm{~m}$ depth in a former tributary of the Elbe river close to the city of Torgau, Germany. It is a medium quartz sand with a very small clay and silt fraction $(<63 \mu \mathrm{m})$ of $4 \%$. Main components of this fraction are quartz and the layered silicate minerals mica (muscovite, illite, biotite), kaolinite, and chlorite (Amiri et al., 2005; Schaffer et al., 2012). These minerals possess points of zero charge in the low pH range. Therefore, the surface is negatively charged at the considered $\mathrm{pH}(\mathrm{pH}=8)$ and cation exchange on these mineral surfaces is potentially possible.

The other two sediments S2 and S3 are from different aquifer layers within the Pleistocene and Holocene fluvial fan of the Gallikos river close to Thessaloniki, Greece. Sediment S2, sampled in around $3 \mathrm{~m}$ depth, is a coarse sand with a clay and silt fraction of $13 \%$ and sediment S3, sampled in approx. $5 \mathrm{~m}$ depth, is a medium sand with a clay and silt fraction of $6 \%$, respectively. Both sediments consist mainly of quartz, feldspars (plagioclase, microcline), and the layered silicate minerals muscovite, smectite, chlorite, and biotite. Especially the clay minerals smectite and chlorite can provide high cation exchange capacities (CEC).

Further, even small fractions of solid organic matter can also provide negative charges originating from the deprotonation of carboxylic groups ( $\mathrm{p} K_{a}$ around 4-5). All sediments used in this study are from aquifers and contain, therefore, in general a low fraction of total organic carbon $f_{O c}$. While the $f_{O c}$ of sediment $S 1$ is around two to three times higher than for sediment S2 and S3, respectively, sediment S1 has a lower CEC than the two other sediments.

To reduce heterogeneities in the column filling, all sediments were sieved and the homogenized fractions $<2 \mathrm{~mm}$ were used. Measured sediment properties are listed in Table 3.2 and further information on sediment characterization methods are given in Chapter 3.2.5.3.

\subsubsection{Model water}

Tap water from Dresden, Germany was used as base matrix for the experiments. The $\mathrm{pH}$ was constant between 7.9 and 8.1 (bicarbonate buffered) for all experiments and 
was only controlled at the column outlet over time. The dissolved organic carbon DOC ranged slightly between 1.7 and $2.1 \mathrm{mg} \mathrm{L}^{-1}$. According to the experimental requirements, different amounts of inorganic salts $\left(\mathrm{NaCl}, \mathrm{CaCl}_{2}, \mathrm{KCl}, \mathrm{KNO}_{3}, \mathrm{MgCl}_{2}\right.$, $\mathrm{Na}_{2} \mathrm{SO}_{4}, \mathrm{NaHCO}_{3}$ ) and beta-blocker (atenolol, metoprolol) were added. The performed experiments and the resulting concentrations of inorganic cations and beta-blockers are listed in Table 3.3. All experiments were carried out at a constant temperature of $10^{\circ} \mathrm{C}$ in a climatic chamber.

Table 3.2 Physicochemical properties of the used sediments and column experimental conditions.

Sorbent and bulk properties

\begin{tabular}{|c|c|c|c|c|c|}
\hline$\underline{\text { Sediment }}$ & $\underline{\text { S1 }}$ & $\underline{\mathrm{S}}$ & $\underline{\mathrm{S3}}$ & & \\
\hline $\mathrm{BET}\left[\mathrm{m}^{2} \mathrm{~g}^{-1}\right]$ & 1.9 & 6.3 & nd & $L[\mathrm{~cm}]$ & 25 \\
\hline $\mathrm{pH}\left(\mathrm{CaCl}_{2}\right)[-]$ & 5.85 & 7.78 & 8.01 & $A\left[\mathrm{~cm}^{2}\right]$ & 9.2 \\
\hline $\mathrm{pH}\left(\mathrm{H}_{2} \mathrm{O}\right)[-]$ & 6.20 & 8.10 & 8.77 & $Q\left[\mathrm{~cm}^{3} \mathrm{~min}^{-1}\right]$ & $0.40-0.50$ \\
\hline$\rho_{b}\left[\mathrm{~g} \mathrm{~cm}^{-3}\right]$ & 1.76 & 1.94 & $1.50 \pm 0.1$ & $v_{f}\left[\mathrm{~m} \mathrm{~d}^{-1}\right]$ & $0.62-0.78$ \\
\hline$n_{e}[\%]$ & 35 & 29 & $38 \pm 2$ & $v_{w}\left[\mathrm{~m} \mathrm{~d}^{-1}\right]$ & $1.91-2.43$ \\
\hline$f_{O C}[\%]$ & 0.23 & 0.11 & 0.07 & $c_{0}\left[\mu \mathrm{g} \mathrm{L}^{-1}\right]$ & $1-30,000$ \\
\hline $\mathrm{CEC}\left[\mathrm{cmol}_{\mathrm{c}} \mathrm{kg}^{-1}\right]$ & 1.36 & 3.09 & 4.40 & & \\
\hline
\end{tabular}

\subsubsection{Column experiments}

The column experiments were carried out in stainless steel columns with dimensions of $250 \times 34 \mathrm{~mm}$. In order to ensure saturated column conditions, the water was pumped upwards. All hydraulic parameters of the columns were kept constant within every experiment. The column packing with different grain-size distributed sediments (Table 3.2) leads to different hydromechanical properties between the experiments. The effective column porosities $n_{e}$ of all experiments were calculated 
from the conductivity breakthrough curves $\kappa(t)$ (microprocessor conductivity meter LF 537 with flow-through cell LDM/S, WTW) of a conservative $\mathrm{Cl}^{-} \operatorname{tracer}(\mathrm{NaCl})$ :

$n_{e}=\frac{Q \cdot t_{i d}}{A \cdot L} \quad$ with $\quad t_{i d}=t_{\max }-\frac{\int_{0}^{t_{\max }} k(t) d t}{\kappa_{0}-\kappa_{b}}$

The ideal breakthrough time $t_{i d}$ of the tracer (center of gravity) was calculated after a cubic spline interpolation of the measured data points. Here, $A$ denotes the crosssectional area of the column, $t_{\max }$ the duration of the experiment, $\kappa_{0}$ the initial conductivity of the tracer and $\kappa_{b}$ the background conductivity of the water at the column outlet before tracer addition.

During the experiments the columns were fed with water (lab pump RHSY Jr., Fluid Metering Inc.), containing different concentrations of the respective beta-blocker and inorganic cations (Table 3.3). Samples were taken with a fraction collector (Retriever II, Teledyne Isco) in a temporal resolution of $45 \mathrm{~min}$ with the aim of atenolol and metoprolol breakthrough curve determinations. Samples volumes were at least 20 $\mathrm{mL}$. Due to the high temporal sampling resolution, not all taken samples were analyzed.

All experimentally obtained breakthrough curves were inversely modeled with analytical solutions of the one-dimensional advection-dispersion-equation. For this purpose, the CXTFIT code (Toride et al., 1995) implemented in the software STANMOD (Version 2.07) was used. The model includes sink terms for sorption and degradation (assumption of first-order rate law). The numerically optimized parameters are the retardation factor $R$, the dispersivity $a$, and the first-order degradation rate constant $\lambda$. In case of unsatisfactory modeling results $\left(R^{2}<0.99\right)$ with the chemical equilibrium model, the two-site chemical non-equilibrium model was used to improve fit quality (Table B2). Selected replicates of the experiments can be found in the Appendix B (Table B1 and B2, Fig. B1-B3).

The experiments were classified into sub-groups from group A to group D (Table 3.3) with respect to their experimental focus. 
Table 3.3 Concentrations of beta-blockers and inorganic main cations for each experiment.

\begin{tabular}{|c|c|c|c|c|c|c|c|}
\hline $\begin{array}{c}\text { Exp. } \\
\text { (Sorbens) }\end{array}$ & Description & Water matrix & 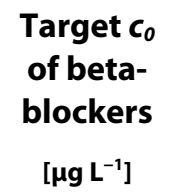 & $\begin{array}{c}\mathrm{Na}^{+} \\
{\left[\mathrm{mg} \mathrm{L}^{-1}\right]}\end{array}$ & $\begin{array}{c}\mathbf{K}^{+} \\
{\left[\mathrm{mg} \mathrm{L}^{-1}\right]}\end{array}$ & $\begin{array}{c}\mathbf{M g}^{2+} \\
{\left[\mathrm{mg} \mathrm{L}^{-1}\right]}\end{array}$ & $\begin{array}{c}\mathrm{Ca}^{2+} \\
{\left[\mathrm{mg} \mathrm{L}^{-1}\right]}\end{array}$ \\
\hline & & & Atenolol & & & & \\
\hline $\mathrm{A} 1(\mathrm{~S} 1)$ & Breakthrough & Tap water & 500 & 8 & 2 & 3 & 47 \\
\hline $\mathrm{A} 2(\mathrm{~S} 1)$ & Breakthrough & Tap water $+\mathrm{CaCl}_{2}$ & 500 & 7 & 2 & 3 & 430 \\
\hline $\mathrm{A} 3(\mathrm{~S} 2)$ & Breakthrough & Tap water & 500 & 8 & 2 & 3 & 41 \\
\hline $\mathrm{A} 4(\mathrm{~S} 2)$ & Breakthrough & Tap water $+\mathrm{CaCl}_{2}$ & 500 & 8 & 2 & 3 & 400 \\
\hline $\mathrm{B} 1(\mathrm{~S} 1)$ & Desorption & Tap water & 0 & 8 & 2 & 3 & 48 \\
\hline $\mathrm{B} 2(\mathrm{~S} 1)$ & Desorption & Tap water $+\mathrm{CaCl}_{2}$ & 0 & 8 & 2 & 3 & 421 \\
\hline $\mathrm{B} 3(\mathrm{~S} 2)$ & Desorption & Tap water & 0 & 7 & 2 & 3 & 42 \\
\hline $\mathrm{B} 4(\mathrm{~S} 2)$ & Desorption & Tap water $+\mathrm{CaCl}_{2}$ & 0 & 8 & 2 & 3 & 405 \\
\hline $\mathrm{C} 1(\mathrm{~S} 3)$ & Breakthrough & Tap water + salt mix & 1 & 732 & 41 & 90 & 80 \\
\hline $\mathrm{C} 2(\mathrm{~S} 3)$ & Breakthrough & Tap water + salt mix & 500 & 743 & 40 & 90 & 81 \\
\hline C3(S3) & Breakthrough & Tap water + salt mix & 5,000 & 726 & 40 & 93 & 82 \\
\hline \multirow[t]{2}{*}{ C4(S3) } & Breakthrough & Tap water + salt mix & 30,000 & 726 & 40 & 93 & 82 \\
\hline & & & Metoprolol & & & & \\
\hline D1(S3) & Breakthrough & Tap water + salt mix & 500 & 726 & 40 & 93 & 82 \\
\hline
\end{tabular}

\subsubsection{Experiments A: Different concentrations of $\mathrm{Ca}^{2+}$}

The effect of inorganic ions on the transport of atenolol due to different competitive conditions was studied here. After equilibrating the columns for at least 1 week $(\mathrm{pH}$, $\mathrm{DOC}=$ const.), atenolol was added to the reservoir containing the model water and breakthrough curves were recorded (experiments A1 and A3). Subsequently, atenolol-free water was used for a complete desorption of the columns (see Section 3.2.4.2). Next, the breakthrough experiment was repeated using the same column (A2 and A4) at identical experimental conditions. But in contrast to the previous breakthrough curves, the reservoir contained besides atenolol additional $\mathrm{CaCl}_{2}$. Thus, the concentration of $\mathrm{Ca}^{2+}$ was increased by a factor of ten (from around 40 to $\left.400 \mathrm{mg} \mathrm{L}^{-1}\right)$. Eventually, the breakthrough curves with and without $\mathrm{CaCl}_{2}$ addition 
were compared. The experiments were conducted with two different sediments (S1 and S2) at initial atenolol concentrations of $c_{0}=500 \mu \mathrm{g} \mathrm{L}^{-1}$.

\subsubsection{Experiments B: Desorption}

As mentioned above, an intermediate desorption step was inserted between the two breakthrough experiments $A 1 / A 2$ and $A 3 / A 4$, respectively. After the breakthrough (A1 and A3) was completed, atenolol-free tap water was used for desorbing atenolol from the columns (experiments B1 and B3). The decreasing atenolol concentrations at the outflow were measured over time. When the atenolol concentrations reached around $5 \%$ of $\mathrm{c}_{0}$, the $\mathrm{Ca}^{2+}$ concentrations were increased tenfold from around 40 to $400 \mathrm{mg} \mathrm{L}^{-1}$ by adding $\mathrm{CaCl}_{2}$ to the reservoir (experiments $\mathrm{B} 2$ and $\mathrm{B} 4$ ). The declining curves for atenolol were observed until it could no longer be detected $\left(c<12 \mu \mathrm{g} \mathrm{L}^{-1}\right)$.

\subsubsection{Experiments C: Different concentrations of atenolol}

In contrast to the experiments with different $\mathrm{Ca}^{2+}$ concentrations (experiments $\mathrm{A} 1-$ A4), the influence of different atenolol concentrations and thus varying ratios of organic to inorganic cations was investigated (experiments C1-C4). The concentrations of inorganic cations were kept constant and the columns were refilled with sediment S3 for each atenolol concentration. After at least 1 week equilibration time, atenolol was added together with $\mathrm{NaCl}$ (conservative tracer) to the reservoir and the breakthrough curves were determined. Atenolol concentrations were varied in a wide range between $c_{0}=1 \mu \mathrm{g} \mathrm{L}^{-1}$ and $c_{0}=30,000 \mu \mathrm{g} \mathrm{L}^{-1}$.

\subsubsection{Experiment D: Comparison with metoprolol}

For comparing the influence of two structurally similar molecules with different hydrophobicity but equal $\mathrm{p} K_{a}$ on the sorption influenced transport, the breakthrough behavior of metoprolol was investigated in experiment D1. Setup, methodology, and concentrations are equal to experiment C2 (see Section 3.2.4.3). 


\subsubsection{Determination of sorption coefficients}

Due to the fact that the simple application of linear free-energy relationships (log $K_{\text {ow }}$ $\log K_{o c}$ correlations) for hydrophobic partitioning is not expected to be applicable for the investigated cationic compounds at $\mathrm{pH}=8$ (see Section 3.1), organic carbon normalized sorption coefficients $K_{o c}=K_{d} / f_{O c}$ were not compared. Instead, the distribution coefficients $K_{d}$ were used directly for the quantitative comparison of the obtained breakthrough curves. Assuming a linear sorption isotherm (or ion exchange isotherm), $K_{d}$ was calculated from $R$ of the respective modeled breakthrough curve, $n_{e}$ obtained from the conservative tracer test and the bulk density $\rho$ with:

$$
K_{d}=\frac{n_{e}}{\rho}(R-1)
$$

Thus, $K_{d}$ represents $R$ normalized to the bulk properties. This implies that $K_{d}$ can be used as effective parameter for the comparison of column experiments even when conducted with different sediments.

The relative contribution of electrostatic (ionic) interactions to the sorption process was estimated as follows: The hydrophobic proportions, derived from the classical $K_{o c}$ concept, were subtracted from $K_{d}$. This can be done as the obtained $K_{d}$ represents the sum of all involved sorption processes (Schwarzenbach et al., 2003). Therefore, $K_{d}$ can be separated into contributions from ionic $\left(K_{d}^{+}\right)$and hydrophobic $\left(K_{d}^{0}\right)$ interactions:

$$
K_{d}=K_{d}^{0}+K_{d}^{+}
$$

It is assumed that $K_{d}{ }^{0}$ can completely be described by hydrophobic partitioning of the sorbates to the fraction of organic carbon of the sorbent. Considering both sorbate species, $K_{d}{ }^{0}$ is a function of $K_{O C}{ }^{0}, K_{O C^{+}}, f_{O C}$ and the degree of protonation $a$ :

$$
K_{d}^{0}=(1-a)\left(K_{O C}{ }^{0} \cdot f_{O C}\right)+a\left(K_{O C}{ }^{+} \cdot f_{O C}\right) \text { with } \quad a=\frac{1}{1+10^{p H-p K_{a}}}
$$

$K_{o c}$ values for the neutral species $\left(K_{o c}{ }^{0}\right)$ can be calculated from $\log K_{o w}-\log K_{o c}$ correlations and with the values in Table 3.1, e.g. after Sabljic et al. (1995) for nonhydrophobic compounds with:

$$
\log K_{o C}=0.52 \cdot \log K_{o w}+1.02
$$


Due to the lack of specific $\log K_{o w}-\log K_{o c}$ correlations for predicting the hydrophobic partitioning of organic cations Eq. (3.5) was slightly modified. The log $\mathrm{Kow}^{+}$ determined by Caron et al. (1999) (Table 3.1) was used instead of log Kow to derive the $K_{o c}$ values for the cationic species $\left(K_{o c}{ }^{+}\right)$.

\subsubsection{Chemical analysis}

\subsubsection{Beta-blockers}

All samples of the experiments with $c_{0} \geq 500 \mu \mathrm{g} \mathrm{L}^{-1}$ were analyzed by highperformance liquid chromatography with UV detection (HPLC, Merck-Hitachi) using a diode array detector (DAD L-4500, Merck-Hitachi). A $150 \times 3 \mathrm{~mm}$ C18-HPLC reversed phase column (Gemini-NX $3 \mu \mathrm{m}$ C18 110A, Phenomenex) was used for chromatographic separation. The separation was operated at $29{ }^{\circ} \mathrm{C}$ with an injection volume of $100 \mu \mathrm{L}$. Before injection all samples were filtered with a cellulose nitrate filter $(<0.45 \mu \mathrm{m}$, Sartorius, Göttingen) to remove all suspended particles. Samples with $c>500 \mu \mathrm{g} \mathrm{L}^{-1}$ were diluted with ultrapure water to the calibration range $(c=25-$ $500 \mu \mathrm{g} \mathrm{L}^{-1}$ ) prior to analysis. The linearity for all calibrations was $\mathrm{R}^{2}>0.99$.

The atenolol samples were analyzed with a detection wavelength of $223 \mathrm{~nm}$ and a constant flow rate of $0.5 \mathrm{~mL} \mathrm{~min}^{-1}$. Eluent A was acetonitrile (HPLC grade, Mallinckrodt Baker, Griesheim, Germany) and eluent B was water (HPLC grade, Mallinckrodt Baker, Griesheim, Germany) containing 5 Vol.-\% acetonitrile and $2.45 \mathrm{mmol} \mathrm{L}^{-1}$ acetic acid (p.a., Merck, Darmstadt, Germany). The elution was performed isocratically by using $19 \% \mathrm{~A}$ and $81 \% \mathrm{~B}$ for $8 \mathrm{~min}$.

The metoprolol samples $\left(c_{0}=500 \mu \mathrm{g} \mathrm{L}^{-1}\right)$ were analyzed with a detection wavelength of $227 \mathrm{~nm}$ and a constant flow rate of $0.3 \mathrm{~mL} \mathrm{~min}^{-1}$. Eluent $A$ was acetonitrile and eluent $\mathrm{B}$ was an aqueous $10 \mathrm{mM} \mathrm{NH}_{4} \mathrm{HCO}_{3}$ (p.a., Mallinckrodt Baker, Griesheim, Germany) buffer with $\mathrm{pH}=8.8$. The elution was performed isocratically by using $20 \%$ $A$ and $80 \% B$ for 8 min.

The atenolol samples of the experiment with $c_{0}=1 \mu \mathrm{g} \mathrm{L}^{-1}$ were analyzed by a method based on solid phase extraction (SPE) and high-performance liquid chromatography coupled with tandem-mass spectrometric detection (HPLC-MS/MS). The instrumentation, sample pretreatment and analysis followed the method of Nödler 
et al. (2010). In contrast to this, a sample volume of $20 \mathrm{~mL}$ was spiked with $1 \mathrm{~mL}$ phosphate buffer and $10 \mu \mathrm{L}(m=100 \mathrm{ng})$ of the internal atenolol- $\mathrm{D}_{7}$ standard solution and filled up to $25 \mathrm{~mL}$ with ultrapure water. The sample solution was preconcentrated by using the SPE on Oasis HLB $(6 \mathrm{~mL}, 500 \mathrm{mg})$ from Waters (Eschborn, Germany). Afterwards, the compounds were eluted by methanol and ethyl acetate and the extract was evaporated to dryness at $40{ }^{\circ} \mathrm{C}$ with a gentle stream of nitrogen. The analytes were re-dissolved in $0.5 \mathrm{~mL}$ of aqueous $5 \mathrm{mM}$ ammonium acetate solution, containing $4 \%$ methanol, resulting in a total pre-concentration factor of 40 .

\subsubsection{Analysis of inorganic cations}

For the analysis of inorganic cations $\left(\mathrm{Na}^{+}, \mathrm{K}^{+}, \mathrm{Mg}^{2+}, \mathrm{Ca}^{2+}\right)$ an ion chromatographic system DX-500 (Dionex) with conductometric detection and a $250 \times 3 \mathrm{~mm}$ cation exchange column (IonPac CS16, Dionex) were used. The separation was performed isocratically at $44^{\circ} \mathrm{C}$ with a $35 \mathrm{mM}$ methanesulfonic acid eluent.

\subsubsection{Sediment analysis}

The specific surface areas of the sediments were determined with the $N_{2}$ adsorption/desorption BET method (DIN ISO 9277, 2003) by using the Autosorb-1-C (Quantachrome) surface analyzer. Sediment $\mathrm{pH}$ values were measured according to the international norm DIN ISO 10390 (2003) with ultrapure water and a $0.01 \mathrm{M} \mathrm{CaCl}_{2}$ solution. The determination of the total organic carbon (TOC) content was carried out by dry combustion of the previously with $4 \mathrm{M} \mathrm{HCl}$ treated sediment at $900{ }^{\circ} \mathrm{C}$ in a total organic carbon analyzer (Dohrmann Boat Sampler $184 \mathrm{~S}$ / Rosemount Dohrmann DC 70). The potential CEC (at $\mathrm{pH}=8.1$ ) was measured in accordance with DIN ISO 13536 (1997). The mineralogical constitutions were characterized by macroscopic observation and combined X-ray diffractometry-thermoanalysis (Siemens diffractometer D5000, Netzsch STA 409 PG Luxx). 


\subsection{Results and discussion}

The obtained sorption coefficients of all experiments can be found in Table 3.4. The modeled parameters and column conditions of the tracer tests as well as for the experiments are listed in Table B1 and B2 in the Appendix B.

\subsubsection{Experiments A:Different concentrations of $\mathrm{Ca}^{2+}$}

A tenfold increase of the $\mathrm{Ca}^{2+}$ concentration resulted for sediment $\mathrm{S} 1$ and $\mathrm{S} 2$ in a reduction close to one half of the retention times for atenolol (Fig. 3.1 and Fig. 3.2). Comparing experiment $\mathrm{A} 1$ with $\mathrm{A} 2, K_{d}$ decreased for sediment $\mathrm{S} 1$ from $3.5 \mathrm{~L} \mathrm{~kg}^{-1}$ $(R=18.5)$ to $1.3 \mathrm{~L} \mathrm{~kg}^{-1}(R=7.4)$. The same behavior was observed for sediment $\mathrm{S} 2$, as $K_{d}$ decreased from $3.2 \mathrm{~L} \mathrm{~kg}^{-1}(R=22.4)$ in experiment $\mathrm{A} 3$ to $1.7 \mathrm{~L} \mathrm{~kg}^{-1}(R=12.1)$ in experiment A4. Apparently, Atenolol was biodegraded in both experiments (around $15-30 \%$ of $\left.c_{0}\right)$.

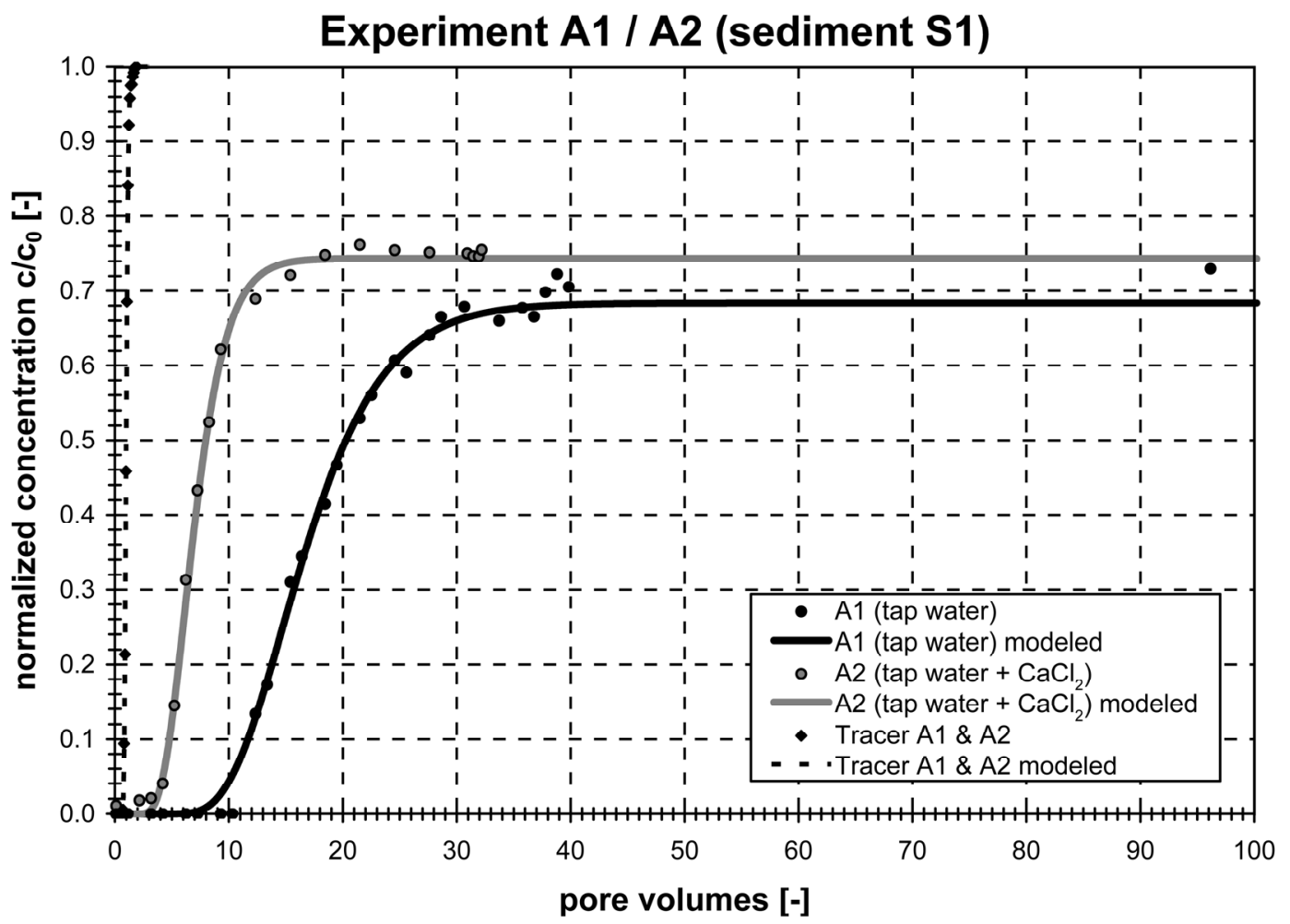

Fig. 3.1 Experimental and modeled breakthrough curves (including tracer tests) of atenolol for sediment $\mathrm{S} 1$ with and without $\mathrm{CaCl}_{2}$ addition $\left(\mathrm{Ca}^{2+}\right.$ concentrations of 40 and $\left.400 \mathrm{mg} \mathrm{L}^{-1}\right)$. Concentrations $c$ of the breakthrough curves were normalized with the initial concentration $c_{0}$. Pore volumes were calculated by normalizing the experiment duration to the ideal breakthrough time of the $\mathrm{Cl}^{-}$tracer. 
Increased competition with inorganic cations leads to a weaker atenolol sorption onto the sediment. The effect can solely be explained by the existence of cation exchange processes, which were already expected from Yamamoto et al. (2009), Ramil et al. (2010), and Schaffer et al. (2012). Higher $\mathrm{Ca}^{2+}$ concentrations lead to a shift of the exchange equilibrium in favor of the double charged $\mathrm{Ca}^{2+}$ and as a consequence the probability for atenolol sorption on exchange sites decreases. According to Eq. (3.3-3.5), the contributions of hydrophobic partitioning to $K_{d}$ are estimated to be $<0.0030 \mathrm{~L} \mathrm{~kg}^{-1}$ for sediment $\mathrm{S} 1$ and $<0.0015 \mathrm{~L} \mathrm{~kg}^{-1}$ for sediment S2. Thus, ionic interactions are clearly dominating even at high concentrations of competing inorganic ions.

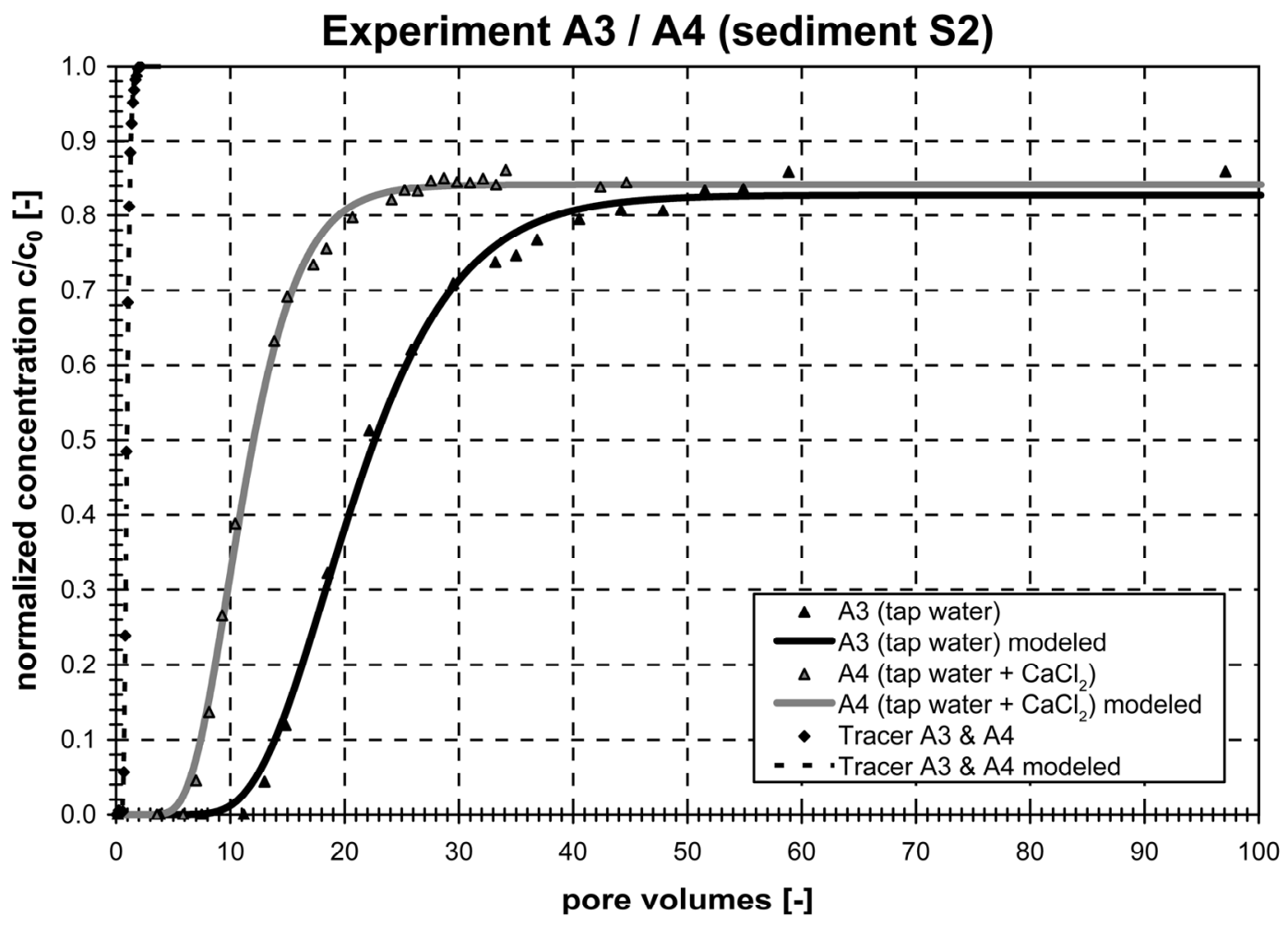

Fig. 3.2 Experimental and modeled breakthrough curves (including tracer tests) of atenolol for sediment $\mathrm{S} 2$ with and without $\mathrm{CaCl}_{2}$ addition $\left(\mathrm{Ca}^{2+}\right.$ concentrations of 40 and $\left.400 \mathrm{mg} \mathrm{L}^{-1}\right)$. Concentrations $c$ of the breakthrough curves were normalized with the initial concentration $c_{0}$. Pore volumes were calculated by normalizing the experiment duration to the ideal breakthrough time of the $\mathrm{Cl}^{-}$tracer.

Despite differences in the sediment properties, the sorption behavior is very similar for both sediments. Neither the differences in $f_{O C}$ nor in CEC seem to have a noticeable effect. Barron et al. (2009) found considerable differences for the log $K_{o c}$ 
values of atenolol and metoprolol between two sorbents (soil and sludge). Further, they report similar to Hyland et al. (2012), and Schaffer et al. (2012) the limitations of the $K_{o c}$ concept for ionizable compounds. Here, it can be confirmed that $K_{o c}$ is not a suitable parameter for comparing and predicting the sorption behavior of organic cations in different aquifers and sediments, since electrostatic interactions are not considered in this approach (Tolls, 2001; Cunningham et al., 2004; Kah and Brown, 2007; Schaffer et al., 2012). As a consequence, the formally calculated Koc changes with the boundary conditions (e.g., ionic strength, pH). In this study, the log $K_{O C}$ decreased from 3.2 to 2.7 (experiment $A 1 / A 2$ ) and from 3.5 to 3.2 (experiment $\mathrm{A} 3 / \mathrm{A} 4)$.

\subsubsection{Experiments B:Desorption}

Desorption with tap water led to similar curves for both sediments (experiments B1 and B3, Fig. 3.3). After horizontally reflecting the desorption curves, their shapes are qualitatively symmetrical compared to the breakthrough curves in experiment $A 1$ and $A 3$, respectively. Therefore, the sorption behavior is likely to be fully reversible.

The quantitative modeling of the desorption curves with CXTFIT under equilibrium conditions led to similar results for $R$ and $K_{d}$ when comparing sorption and desorption (Table 3.4 and Table B2). The observed higher values for $a$ in case of desorption compared to sorption are expected to be caused by kinetic effects (Rahman et al. 2003, Worch, 2004). As initial condition in the desorption model the columns were assumed to be in sorption equilibrium with atenolol $\left(c\left(x, t_{0}\right)=0.73\right.$ for experiment B1 and 0.85 for experiment B3) and as upper boundary condition the columns were fed with water containing no atenolol $\left(c_{0}=0\right)$.

Afterwards (experiments B2 and B4), the addition of $\mathrm{CaCl}_{2}$ resulted in an increase in atenolol concentration (small peak) for both sediments (Fig. 3.3). Due to the higher competition with $\mathrm{Ca}^{2+}$, a new desorption equilibrium is established resulting in an increased desorption. Therefore, strong evidence for cation exchange as the main retardation process for the cationic species of beta-blockers on natural surfaces is apparent. 


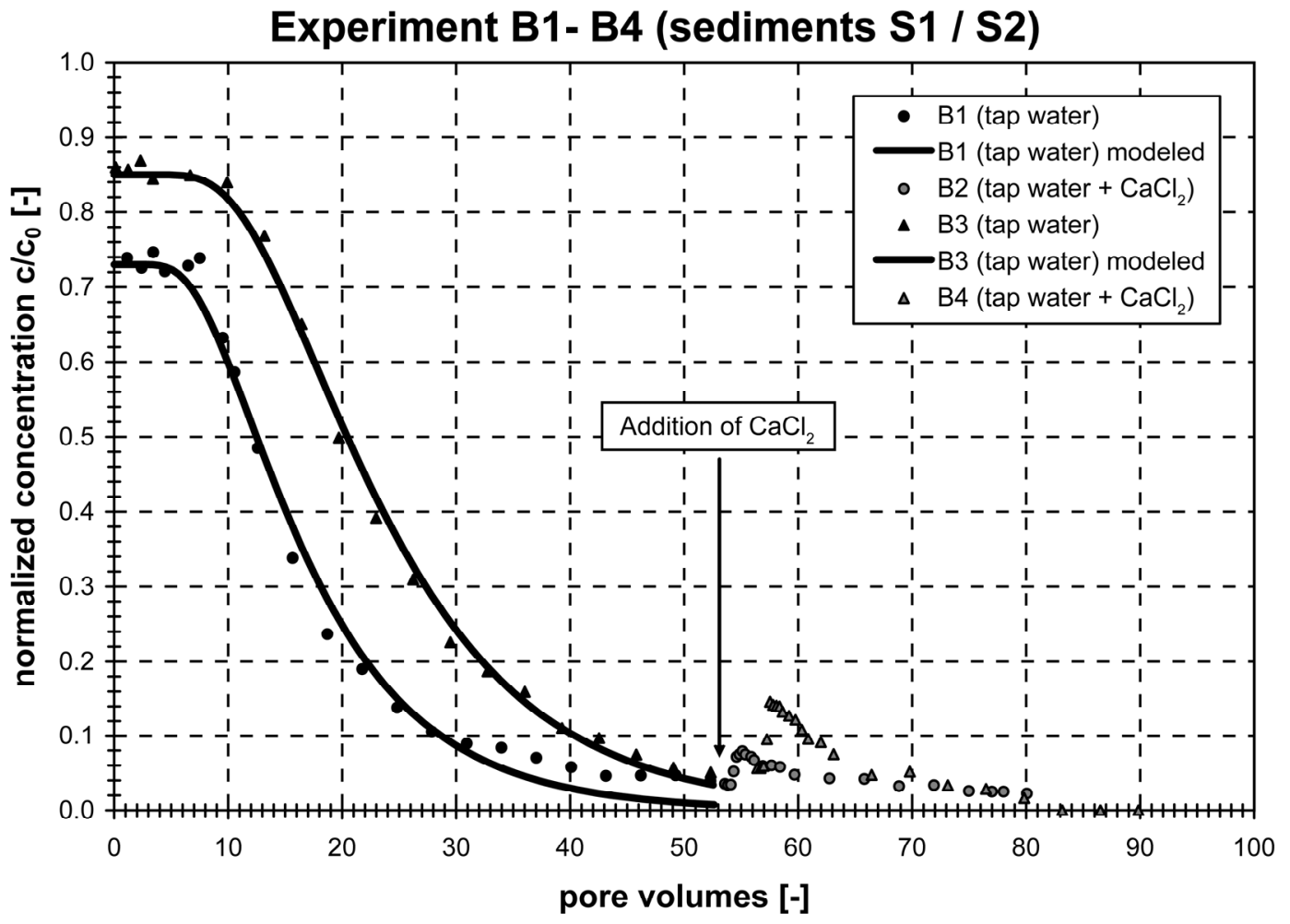

Fig. 3.3 Experimental and modeled desorption curves of atenolol for sediments S1 and S2 with $\mathrm{CaCl}_{2}$ addition after 53 pore volumes $\left(\mathrm{Ca}^{2+}\right.$ concentrations of 40 and $\left.400 \mathrm{mg} \mathrm{L}^{-1}\right)$. Concentrations $c$ of desorption curves were normalized with the initial concentration $c_{0}$ of the previous breakthrough curves. Pore volumes were calculated by normalizing the experiment duration to the ideal breakthrough time of the $\mathrm{Cl}^{-}$tracer.

\subsubsection{Experiments C: Different concentrations of atenolol}

No significant influence on the transport behavior of atenolol could be observed despite several orders of magnitude difference in atenolol concentrations at identical conditions (Fig. 3.4). $R$ varied between 4.3 for $c_{0}=500 \mu \mathrm{g} \mathrm{L}^{-1}$ in experiment $\mathrm{C} 2$ and 5.4 for $c_{0}=1 \mu \mathrm{g} \mathrm{L}^{-1}$ in experiment $\mathrm{C} 1$. Due to the independence from the column bulk properties, the obtained $K_{d}$ values are virtually equal. $K_{d}$ was $0.8 \mathrm{~L} \mathrm{~kg}^{-1}$ for $\mathrm{C} 1$ and $\mathrm{C} 2$, $0.9 \mathrm{~L} \mathrm{~kg}^{-1}$ for $\mathrm{C} 3$, and $1.0 \mathrm{~L} \mathrm{~kg}^{-1}$ for $\mathrm{C} 4$. As with experiments $\mathrm{A} 1-\mathrm{A} 4$, some biodegradation was observed. In experiment $\mathrm{C} 1$ the presence of the atenolol metabolite atenolol acid (Radjenović et al., 2008) was confirmed by LC-MS/MS analysis with atenolol acid as reference substance.

The $K_{d}$ values are considerably lower compared to experiment A3 and A4 with a similar sediment. This is due to increasing concentrations of inorganic cations (ionic strength) resulting in stronger competition at the sorbent. Therefore, the sorption of atenolol to the available exchange sites decreases. 
In contrast, $K_{d}$ values are equal at constant ionic strength. This implies that even at very high concentrations of inorganic cations the affinity of atenolol to the sorbent is independent from its concentration. At the investigated conditions, the calculated $K_{d}^{0}$ of $<0.001 \mathrm{~L} \mathrm{~kg}^{-1}$ indicates that around $99.9 \%$ of the observed total sorption is caused by ionic interactions. Thus, the underlying sorption mechanism is not changing and a linear sorption behavior can be expected over a wide concentration range $\left(1-30,000 \mu \mathrm{g} \mathrm{L}^{-1}\right)$. Hence, the influence of the concentration ratio of atenolol to inorganic cations on the transport of atenolol is negligible at all environmentally relevant concentrations. Absolute concentrations of involved cations are rather important, since these define the competitive system. Therefore, it is postulated that only very high molar atenolol concentrations in the range of the inorganic cation concentrations should have a noticeable influence on the exchange equilibrium and thus on the transport behavior of beta-blockers.

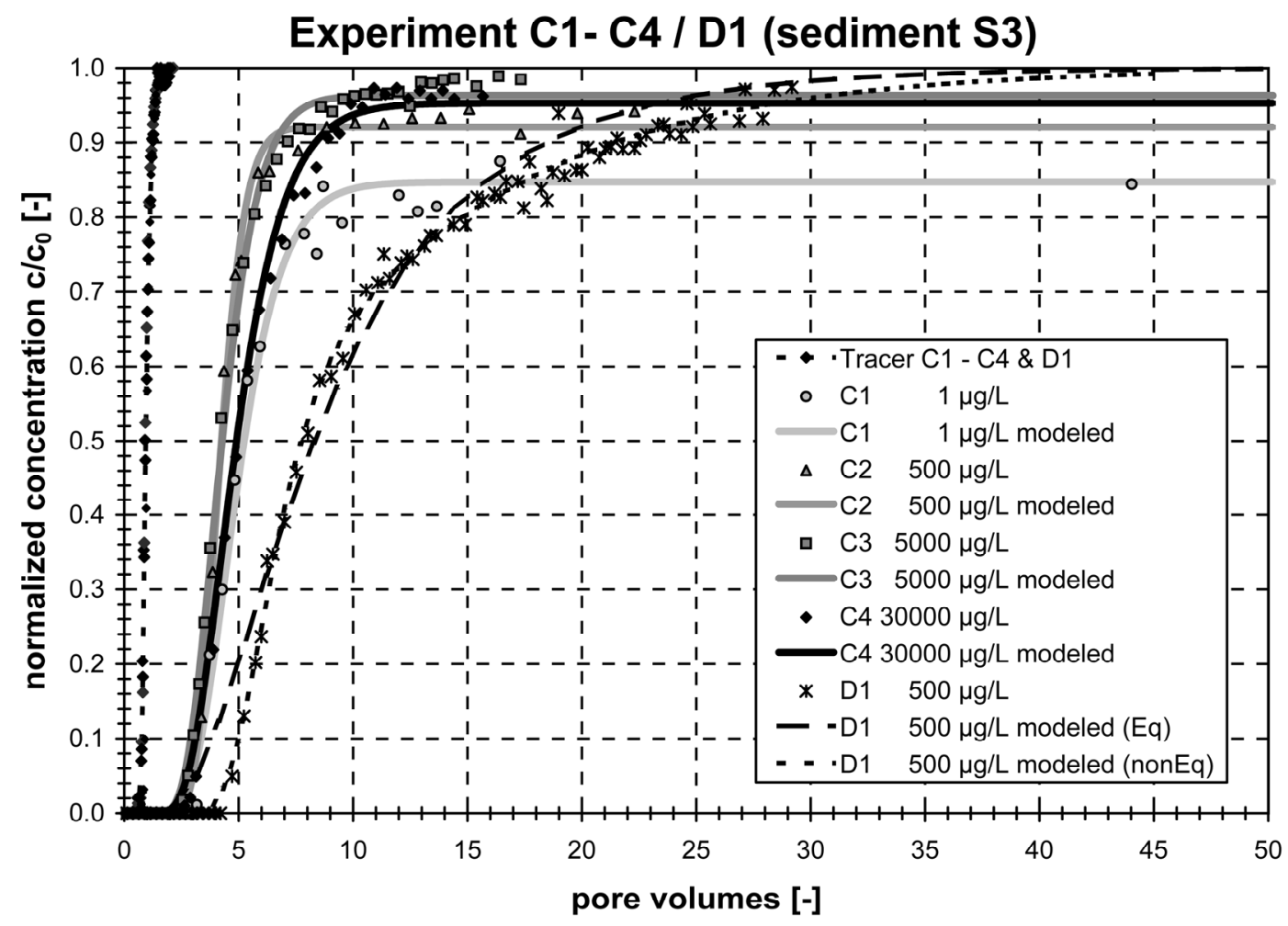

Fig. 3.4 Experimental and modeled breakthrough curves (including tracer tests) for different concentrations of atenolol (C1-C4) and metoprolol (D1, Eq=chemical equilibrium model, nonEq = chemical non-equilibrium model) in sediment S3 at constant ionic strength. Concentrations $c$ of the breakthrough curves were normalized with the initial concentration $c_{0}$. Pore volumes were calculated by normalizing the experiment duration to the ideal breakthrough time of the $\mathrm{Cl}^{-}$tracer. 
Table 3.4 Distribution coefficients and calculated relative proportion of cation exchange.

\begin{tabular}{|c|c|c|c|c|c|c|c|c|c|c|}
\hline Exp. & $\begin{array}{c}\rho_{b} \\
{\left[\mathrm{~g} \mathrm{~cm}^{3}\right]}\end{array}$ & $\begin{array}{c}K_{d} \\
{\left[\mathbf{L ~ k g}^{-1}\right]}\end{array}$ & $\begin{array}{c}\text { lower } \\
K_{d} \\
{\left[\mathbf{~ k g}^{-1}\right]}\end{array}$ & $\begin{array}{c}\text { upper } \\
\boldsymbol{K}_{\boldsymbol{d}} \\
{\left[\mathbf{L ~ k g}^{-1}\right]}\end{array}$ & $\begin{array}{c}\boldsymbol{f}_{O C} \\
{\left[\mathbf{g ~ g}^{-1}\right]}\end{array}$ & $\begin{array}{c}K_{d}{ }^{0} \\
{\left[L \mathbf{k g}^{-1}\right]}\end{array}$ & $\begin{array}{c}K_{d}^{+} \\
{\left[\mathbf{L ~ k g}^{-1}\right]}\end{array}$ & $\begin{array}{c}\text { lower } \\
K_{d^{+}} \\
{\left[\mathbf{L ~ k g}^{-1}\right]}\end{array}$ & $\begin{array}{c}\text { upper } \\
K_{d}^{+} \\
{\left[\mathbf{~ k g}^{-1}\right]}\end{array}$ & $\begin{array}{c}\boldsymbol{K}_{\boldsymbol{d}}^{+} / \boldsymbol{K}_{\boldsymbol{d}} \\
{[\%]}\end{array}$ \\
\hline $\mathrm{A} 1$ & 1.76 & 3.48 & 3.04 & 3.97 & 0.0023 & 0.0030 & 3.48 & 3.04 & 3.97 & 99.91 \\
\hline $\mathrm{A} 2$ & 1.76 & 1.28 & 1.12 & 1.45 & 0.0023 & 0.0030 & 1.27 & 1.12 & 1.45 & 99.76 \\
\hline $\mathrm{A} 3$ & 1.94 & 3.20 & 2.80 & 3.67 & 0.0011 & 0.0014 & 3.20 & 2.80 & 3.66 & 99.96 \\
\hline A4 & 1.94 & 1.66 & 1.47 & 1.88 & 0.0011 & 0.0014 & 1.66 & 1.47 & 1.88 & 99.91 \\
\hline B1 & 1.76 & 3.40 & 2.92 & 3.95 & 0.0023 & 0.0030 & 3.40 & 2.92 & 3.95 & 99.91 \\
\hline B3 & 1.94 & 3.61 & 3.19 & 4.08 & 0.0011 & 0.0014 & 3.61 & 3.19 & 4.08 & 99.96 \\
\hline $\mathrm{C} 1$ & 1.74 & 0.80 & 0.70 & 0.92 & 0.0007 & 0.0009 & 0.80 & 0.69 & 0.92 & 99.89 \\
\hline $\mathrm{C} 2$ & 1.72 & 0.75 & 0.66 & 0.85 & 0.0007 & 0.0009 & 0.75 & 0.66 & 0.85 & 99.88 \\
\hline $\mathrm{C} 3$ & 1.68 & 0.86 & 0.76 & 0.96 & 0.0007 & 0.0009 & 0.86 & 0.76 & 0.96 & 99.89 \\
\hline $\mathrm{C} 4$ & 1.74 & 1.00 & 0.89 & 1.13 & 0.0007 & 0.0009 & 1.00 & 0.89 & 1.13 & 99.91 \\
\hline D1_Eq & 1.69 & 2.21 & 1.94 & 2.51 & 0.0007 & 0.0037 & 2.20 & 1.93 & 2.51 & 99.83 \\
\hline D1_nonEq & 1.69 & 2.32 & 2.06 & 2.60 & 0.0007 & 0.0037 & 2.31 & 2.06 & 2.60 & 99.84 \\
\hline
\end{tabular}

Exp. $=$ experiment,$\rho_{b}=$ bulk density, $K_{d}=$ observed distribution coefficient (including $95 \%$ confidence limits of $R$ and $5 \%$ error for $\rho_{b}$ and $n_{e}$ respectively ), $f_{O C}=$ fraction of organic carbon, $K_{d}{ }^{0}=$ calculated distribution coefficient attributed to non-polar interactions, $K_{d}{ }^{+}=$determined distribution coefficient attributed to cation exchange, $\mathrm{Eq}=$ equilibrium model, $\mathrm{nonEq}=$ non-equilibrium model

\subsubsection{Experiment D: Comparison with metoprolol}

At $c_{0}=500 \mu \mathrm{g} \mathrm{L}^{-1}$ and comparable concentrations of inorganic cations, the breakthrough curve of metoprolol (Fig. 3.4) showed a significantly higher retardation $(R=10.8)$ when compared with atenolol $(R=4.3)$. The obtained $K_{d}$ of $2.3 \mathrm{~L} \mathrm{~kg}^{-1}$ for metoprolol in experiment D1 was three times higher than in experiment C2 for atenolol $\left(K_{d}=0.8 \mathrm{~L} \mathrm{~kg}^{-1}\right)$. Biodegradation was not detected $\left(100 \%\right.$ of $c_{0}$ were retrieved).

The higher sorption of metoprolol compared to atenolol is in accordance with the results of Barron et al. (2009) and Ramil et al. (2010) who also found significantly higher $K_{d}$ values for metoprolol. However, only around $0.15 \%$ of the obtained $K_{d}$ of metoprolol can be attributed to non-polar hydrophobic partitioning $\left(K_{d}^{0}=0.004 \mathrm{~L} \mathrm{~kg}^{-1}\right)$. Although, partitioning of metoprolol is stronger than for atenolol 
(four times higher $K_{d}^{0}$ at $\mathrm{pH}=8$ ) it can still be neglected for the prediction of transport parameters in aquifers sediments. This is caused by the very low TOC of these sediments while simultaneously the fraction of the cationic species is very high. Hence, cation exchange is still the controlling sorption process. Despite the similar molecular structure of both molecules, considerable differences remain. The obtained electrostatic contribution of $K_{d}^{+}=0.8$ of atenolol is significantly lower than for metoprolol with $K_{d}{ }^{+}=2.3$. This might be caused by several factors, e.g., different molecular geometry and charge density distributions, slightly different $\mathrm{p} K_{a}$ values, and uncertainties caused by the applied $\log K_{o w}-\log K_{o c}$ correlations.

\subsection{Conclusions}

The transport and sorption behavior of the cationic beta-blockers atenolol and metoprolol in natural aquifer sediments were studied under saturated conditions using column experiments. By means of the application of different sediments and variable concentrations of inorganic cations and beta-blockers, the influence of cation exchange on the transport of protonated organic bases could be characterized. As a result, a first insight into the relevance and the relative contribution of cation exchange processes on the sorption influenced transport of beta-blockers was gained. Eventually, the obtained results offer a better understanding of relevant processes, which have to be considered in future modeling approaches in terms of cationic organics. The major conclusions of the presented study are:

- The dramatically decreased sorption of atenolol at increased $\mathrm{Ca}^{2+}$ concentrations indicates that cation exchange processes are highly relevant and play a major role for the transport of cationic beta-blockers in aquifers.

- The desorption curves support the significant role of cation exchange processes on sorption and lead to the expectation that sorption of betablockers is fully reversible.

- Due to cation exchange as dominating sorption mechanism, the sole application of $\log K_{o w}-\log K_{o c}$ correlations for non-ionic and hydrophobic compounds is insufficient for cationic beta-blockers. Therefore, the commonly 
determined $K_{d}$ and $K_{O C}$ values in sorption studies at $\mathrm{pH}<\mathrm{p} K_{a}$ are not transferable to other competitive systems and thus not representative for systems with different concentrations of inorganic cations.

- No influence of the atenolol concentration on the sorption ( $K_{d}$ values) was observed even at comparably high concentrations of competing inorganic cations.

- As a consequence, a variation in the main cation composition in the water phase bears the possibility of beta-blocker remobilization or accelerated transport, e.g. during salt water intrusions in coastal aquifers.

\subsection{Acknowledgments}

This work partly pertains to a research project jointly funded by Energie BadenWürttemberg (EnBW, Karlsruhe) and by the German Ministry for Environment, Nature Conservation and Nuclear Safety (BMU, project key: 0325111B), with operational support from local Energy and Water Supply Plants (EWB). Further, we acknowledge the German Federal Ministry of Education and Research (promotional reference No. 02WRS1277A, AGRO: "Risikomanagement von Spurenstoffen und Krankheitserregern in ländlichen Karsteinzugsgebieten") for the financial support. The authors would also like to thank Zahra Fona, Susann Kutzner and Anne Niedbala for carrying out several experiments and parts of the sediment analysis.

\subsection{References}

Amiri, F., Börnick, H., Worch, E., 2005. Sorption of phenols onto sandy aquifer material: the effect of dissolved organic matter (DOM). Water Research 39 (5), 933-941.

Barron, L., Havel, J., Purcell, M., Szpak, M., Kelleher, B., Paull, B., 2009. Predicting sorption of pharmaceuticals and personal care products onto soil and digested sludge using artificial neural networks. Analyst 134 (4), 663-670.

Bi, E., Schmidt, T.C., Haderlein, S.B., 2006. Sorption of heterocyclic organic compounds to reference soils: column studies for process identification. Environmental Science and Technology 40 (19), 5962-5970.

Brownawell, B.J., Chen, H., Collier, J.M., Westall, J.C., 1990. Adsorption of organic cations to natural materials. Environmental Science and Technology, 24 (8), 1234-1241. 
Caron, G., Steyaert, G., Pagliara, A., Reymond, F., Crivori, P., Gaillard, P., Carrupt, P.-A., Avdeef, A., Comer, J., Box, K.J., Girault, H.H., Testa, B., 1999. Structure-lipophilicity relationships of neutral and protonated $\beta$-blockers; Part I: Intra- and intermolecular effects in isotropic solvent systems. Helvetica Chimica Acta 82 (8), 1211-1222.

Carmosini, N., Lee, L.S., 2009. Ciprofloxacin sorption by dissolved organic carbon from reference and bio-waste materials. Chemosphere 77 (6), 813-820.

Chiou, C.T., Peters, L.J., Freed, V.H., 1979. Physical concept of soil-water equilibria for nonionic organic compounds. Science 206 (4420), 831-832.

Cleuvers, M., 2005. Initial risk assessment for three $\beta$-blockers found in the aquatic environment. Chemosphere 59 (2), 199-205.

Cunningham, V.L., Constable, D.J.C., Hannah, R.E., 2004. Environmental risk assessment of paroxetine. Environmental Science and Technology 38 (12), 3351-3359.

Daughton, C.G., Ternes, T.A., 1999. Pharmaceuticals and personal care products in the environment: Agents of subtle change? Environmental Health Perspectives 107 (Suppl 6), 907-938.

DIN ISO 9277, 2003. Determination of the specific surface area of solids by gas adsorption using the BET method. Deutsches Institut für Normung e. V., Beuth, Berlin, Germany.

DIN ISO 10390, 2003. Soil quality - Determination of pH. Deutsches Institut für Normung e. V., Beuth, Berlin, Germany.

DIN ISO 13536, 1997. Soil quality - Determination of the potential cation exchange capacity and exchangeable cations using barium chloride solution buffered at $\mathrm{pH}=8.1$. Deutsches Institut für Normung e. V., Beuth, Berlin, Germany.

Fábrega, J.R., Jafvert, C.T., Li, H., Lee, L.S., 1998. Modeling short-term soil-water distribution of aromatic amines. Environmental Science and Technology 32 (18), 2788-2794.

Fábrega, J.R., Jafvert, C.T., Li, H., Lee, L.S., 2001. Modeling competitive cation exchange of aromatic amines in water-saturated soils. Environmental Science and Technology 35 (13), 2727-2733.

Figueroa, R.A., Leonard, A., MacKay, A.A., 2004. Modeling tetracycline antibiotic sorption to clays. Environmental Science and Technology 38 (2), 476-483.

Franco, A., Trapp, S., 2008. Estimation of the soil-water partition coefficient normalized to organic carbon for ionizable organic chemicals. Environmental Toxicology and Chemistry 27 (10), 19952004.

Franco, A., Fu, W., Trapp, S., 2009. Influence of soil pH on the sorption of ionisable chemicals: modelling advances. Environmental Toxicology and Chemistry 28 (3), 458-464.

Halling-Sørensen, B., Nors Nielsen, S., Lanzky, P.F., Ingerslev, F., Holten Lützhøft, H.C., Jørgensen, S.C., 1998. Occurrence, fate and effects of pharmaceutical substances in the environment - a review. Chemosphere 36 (2), 357-393.

Heberer, T., 2002. Occurrence, fate, and removal of pharmaceutical residues in the aquatic environment: a review of recent research data. Toxicology Letters 131 (1-2), 5-17.

Hyland, K.C., Dickenson, E.R.V., Drewes, J.E., Higgins, C.P., 2012. Sorption of ionized and neutral emerging trace organic compounds onto activated sludge from different wastewater treatment configurations. Water Research 46 (6), 1958-1968.

Kah, M., Brown, C.D., 2007. Prediction of the adsorption of ionizable pesticides in soils. Journal of Agricultural and Food Chemistry 55 (6), 2312-2322. 
Karickhoff, S.W., 1981. Semi-empirical estimation of sorption of hydrophobic pollutants on natural sediments and soils. Chemosphere 10 (8), 833-846.

Katayama, A., Bhula, R., Burns, G.R., Carazo, E., Felsot, A., Hamilton, D., Harris, C., Kim, Y.-H., Kleter, G., Koerdel, W., Linders, J., Peijnenburg, J.G.M.W., Sabljic, A., Stephenson, R.G., Racke, D.K., Rubin, B., Tanaka, K., Unsworth, J., Wauchope, R.D., 2010. Bioavailability of xenobiotics in the soil environment. Reviews of Environmental Contamination and Toxicology 203, 1-86.

Kibbey, T.C.G., Paruchuri, R., Sabatini, D.A., Chen, L., 2007. Adsorption of beta blockers to environmental surfaces. Environmental Science and Technology 41 (15), 5349-5356

Li, H., Lee, L.S., Fabrega, J.R., Jafvert, C.T., 2001. Role of pH in partitioning and cation exchange of aromatic amines on water-saturated soils. Chemosphere 44 (4), 627-635.

Maurer, M., Escher, B.I., Richle, P., Schaffner, C., Alder, A.C., 2007. Elimination of $\beta$-blockers in sewage treatment plants. Water Research 41 (7), 1614-1622.

Nicholls, P.H., Evans, A.A., 1991. Sorption of ionizable organic compounds by field soils. Part 2: cations, bases and zwitterions. Pesticide Science 33 (3), 331-345.

Nödler, K., Licha, T., Bester, K., Sauter, M., 2010. Development of a multi-residue analytical method, based on liquid chromatography-tandem mass spectrometry, for the simultaneous determination of 46 micro-contaminants in aqueous samples. Journal of Chromatography $A$ $1217(42), 6511-6521$.

Nödler, K., Licha, T., Fischer, S., Wagner, B., Sauter, M., 2011. A case study on the correlation of microcontaminants and potassium in the Leine River (Germany). Applied Geochemistry 26 (12), 21722180.

Radjenović, J., Pérez, S., Petrović, M., Barceló, D., 2008. Identification and structural characterization of biodegradation products of atenolol and glibenclamide by liquid chromatography coupled to hybrid quadrupole time-of-flight and quadrupole ion trap mass spectrometry. Journal of Chromatography A 1210 (2), 142-153.

Rahman, M.; Amiri, F.; Worch, E., 2003. Application of mass transfer model for describing nonequilibrium transport of HOCs through natural geosorbents. Water Research 37 (19), 46734684.

Ramil, M., El Aref, T., Fink, G., Scheurer, M., Ternes, T.A., 2010. Fate of beta blockers in aquatic-sediment systems: sorption and biotransformation. Environmental Science and Technology 44 (3), 962970.

Sabljic, A., Guesten, H., Verhaar, H., Hermens, J., 1995. QSAR modelling of soil sorption. Improvements and systematics of log $K_{o c}$ vs. log Kow correlations. Chemosphere 31 (11-12), 4489-4514.

Sacher, F., Lange, F.T., Brauch, H.-J., Blankenhorn, l., 2001. Pharmaceuticals in groundwaters: Analytical methods and results of a monitoring program in Baden-Württemberg, Germany. Journal of Chromatography A 938 (1-2), 199-210.

Schaffer, M., Boxberger, N., Börnick, H., Licha, T., Worch, E., 2012. Sorption influenced transport of ionizable pharmaceuticals onto a natural sandy aquifer sediment at different $\mathrm{pH}$. Chemosphere 87(5), 513-520.

Schwarzenbach, R.P., Gschwend, P.M., Imboden, D.M., 2003. Environmental Organic Chemistry, $2^{\text {nd }}$ ed. John Wiley \& Sons, Hoboken. 
Stevens-Garmon, J., Drewes, J.E., Khan, S.J., McDonald, J.A., Dickenson, E.R.V., 2011. Sorption of emerging trace organic compounds onto wastewater sludge solids. Water Research 45 (11), 3417-3426.

ter Laak, T.L., Gebbink, W.A., Tolls, J., 2006. The effect of pH and ionic strength on the sorption of sulfachloropyridazine, tylosin, and oxytetracycline to soil. Environmental Toxicology and Chemistry 25 (4), 904-911.

Ternes, T.A., 1998. Occurrence of drugs in german sewage treatment plants and rivers. Water Research 32 (11), 3245-3260.

Tolls, J., 2001. Sorption of veterinary pharmaceuticals in soils: a review. Environmental Science and Technology 35 (17), 3397-3406.

Toride N., Leij F.J., van Genuchten M.T., 1995. The CXTFIT code for estimating transport parameters from laboratory or field tracer experiments. Version 2.0. U.S. Salinity Laboratory, U.S. Department of Agriculture, Riverside, CA, Research Report 137.

Worch, E., 2004. Modelling the solute transport under nonequilibrium conditions on the basis of mass transfer equations. Journal of Contaminant Hydrology 68 (1-2), 97-120.

Yamamoto, H., Hayashi, A., Nakamura, Y., Sekizawa, J., 2005. Fate and partitioning of selected pharmaceuticals in aquatic environment. Environmental Sciences 12 (6), 347-358.

Yamamoto, H., Nakamura, Y., Moriguchi, S., Nakamura, Y., Honda, Y., Tamura, I., Hirata, Y., Hayashi, A., Sekizawa, J., 2009. Persistence and partitioning of eight selected pharmaceuticals in the aquatic environment: Laboratory photolysis, biodegradation, and sorption experiments. Water Research $43(2), 351-362$.

Zachara, J.M., Ainsworth, C.C., Felice, L.J., Resch, C.T., 1986. Quinoline sorption to subsurface materials: role of $\mathrm{pH}$ and retention of the organic cation. Environmental Science and Technology 20 (6), 620-627. 


\section{Chapter 4}

\section{Influence of competing inorganic cations on the ion exchange equilibrium of the monovalent organic cation metoprolol on natural sediment}

Anne Niedbala', Mario Schaffer ${ }^{1, *}$, Tobias Licha1, Karsten Nödler ${ }^{1}$, Hilmar Börnick ${ }^{2}$, Hans Ruppert ${ }^{3}$, Eckhard Worch ${ }^{2}$

\section{Citation:}

Niedbala, A., Schaffer, M., Licha, T., Nödler, K., Börnick, H., Ruppert, H., Worch, E., 2013. Influence of competing inorganic cations on the ion exchange equilibrium of the monovalent organic cation metoprolol on natural sediment. Chemosphere 90 (6), 1945-1951.

\footnotetext{
${ }^{1}$ Geoscience Centre, Dept. Applied Geology, University of Göttingen, Goldschmidtstr. 3, 37077 Göttingen, Germany

${ }^{2}$ Institute of Water Chemistry, Dresden University of Technology, 01062 Dresden, Germany

${ }^{3}$ Geoscience Centre, Dept. Sedimentology and Environmental Geology, University of Göttingen, Goldschmidtstr. 3, 37077 Göttingen, Germany

* Corresponding author
} 


\section{Abstract}

The aim of this study was to systematically investigate the influence of the monoand divalent inorganic ions $\mathrm{Na}^{+}$and $\mathrm{Ca}^{2+}$ on the sorption behavior of the monovalent organic cation metoprolol on a natural sandy sediment at $\mathrm{pH}=7$. Isotherms for the beta-blocker metoprolol were obtained by sediment-water batch tests over a wide concentration range $\left(1-100,000 \mu \mathrm{g} \mathrm{L}^{-1}\right)$. Concentrations of the competing inorganic ions were varied within freshwater relevant ranges. Data fitted well with the Freundlich sorption model and resulted in very similar Freundlich exponents ( $n=0.9$ ), indicating slightly non-linear behavior. Results show that the influence of $\mathrm{Ca}^{2+}$ compared to $\mathrm{Na}^{+}$is more pronounced. A logarithmic correlation between the Freundlich coefficient $K_{F r}$ and the concentration or activity of the competing inorganic ions was found allowing the prediction of metoprolol sorption on the investigated sediment at different electrolyte concentrations. Additionally, the organic carbon of the sediment was completely removed for investigating the influence of organic matter on the sorption of metoprolol. The comparison between the experiments with and without organic carbon removal revealed no significant contribution of the organic carbon fraction (0.1\%) to the sorption of metoprolol on the in this study investigated sediment. Results of this study will contribute to the development of predictive models for the transport of organic cations in the subsurface. 


\subsection{Introduction}

A large number of anthropogenic organic compounds detected in the aquatic environment (Daughton and Ternes, 1999; Schwarzenbach et al., 2006) are bases with corresponding logarithmic acid constants $\mathrm{p} K_{a}$ above the common $\mathrm{pH}$ range of natural freshwaters. Therefore, these bases are protonated and thus positively charged. The most common (micro)-contaminants with these properties belong to the groups of industrial precursors (e.g., alkyl amines), pesticides (e.g., fungicides), pharmaceuticals and cationic surfactants. Despite their high polarity, sorption to environmental surfaces, such as soils, riverbed and aquifer sediments can play a significant role for the removal of these compounds from the aqueous phase, because a variety of these geosorbents (e.g., clays, organic matter) possess a negative surface charge (Kibbey et al., 2007; Schaffer et al., 2012a). Hence, sorption may be a significant attenuation process for organic bases during riverbank filtration, soil aquifer treatment, and artificial groundwater recharge.

In contrast to neutral compounds and the anionic species of organic acids, the experimentally determined distribution coefficients or organic carbon normalized sorption coefficients $K_{O C}$ of organic cations are usually higher than estimated merely from $n$-octanol/water distribution coefficients $K_{\text {ow }}$ and $\log D$, respectively (Tolls, 2001; Kah and Brown, 2007; Schaffer et al., 2012a; 2012b). The reason is that $\mathrm{pH}$ effects and additional electrostatic contributions to the overall sorption of organic cations (e.g., ion exchange, hydrogen bonding, formation of surface complexes, etc.) cannot be taken into account by predicting the sorption only by means of linear-free energy relationships for hydrophobic partitioning (log $K_{o w}-\log K_{o c}$ correlations).

For several basic pesticides Weber et al. (2004) reported empirical compound-specific correlations for $K_{d}$ with selected soil properties (organic matter, clay content, $\mathrm{pH}$ ). However, this approach only gave poor fit qualities suggesting a more complex sorption mechanism for basic pesticides. An extended predictive semi-empirical model based on regressions for organic bases was proposed by Franco and Trapp (2008) and Franco et al. (2009). This recent modeling approach allows considering the $\mathrm{pH}$ dependent speciation of the sorbates in solution and generally improves the prediction for basic compounds (Franco and Trapp, 2008; Franco et al., 2009; Schaffer et al., 2012a). However, the obtained results are still not valid for all compounds and 
at different boundary conditions (Schaffer et al., 2012a). This is because ionic interactions and especially cation exchange processes are not explicitly considered therein. Schaffer et al. (2012b) demonstrated the dominating role of cation exchange processes for two cationic beta-blockers at $\mathrm{pH}=8$ and quantified their contribution to the whole sorption process with $>99 \%$. Consequently, sorption of organic cations onto environmental media mainly depends on (1) the organic molecule (e.g., hydrophobicity, type and location of protonated moiety, molecule size), (2) the composition of the aqueous phase (e.g., $\mathrm{pH}$, ionic content) and, (3) the composition and type of the sorbent (e.g., clay content and type, organic matter) (Calvet, 1989; Limousin et al., 2007). As the influencing variables are numerous, it is necessary to address them individually. In this study, the influence of the ionic composition of the aqueous phase (No. 2) is addressed. Strong effects of competing inorganic cations were earlier shown by Brownawell et al. (1990), Nicholls and Evans (1991), Polubesova et al. (1997), Laird and Fleming (1999), Bilgiç (2005), Sassman and Lee (2005), Bi et al. (2006), ter Laak et al. (2006), Schaffer et al. (2012b), and Droge and Goss (2012). In general, a reduced sorption for organic cations on different geosorbents with increasing concentrations of competing cations was observed.

Sorption models considering cation exchange or binding as surface complexes to negatively charged sites were introduced and applied for different organic cations by several authors (e.g., Nir et al., 1986; Margulies et al., 1988; Brownawell et al., 1990; Rytwo et al., 1995; Fábrega et al., 1998; 2001). The common drawback of these models is, however, the use of an inverse optimization procedure. That means the models are non-predictive since the solutions are best fitted into measured isotherm data. To date, the influence of changing boundary conditions, including sorption in different competitive systems, cannot be modeled predictively.

The prerequisite for creating suitable models for competitive sorption of organic cations based on mechanistic principles is the understanding of all involved processes and their dependences from boundary conditions together with a sufficient mathematical description. Beside the $\mathrm{pH}$, which determines the speciation of the sorbates and the variable surface charges, knowledge on the competition from inorganic cations is most essential. Among the few studies available today, Bäuerlein et al. (2012) and Droge and Goss (2012) recently demonstrated and quantified the 
changed sorption behavior of organic cations caused by competition with different inorganic cations on ion exchange polymers and organic matter, respectively. Brownawell et al. (1990), Nicholls and Evans (1991), Figueroa et al. (2004), ter Laak et al. (2006), Bi et al. (2006), Schaffer et al. (2012b) investigated semi-quantitatively the sorption of organic cations by deliberately varying background electrolyte concentrations. Further studies with main focus on competitive sorption between organic and inorganic cations, especially conducted with natural sediments are not yet available.

Therefore, the aim of this study is the systematic investigation of cation exchange processes for organic cations on natural sediment. Isotherms for the basic betablocker metoprolol were obtained over a wide concentration range (1$100,000 \mu \mathrm{g} \mathrm{L}^{-1}$ ) starting from environmentally relevant concentrations on a sandy aquifer material at $\mathrm{pH}=7$. Solely the concentrations of the competing inorganic cations $\mathrm{Na}^{+}$and $\mathrm{Ca}^{2+}$ in solution were varied within relevant ranges of freshwater. Isotherm parameters were calculated, compared, and related to the type and concentration of the considered inorganic cation. Additionally, the influence of complete organic carbon removal from the sediment on the sorption of metoprolol is reported. The experiments shall provide further information on the boundary conditions for the cation exchange equilibrium of organic cations. Due to the systematic consideration and quantitative description of the influence of competing cations, valuable contributions for future model developments are expected.

\subsection{Materials and methods}

\subsubsection{Chemicals}

Metoprolol (physicochemical properties shown in Table 4.1) as tartrate salt was purchased from Sigma-Aldrich (Steinheim, Germany) with a minimum content of $99 \%$. One of its major metabolites metoprolol acid and the internal reference standard metoprolol-D 7 were purchased from LGC Promochem (Wesel, Germany). All other used fine chemicals were of high purity ( $>98 \%$, analytical grade) and were purchased from VWR (Darmstadt, Germany). Ultrapure water for the preparation of 
all solutions was obtained from a combined water purification system consisting of

Elix 5 and Milli-Q Gradient A10, both from Millipore (Schwalbach, Germany).

Table 4.1 Physicochemical properties of the sorbate and sorbent.

\begin{tabular}{llllll}
\hline Compound Structure & ${ }^{\mathrm{a}, \mathrm{b}} \mathrm{p} K_{a}$ & ${ }^{\mathrm{a}, \mathrm{c}} \log K_{\text {ow }}$ & ${ }^{\mathrm{a}, \mathrm{d}} \log K_{\text {ow }}{ }^{+}$ & ${ }^{\mathrm{e}} \log D_{\mathrm{pH}=7}$ \\
\hline Metoprolol & & & & & \\
\end{tabular}

CAS number 37350-58-6

\begin{tabular}{|c|c|c|c|c|}
\hline \multicolumn{3}{|c|}{ Mineral composition of the sorbent } & \multicolumn{2}{|c|}{ Physicochemical properties of the sorbent } \\
\hline $\begin{array}{l}\text { Mineral } \\
\text { class }\end{array}$ & Qualitative & $\begin{array}{l}\text { Quantitative } \\
{[\% w / w]}\end{array}$ & & \\
\hline \multirow{4}{*}{ Silicates } & Quartz & 40 & $\mathrm{pH}\left(\mathrm{H}_{2} \mathrm{O}\right)$ & 8.8 \\
\hline & Hornblende & 3 & $\mathrm{pH}\left(\mathrm{CaCl}_{2}\right)$ & 8.1 \\
\hline & Actinolite & 1 & TOC (\%) & 0.1 \\
\hline & Diopside & 1 & CEC $\left(\mathrm{cmol}_{\mathrm{c}} \mathrm{kg}^{-1}\right)$ & 4.4 \\
\hline \multirow{4}{*}{$\begin{array}{l}\text { Phyllo- } \\
\text { silicates }\end{array}$} & Muscovite & 9 & & \\
\hline & Smectite & 6 & & \\
\hline & Chlorite & 4 & & \\
\hline & Biotite & 2 & & \\
\hline \multirow{3}{*}{ Feldspars } & Plagioclase & 20 & & \\
\hline & Microcline & 11 & & \\
\hline & Orthoclase & 3 & & \\
\hline \multicolumn{5}{|c|}{$\mathrm{TOC}=$ total organic carbon, $\mathrm{CEC}=$ potential cation exchange capacity at $\mathrm{pH}=8.1}$. \\
\hline \multicolumn{5}{|c|}{ a Caron et al. (1999). } \\
\hline \multicolumn{5}{|c|}{${ }^{\mathrm{b}} \mathrm{p} K_{a}$ value refers to $\mathrm{p} K_{a}$ value for the conjugate acid (protonated species). } \\
\hline \multicolumn{5}{|c|}{ ' $\log$ Kow value refers to the neutral species. } \\
\hline \multicolumn{5}{|c|}{${ }^{\mathrm{d}} \log \mathrm{Kow}^{+}$value refers to the cationic species. } \\
\hline \multicolumn{5}{|c|}{$\begin{array}{l}\text { e } \log D \text { value refers to all species at } \mathrm{pH}=7 \text {. SciFinder Scholar } 2007 \text { predicted values, calculated using Advanced } \\
\text { Chemistry Development (ACD/Labs) Software V } 11.02 \text { (1994-2012 ACD/Labs). }\end{array}$} \\
\hline
\end{tabular}

\subsubsection{Sorbent}

The sediment used originates from a Pleistocene and Holocene alluvial fan, which is part of a shallow aquifer in Sindos, Northern Greece. The sediment can be assigned to the texture class of medium sand. The homogenized bulk sediment $(<2 \mathrm{~mm})$ was 
used in all experiments. Preliminary experiments with various particle size fractions of the sediment exhibited no significant differences in sorption (Fig. C1).

Selected physicochemical properties of the sediment are listed in Table 4.1, further can be found in Schaffer et al. (2012b) (denoted as sediment S3). Additionally, the mineral composition of the bulk sediment was determined by powder X-ray diffraction (XRD) with a Philips X'Pert MPD diffractometer (PANalytical, Almelo, Netherlands), equipped with a PW 3373/00 Cu LFF X-ray tube and a PW 3050/10 goniometer. The dominant mineral classes are silicates, feldspars, and phyllosilicates (Table 4.1). Among the detected mineral phases, the clay minerals chlorite and smectite are expected to bear the highest potential for sorption and cation exchange, respectively, of organic cations due to their high cation exchange capacities (CEC). Several minerals in the sediment provide a much lower CEC, but should also carry negative net surface charges under typical groundwater $\mathrm{pH}$ conditions, since their point of zero charge $\left(\mathrm{pH}_{\mathrm{pzc}}\right)$ is low $\left(\mathrm{pH}_{\mathrm{pzc}}<5\right.$; Scheffer and Schachtschabel, 2010). In addition, the total organic carbon (TOC) content of the sediment is very low, which is vital for separating electrostatic interactions from hydrophobic partitioning.

The $\mathrm{pH}$ of the sediment was adjusted over a two week period with $1 \mathrm{M} \mathrm{HCl}$ to $\mathrm{pH}=7$ in order to ensure stable $\mathrm{pH}$ conditions during the batch experiments and the sole existence of the cationic metoprolol species. Afterwards, the sediment was washed with pure water and dried at $40{ }^{\circ} \mathrm{C}$ for $24 \mathrm{~h}$. The final $\mathrm{pH}$ was confirmed by measuring the $\mathrm{pH}$ in its aqueous suspension.

For a subsample of the aquifer material, the organic matter of the sediment was completely removed with the method after Gao et al. (1998) using $30 \% \mathrm{H}_{2} \mathrm{O}_{2}$. This was done to assess the contribution of organic matter on the sorption of metoprolol. The TOC of the sediment, before and after treatment with $\mathrm{H}_{2} \mathrm{O}_{2}$ was determined with a TOC-L analyzer (Shimadzu, Duisburg, Germany) utilizing the suspension method combined with catalytic oxidation at $680^{\circ} \mathrm{C}$. 


\subsubsection{Model water}

For the isotherm determination, solutions with six different concentrations of metoprolol between $3.7 \mathrm{E}-06$ and $3.7 \mathrm{E}-01 \mathrm{mmol} \mathrm{L}^{-1} \quad\left(1-100,000 \mu \mathrm{g} \mathrm{L}^{-1}\right)$ were prepared in ultrapure water. Different competitive conditions were realized by adding defined amounts of $\mathrm{NaCl}$ or $\mathrm{CaCl}_{2} \cdot 6 \mathrm{H}_{2} \mathrm{O}$ to the metoprolol containing solutions. The target concentrations of each inorganic cation were $0.37,3.7$, and $37 \mathrm{mmol} \mathrm{L}^{-1}$. The selected concentrations cover almost entirely the typical stream water concentration ranges in Europe for $\mathrm{Na}^{+}\left(c=0.01-175 \mathrm{mmol} \mathrm{L}^{-1}\right.$, median: $\left.0.28 \mathrm{mmol} \mathrm{L}^{-1}\right)$ and $\mathrm{Ca}^{2+}\left(c=0.006-14.8 \mathrm{mmol} \mathrm{L}^{-1}\right.$, median: $\left.1 \mathrm{mmol} \mathrm{L}^{-1}\right)$ (Salminen et al., 2005). An overview of all applied concentrations and corresponding activities is given in Table 4.2.

Table 4.2 Freundlich regression parameters of all batch experiment series.

\begin{tabular}{|c|c|c|c|c|c|c|c|c|c|c|c|}
\hline \multirow{2}{*}{$\begin{array}{l}\text { Water } \\
\text { matrix }\end{array}$} & \multicolumn{3}{|c|}{ Added electrolyte } & \multicolumn{8}{|c|}{ Freundlich regression parameters } \\
\hline & c & $\begin{array}{c}\log c \\
{[\mathrm{mmol} \mathrm{L}}\end{array}$ & $\begin{array}{l}\log a \\
-1]\end{array}$ & $\log K_{F r}$ & $\begin{array}{l}\text { lower } \\
\log K_{F r} \\
{\left[\mathbf{L ~ k g}^{-1}\right]^{\mathbf{n}}}\end{array}$ & $\begin{array}{l}\text { upper } \\
\log K_{F r}\end{array}$ & $n$ & $\begin{array}{c}\text { lower } \\
n \\
{[-]}\end{array}$ & $\begin{array}{c}\text { upper } \\
n\end{array}$ & $\begin{array}{l}\mathbf{R}^{2} \\
{[-]}\end{array}$ & $\begin{array}{c}\text { SSE } \\
{[-]}\end{array}$ \\
\hline & & - & & 1.20 & 1.10 & 1.30 & 0.92 & 0.86 & 0.98 & 0.9962 & $9.9 \mathrm{E}-02$ \\
\hline pure water & & & - & 1.20 & 1.10 & 1.30 & 0.92 & 0.86 & 0.99 & 0.9963 & $9.8 \mathrm{E}-02$ \\
\hline pure water & 0.37 & -0.43 & & 1.04 & 0.95 & 1.13 & 0.87 & 0.83 & 0.91 & 0.9989 & $1.6 \mathrm{E}-02$ \\
\hline$+\mathrm{NaCl}$ & & & -0.44 & 1.05 & 0.96 & 1.14 & 0.87 & 0.83 & 0.91 & 0.9989 & $1.6 \mathrm{E}-02$ \\
\hline pure water & 3.7 & 0.57 & & 0.98 & 0.91 & 1.06 & 0.91 & 0.88 & 0.94 & 0.9994 & $9.5 \mathrm{E}-03$ \\
\hline$+\mathrm{NaCl}$ & & & 0.54 & 1.01 & 0.94 & 1.08 & 0.91 & 0.88 & 0.94 & 0.9994 & $9.6 \mathrm{E}-03$ \\
\hline pure water & 37 & 1.57 & & 0.78 & 0.67 & 0.90 & 0.93 & 0.89 & 0.98 & 0.9986 & $2.2 \mathrm{E}-02$ \\
\hline$+\mathrm{NaCl}$ & & & 1.49 & 0.86 & 0.75 & 0.96 & 0.93 & 0.89 & 0.98 & 0.9986 & $2.2 \mathrm{E}-02$ \\
\hline pure water & 0.37 & -0.43 & & 0.97 & 0.88 & 1.06 & 0.91 & 0.88 & 0.95 & 0.9990 & $1.5 \mathrm{E}-02$ \\
\hline$+\mathrm{CaCl}_{2}$ & & & -0.50 & 0.98 & 0.89 & 1.07 & 0.92 & 0.88 & 0.95 & 0.9990 & $1.5 \mathrm{E}-02$ \\
\hline pure water & 3.7 & 0.57 & & 0.76 & 0.60 & 0.93 & 0.92 & 0.85 & 0.99 & 0.9970 & $4.7 \mathrm{E}-02$ \\
\hline$+\mathrm{CaCl}_{2}$ & & & 0.38 & 0.81 & 0.65 & 0.97 & 0.92 & 0.85 & 0.99 & 0.9970 & 4.7E-02 \\
\hline pure water & 37 & 1.57 & & 0.50 & 0.16 & 0.84 & 0.89 & 0.75 & 1.03 & 0.9869 & $1.9 \mathrm{E}-01$ \\
\hline$+\mathrm{CaCl}_{2}$ & & & 1.13 & 0.60 & 0.27 & 0.93 & 0.89 & 0.75 & 1.03 & 0.9869 & $1.9 \mathrm{E}-01$ \\
\hline
\end{tabular}

SSE = sum of squared errors, see Eq. (C2) 


\subsubsection{Batch-equilibrium experiments}

Isotherms were determined using the batch equilibrium method. Every isotherm point represents the average of three experiments (triplicate). As observed in preliminary tests an experimental duration of $72 \mathrm{~h}$ was found sufficient to ensure equilibrium conditions without any mass loss due to biotransformation. The latter was further monitored by the absence of the transformation product metoprolol acid. Only when the sediment-water batch tests were carried out for more than 5 days significant concentrations of metoprolol acid were detected (around $5-10 \%$ of $c_{0}$ from metoprolol). All batch experiments were conducted with a constant sediment-to-liquid ratio of 1:10 (m:V) in $40 \mathrm{~mL}$ glass vials with PTFE-lined caps or $100 \mathrm{~mL}$ glass bottles (both borosilicate glass), if pre-concentration with solid phase extraction (SPE) prior to analysis was necessary $\left(c_{0}=1\right.$ and $\left.10 \mu \mathrm{g} \mathrm{L}^{-1}\right)$. The metoprolol solutions containing the respective electrolyte were added to the dry sediment. The vials were sealed and shaken in a horizontal shaker (KS 501D, IKA, Staufen, Germany) with $250 \mathrm{rpm}$ at $20 \pm 1{ }^{\circ} \mathrm{C}$. After the equilibration time, both phases were separated by centrifugation in glass centrifuge tubes for $10 \mathrm{~min}$ at 4,000 rpm (Centrifuge 5804, Eppendorf, Hamburg, Germany).

After analysis, the sorbed amount $q_{e q}\left[\mathrm{M} \mathrm{M}^{-1}\right]$ was calculated from the mass loss of metoprolol in the solution with:

$q_{e q}=\frac{V_{0}\left(c_{0}-c_{e q}\right)}{m_{A}}$

where $c_{e q}\left[\mathrm{M} \mathrm{L}^{-3}\right]$ is the equilibrium concentration in the aqueous phase, $c_{0}\left[\mathrm{M} \mathrm{L}^{-3}\right]$ is the initial concentration in the aqueous phase, $V_{0}\left[L^{3}\right]$ is the volume of aqueous phase, and $m_{A}[\mathrm{M}]$ is the mass of the sorbent.

\subsubsection{Chemical analysis}

\subsubsection{Analysis of metoprolol and metoprolol acid}

The samples were kept frozen at $-18^{\circ} \mathrm{C}$ until analysis. SPE was used for samples with the lowest initial concentrations of metoprolol $\left(1 \mu \mathrm{g} \mathrm{L}^{-1}, 10 \mu \mathrm{g} \mathrm{L}^{-1}\right)$ and conducted according to Nödler et al. (2010) by using Oasis HLB cartridges $(6 \mathrm{~mL}, 500$ mg; Waters, Eschborn, Germany). Prior to extraction, samples were spiked with $250 \mathrm{ng}$ of the 
internal standard metoprolol- $D_{7}$. Samples with higher initial concentrations of metoprolol were diluted into the operating range of the linear calibration curve (2.5$1,000 \mu \mathrm{g} \mathrm{L}^{-1}$ ) and spiked with the same amount of internal standard. The quantification of metoprolol and metoprolol acid was performed by HPLC-ESI-MS/MS as described in Barbieri et al. (2012). Before analysis, all samples, sample extracts (from SPE), and standard solutions were centrifuged at $1500 \mathrm{rpm}$ (Christ RVC 2-18, Fisher Scientific, Schwerte, Germany) for $30 \mathrm{~min}$ at room temperature. Nine concentration levels $\left(2.5-1,000 \mu \mathrm{g} \mathrm{L}^{-1}\right)$ were used for the calibration and the correlation coefficients exceeded 0.99 .

\subsubsection{Analysis of inorganic cations}

The determination of inorganic cations $\left(\mathrm{Na}^{+}, \mathrm{K}^{+}, \mathrm{Mg}^{2+}, \mathrm{Ca}^{2+}\right)$ was conducted by using a DX-500 Ion Chromatography System with conductometric detection and electrochemical suppression (Dionex, Sunnyvale, USA). This isocratic system runs with $20 \mathrm{mM}$ methanesulfonic acid as the eluent with a flow rate of $0.45 \mathrm{~mL} \mathrm{~min}^{-1}$ at a temperature of $44^{\circ} \mathrm{C}$. Separation was achieved by using an lonPac CS12 column system (200 $\times 3 \mathrm{~mm}, 5 \mu \mathrm{m}$; Dionex).

\subsection{Results and discussion}

\subsubsection{Role of organic matter}

The organic carbon measurements confirmed the complete removal of organic matter from the sediment below the analytical detection limit of TOC $=100 \mu \mathrm{g} \mathrm{g}^{-1}$. The comparison of sorption between TOC-free and untreated sediment allows investigating the contribution of organic matter on the sorption of the cationic metoprolol species.

The sorbed amount of metoprolol on the sediment was $571.7 \pm 34.5 \mu \mathrm{g} \mathrm{kg}^{-1}(95 \%$ confidence intervals) before and $546.1 \pm 11.5 \mu \mathrm{g} \mathrm{kg}^{-1}$ after $\mathrm{H}_{2} \mathrm{O}_{2}$ treatment. Thus, no significant difference was detected. As a consequence, sorption onto organic carbon (partitioning, complexation and sorption on sites with variable charges) can be neglected for this sediment and coulomb forces between the cation and the 
negatively charged surfaces control the sorption of metoprolol at $\mathrm{pH}=7$. Furthermore, the data confirm the results from Schaffer et al. (2012b) who highlighted the dominating role of cation exchange and the minor influence of organic matter for the sorption of atenolol and metoprolol on aquifer sediments low in TOC fraction relative to other exchange sites (e.g., clays).

\subsubsection{Influence of competing inorganic ions}

All sorption data fitted well with the Freundlich sorption model (Fig. 4.1, Table 4.2) and were evaluated applying a linear least-square regression of the linearized Freundlich equation (for more details see Appendix C2, Figs. C2-C8):

$\log q_{e q}=\log K_{F r}+n \cdot \log c_{e q}$

where $K_{F r}$ is the Freundlich coefficient and the Freundlich exponent $n$ describing the isotherm's non-linearity. For low concentrations in the environmentally relevant range the data may be approximated with a linear isotherm. However, in order to describe all investigated concentrations with one equation the Freundlich model was used. This model is commonly employed for the description of sorption (including ion exchange) on heterogeneous sorbents with different sorption sites, such as the used bulk sediment (Sposito, 1980; Schwarzenbach et al., 2003; Droge and Goss, 2012). Freundlich behavior for organic cation sorption onto geosorbents was also observed by Baker und Luh (1971), Zachara et al. (1986), Brownawell et al. (1990), Nicholls and Evans (1991), Kulshrestha et al. (2004), Sassman and Lee (2005), Burgos and Pisutpaisal (2006), ter Laak et al. (2006), Bäuerlein et al. (2012), Droge and Goss (2012). The obtained average of $n=0.9$ indicates that sorption of metoprolol to the aquifer material is slightly non-linear in the investigated concentration range. Very similar values for $n$ between all experiments allow the direct comparison of $K_{F r}$ for all isotherms (Table 4.2). Furthermore, identical binding mechanisms to the exchange sites under $\mathrm{Na}^{+}$and as well as under $\mathrm{Ca}^{2+}$ competition can be assumed due to the same isotherm non-linearity. Comparable $n$ were reported for the sorption of several organic cations onto organic matter (Pahokee peat) by Droge and Goss (2012). The values in their study ranged between $n=0.75$ and $n=0.96$. 
From the thermodynamic point of view, the use of activities instead of concentrations would be more appropriate (Trapp et al. 2010). Nevertheless, the comparison of the isotherms plotted against $c_{e q}$ with the isotherms plotted against the equilibrium activity of metoprolol $a_{e q}$ (using Davies activity coefficients) in solution revealed no significant difference for $\log K_{F r}$ and $n$ (Fig. 4.1, Table 4.2).
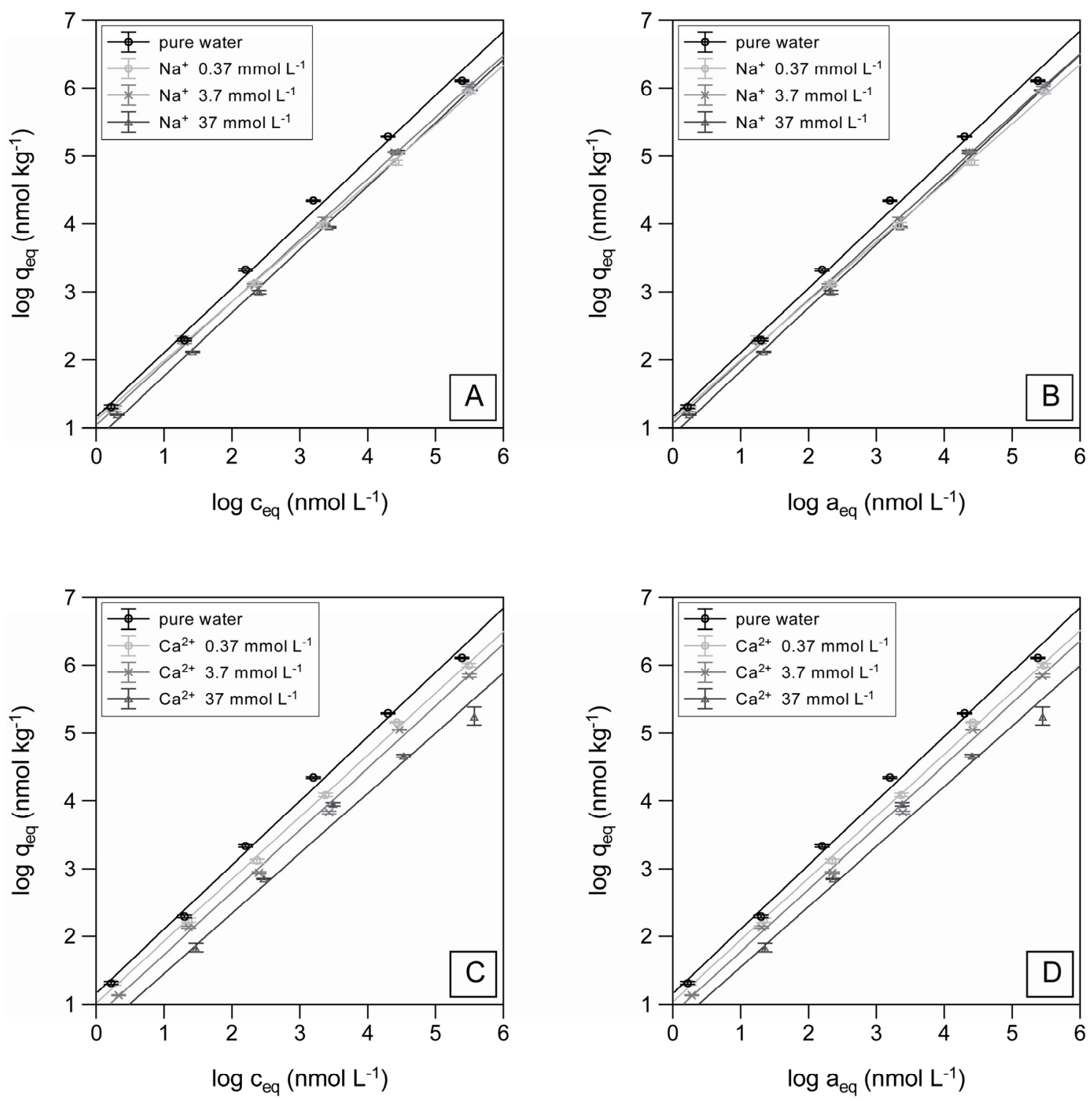

Fig. 4.1 A-B: Freundlich sorption isotherms of metoprolol on sandy aquifer sediment from water with various $\mathrm{Na}^{+}$concentrations or $\mathrm{Na}^{+}$activities at $\mathrm{pH}=7.0$; $\mathrm{C}-\mathrm{D}$ : Freundlich sorption isotherms of metoprolol on sandy aquifer sediment from water with various $\mathrm{Ca}^{2+}$ concentrations or $\mathrm{Ca}^{2+}$ activities at $\mathrm{pH}=7.0$. Data points represent the average of batch triplicates. Error bars show the range of measured minimum and maximum values. 
In general, decreasing sorption of metoprolol to the aquifer material with increasing concentrations of $\mathrm{Na}^{+}$and $\mathrm{Ca}^{2+}$ was observed compared to the reference isotherm using pure water. According to the cation exchange theory, the free inorganic cations in solution compete with metoprolol for the negatively charged surface sites. For equal molar concentrations of $\mathrm{Na}^{+}$and $\mathrm{Ca}^{2+}$, the sorbed amounts of metoprolol under $\mathrm{Ca}^{2+}$ competition are significantly smaller than for $\mathrm{Na}^{+}$. This confirms the expected behavior from the theory as $\mathrm{Ca}^{2+}$ cations should have a higher affinity to exchange sites than $\mathrm{Na}^{+}$due to their higher valence. Furthermore, the larger shifts (y-axis) of the $\mathrm{Ca}^{2+}$ isotherms than for the $\mathrm{Na}^{+}$isotherms at increasing concentrations also demonstrate the more efficient displacement of exchangeable cations from the exchanger with $\mathrm{Ca}^{2+}$ than with $\mathrm{Na}^{+}$(Fig. 4.1).

In order to compare and quantify the role of competing $\mathrm{Na}^{+}$and $\mathrm{Ca}^{2+}$ on the exchange equilibrium, the obtained sorption coefficients were correlated with the inorganic cation concentrations in solution (Fig. 4.2). Figure 4.2A shows log $K_{F r}$ as a function of the logarithmized concentration $\log c$ and Figure $4.2 \mathrm{~B}$ as a function of the logarithmized activity $\log a$. For both considered inorganic cations a linear correlation for the logarithmized variables was found. Similar dependences between electrolyte concentration and sorption coefficients were observed earlier by Figueroa et al. (2004) for the cationic species of oxytetracycline on clay, and for several organic cations on exchange polymers (Bäuerlein et al., 2012), and on organic matter (Droge and Goss, 2012).

As mentioned above, the influence of $\mathrm{Ca}^{2+}$ on the exchange equilibrium of metoprolol is stronger than for $\mathrm{Na}^{+}$. At equal molar concentrations of $\mathrm{Ca}^{2+}$ and $\mathrm{Na}^{+} \mathrm{K}_{\mathrm{Fr}}$ of metoprolol suffering $\mathrm{Ca}^{2+}$ competition is lower than for $\mathrm{Na}^{+}$competition. Figure 4.2 investigates how this difference is maintained with rising concentrations of $\mathrm{Na}^{+}$and $\mathrm{Ca}^{2+}$. Surprisingly, $\mathrm{Ca}^{2+}$ still shows almost twice the effect than $\mathrm{Na}^{+}$, although the classical ion exchange equation would suggest an inverted image (Droge and Goss, 2012). The comparison of the regression lines shows that the slopes differ by a factor of around two (1.82). Furthermore, the influence (slope) for $\mathrm{Ca}^{2+}$ is in the same order of magnitude $(-0.28$ vs. -0.23$)$ compared to the results reported by Schaffer et al. (2012b). There, the sorption of atenolol on a very similar sediment was investigated under varying $\mathrm{Ca}^{2+}$ concentrations $\left(1\right.$ to $\left.10 \mathrm{mmol} \mathrm{L}^{-1}\right)$ in a column experiment. 
The hypothetical point of intersection of the $\mathrm{Na}^{+}$and $\mathrm{Ca}^{2+}$ regression lines reflecting a reference point below which competition should have no further influence was calculated with $\log c=-1.27\left(c=0.054 \mathrm{mmol} \mathrm{L}^{-1}\right)$ and $\log K_{F r}=1.17\left(K_{F r}=14.85\right)$. This point corresponds very well with the measured $\log K_{F r}=1.2\left(K_{F r}=15.85\right)$ in pure water and thus without competition.
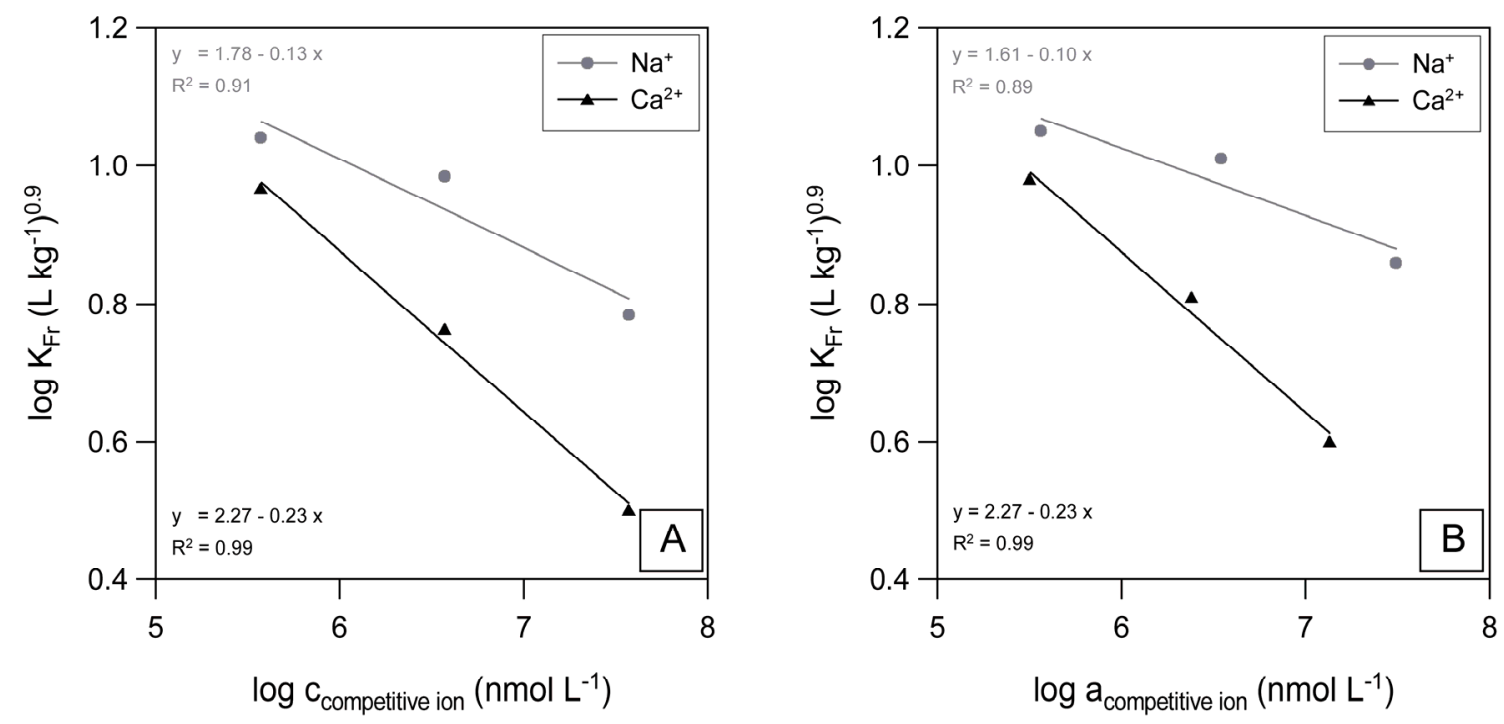

Fig. 4.2 A: Relation between the Freundlich coefficients $\log K_{F r}$ and the concentration of the competing ions $\mathrm{Na}^{+}$and $\mathrm{Ca}^{2+} ; \mathrm{B}$ : Relation between the Freundlich coefficients $\log \mathrm{K}_{\mathrm{Fr}}$ and the activity of the competing ions $\mathrm{Na}^{+}$and $\mathrm{Ca}^{2+}$.

Finally, the comparison between $\log K_{F r}$ expressed as a function of a (Fig. 4.2B) instead of a function of $c$ leads to very similar results. The dependencies are identical and only the slope ratio of 2.36 between $\mathrm{Ca}^{2+}$ and $\mathrm{Na}^{+}$differs slightly. Thus, the use of concentrations instead of activities for simplifying the isotherm evaluation is reasonable within the considered concentration range and allows a better comparability with literature data.

\subsection{Summary and conclusions}

Batch equilibrium sorption experiments with metoprolol as organic cation onto natural sediment were carried out under different competitive conditions with respect to the background concentrations of the inorganic cations $\mathrm{Na}^{+}$and $\mathrm{Ca}^{2+}$. All obtained isotherms could be characterized sufficiently by the application of the 
Freundlich sorption model in the investigated concentration range. Furthermore, the role of organic matter on organic cation sorption was tested. Due to the systematic and defined variation of $\mathrm{Na}^{+}$and $\mathrm{Ca}^{2+}$ concentrations and the constancy of all other parameters, the direct evaluation of competition between inorganic and organic cations was possible. Two logarithmic relationships were found in this systematic study. Eventually, the results are an important step for understanding and predicting the sorption of organic cations. On the basis of the results presented in this study, the following conclusions can be drawn:

- The investigations on the sediment's organic carbon demonstrate that for natural sediments low in organic carbon relative to other constituents potentially acting as cation exchangers (e.g., clays) the sorption of the cationic metoprolol species can be neglected.

- Competitive sorption isotherms generally show a decreasing sorption of metoprolol with increasing background concentrations of the inorganic cations $\mathrm{Na}^{+}$and $\mathrm{Ca}^{2+}$. Additionally, a decrease of $\log K_{\mathrm{Fr}}$ values with increasing concentrations of competing cations was found. These results confirm that cation exchange is the main mechanism for metoprolol sorption onto geosorbents low in organic carbon at $\mathrm{pH}<\mathrm{p} K_{a}-1$.

- Isotherms show that the influence of $\mathrm{Ca}^{2+}$ compared to $\mathrm{Na}^{+}$on the sorption of metoprolol is more pronounced with increasing concentrations.

- For all experiments a similar Freundlich coefficient of $n=0.9$ was found. This may be attributed to identical binding mechanisms and the sorption onto the same sorption sites.

- The evaluation of sorption data based on either activity or concentration leads to very similar results. Thus, the concentration commonly used to interpret isotherm data seems to be an adequate approximation. It certainly simplifies data evaluation within the investigated electrolyte concentration range and allows data comparison between different authors even when they have not stated the full water chemistry but evaluated isotherms based on concentrations. 
- Finally, this study showed a logarithmic correlation between the Freundlich coefficient $K_{F r}$ and the concentration/activity of the inorganic competing ions $\left(\mathrm{Na}^{+}\right.$and $\left.\mathrm{Ca}^{2+}\right)$. This enables the sorption behavior prediction for metoprolol on the investigated sediment at different competing concentrations.

\subsection{Acknowledgments}

This work partly pertains to a research project jointly funded by Energie BadenWürttemberg (EnBW, Karlsruhe) and by the German Ministry for Environment, Nature Conservation and Nuclear Safety (BMU, project key: 0325111B), with operational support from local Energy and Water Supply Plants (EWB). Further, we acknowledge the German Federal Ministry of Education and Research (promotional reference No. 02WRS1277A, AGRO: “Risikomanagement von Spurenstoffen und Krankheitserregern in ländlichen Karsteinzugsgebieten") for the financial support.

\subsection{References}

Baker, R.A., Luh, M.-D., 1971. Pyridine sorption from aqueous solution by montmorillonite and kaolinite. Water Research 5 (10), 839-848.

Barbieri, M., Licha, T., Nödler, K., Carrera, J., Ayora, C., Sanchez-Vila, X., 2012. Fate of beta-blockers in aquifer material under nitrate reducing conditions: Batch experiments. Chemosphere 89 (11), $1272-1277$.

Bäuerlein, P.S., ter Laak, T.L., Hofman-Caris, R.C.H.M., de Voogt, P., Droge, S.T.J., 2012. Removal of charged micropollutants from water by ion-exchange polymers - Effects of competing electrolytes. Water Research 46 (16), 5009-5018.

Bi, E., Schmidt, T.C., Haderlein, S.B., 2006. Sorption of heterocyclic organic compounds to reference soils: column studies for process identification. Environmental Science and Technology 40 (19), 5962-5970.

Bilgiç, C., 2005. Investigation of the factors affecting organic cation adsorption on some silicate minerals. Journal of Colloid and Interface Science 281 (1), 33-38.

Brownawell, B.J., Chen, H., Collier, J.M., Westall, J.C., 1990. Adsorption of organic cations to natural materials. Environmental Science and Technology 24 (8), 1234-1241.

Burgos, W.D., Pisutpaisal, N., 2006. Sorption of naphthoic acids and quinoline compounds to estuarine sediment. Journal of Contaminant Hydrology 84 (3-4), 107-126.

Calvet, R., 1989. Adsorption of organic chemicals in soils. Environmental Health Perspectives 83, 145177. 
Caron, G., Steyaert, G., Pagliara, A., Reymond, F., Crivori, P., Gaillard, P., Carrupt, P.-A., Avdeef, A., Comer, J., Box, K.J., Girault, H.H., Testa, B., 1999. Structure-lipophilicity relationships of neutral and protonated $\beta$-blockers; Part I: Intra- and intermolecular effects in isotropic solvent systems. Helvetica Chimica Acta 82 (8), 1211-1222.

Daughton, C.G., Ternes, T.A., 1999. Pharmaceuticals and personal care products in the environment: Agents of subtle change? Environmental Health Perspectives 107 (Suppl 6), 907-938.

Droge, S., Goss, K.-U., 2012. Effect of sodium and calcium cations on the ion-exchange affinity of organic cations for soil organic matter. Environmental Science and Technology 46 (11), 58945901.

Fábrega, J.R., Jafvert, C.T., Li, H., Lee, L.S., 1998. Modeling short-term soil-water distribution of aromatic amines. Environmental Science and Technology 32 (18), 2788-2794.

Fábrega, J.R., Jafvert, C.T., Li, H., Lee, L.S., 2001. Modeling competitive cation exchange of aromatic amines in water-saturated soils. Environmental Science and Technology 35 (13), 2727-2733.

Figueroa, R.A., Leonard, A., MacKay, A.A., 2004. Modeling tetracycline antibiotic sorption to clays. Environmental Science and Technology 38, 476-483.

Franco, A., Trapp, S., 2008. Estimation of the soil-water partition coefficient normalized to organic carbon for ionizable organic chemicals. Environmental Toxicology and Chemistry 27 (10), 19952004.

Franco, A., Fu, W., Trapp, S., 2009. Influence of soil pH on the sorption of ionisable chemicals: modelling advances. Environmental Toxicology and Chemistry 28 (3), 458-464.

Gao, J. P., Maguhn, J., Spitzauer, P., Kettrup, A., 1998. Sorption of pesticides in the sediment of the Teufelsweiher pond (Southern Germany). I: Equilibrium assessments, effect of organic carbon content and pH. Water Research 32 (5), 1662-1672.

Kah, M., Brown, C.D., 2007. Prediction of the adsorption of ionizable pesticides in soils. Journal of Agricultural and Food Chemistry 55 (6), 2312-2322.

Kibbey, T.C.G., Paruchuri, R., Sabatini, D.A., Chen, L., 2007. Adsorption of beta blockers to environmental surfaces. Environmental Science and Technology 41 (15), 5349-5356.

Kulshrestha, P., Giese, R.F., Aga, D.S., 2004. Investigating the molecular interactions of oxytetracycline in clay and organic matter: insights on factors affecting its mobility in soil. Environmental Science and Technology 38 (15), 4097-4105.

Laird, D.A., Fleming, P.D., 1999. Mechanisms for adsorption of organic bases on hydrated smectite surfaces. Environmental Toxicology and Chemistry 18 (8), 1668-1672.

Limousin, G., Gaudet, J.-P., Charlet, L., Szenknect, S., Barthès, V., Krimissa, M., 2007. Sorption isotherms: a review on physical bases, modeling and measurement. Applied Geochemistry 22 (2), 249-275.

Margulies, L., Rozen, H., Nir, S., 1988. Model for competitive adsorption of organic cations on clays. Clays and Clay Minerals 36 (3), 270-276.

Nicholls, P.H., Evans, A.A., 1991. Sorption of ionizable organic compounds by field soils. Part 2: cations, bases and zwitterions. Pesticide Science 33 (3), 331-345.

Nir, S., 1986. Specific and nonspecific cation adsorption to clays: solution concentrations and surface potentials. Soil Science Society of America Journal 50 (1), 52-57.

Nödler, K., Licha, T., Bester, K., Sauter, M., 2010. Development of a multi-residue analytical method, based on liquid chromatography-tandem mass spectrometry, for the simultaneous 
determination of 46 micro-contaminants in aqueous samples. Journal of Chromatography $A$ 1217 (42), 6511-6521.

Polubesova, T., Rytwo, G., Nir, S., Serban, C., Margulies, L., 1997. Adsorption of benzyltrimethylammonium and benzyltriethylammonium on montmorillonite; experimental studies and model calculations. Clays and Clay Minerals 45 (6), 834-841.

Rytwo, G., Nir, S., Margulies, L., 1995. Interactions of monovalent organic cations with montmorillonite: Adsorption studies and model calculations. Soil Science Society of America Journal 59 (2), 554564.

Salminen, R., Batista, M.J., Bidovec, M., Demetriades, A., De Vivo, B., De Vos, W., Duris, M., Gilucis, A., Gregorauskiene, V., Halamic, J., Heitzmann, P., Lima, A., Jordan, G., Klaver, G., Klein, P., Lis, J., Locutura, J., Marsina, K., Mazreku, A., O'Connor, P.J., Olsson, S.Å., Ottesen, R.T., Petersell, V., Plant, J.A., Reeder, S., Salpeteur, I., Sandström, H., Siewers, U., Steenfelt, A., Tarvainen, T., 2005. FOREGS Geochemical Atlas of Europe, Part 1: Background Information, Methodology and Maps, Geological Survey of Finland, Espoo.

Sassman, S.A., Lee, L.S., 2005. Sorption of three tetracyclines by several soils: Assessing the role of $\mathrm{pH}$ and cation exchange. Environmental Science and Technology 39 (19), 7452-7459.

Schaffer, M., Boxberger, N., Börnick, H., Licha, T., Worch, E., 2012a. Sorption influenced transport of ionizable pharmaceuticals onto a natural sandy aquifer sediment at different $\mathrm{pH}$. Chemosphere 87 (5), 513-520.

Schaffer, M., Börnick, H., Nödler, K., Licha, T., Worch, E., 2012b. Role of cation exchange processes on the sorption influenced transport of cationic $\beta$-blockers in aquifer sediments. Water Research 46 (17), 5472-5482.

Scheffer, F., Schachtschabel, P., 2010. Lehrbuch der Bodenkunde, $16^{\text {th }}$ ed. Spektrum Akademischer Verlag, Heidelberg.

Schwarzenbach, R.P., Gschwend, P.M., Imboden, D.M., 2003. Environmental organic chemistry, $2^{\text {nd }}$ ed. John Wiley \& Sons, Hoboken.

Schwarzenbach, R.P., Escher, B.I., Fenner, K., Hofstetter, T.B., Johnson, C.A., von Gunten, U., Wehrli, B., 2006. The challenge of micropollutants in aquatic systems. Science 313 (5790), 1072-1077.

Sposito, G., 1980. Derivation of the Freundlich equation for ion exchange reactions in soils. Soil Science Society of America Journal 44 (3), 652-654.

ter Laak, T.L., Gebbink, W.A., Tolls, J., 2006. The effect of pH and ionic strength on the sorption of sulfachloropyridazine, tylosin, and oxytetracycline to soil. Environmental Toxicology and Chemistry 25 (4), 904-911.

Trapp, S., Franco, A., Mackay, D., 2010. Activity-based concept for transport and partitioning of ionizing organics. Environmental Science and Technology 44 (16), 6123-6129.

Tolls, J., 2001. Sorption of veterinary pharmaceuticals in soils: a review. Environmental Science and Technology 35 (17), 3397-3406.

Weber, J.B., Wilkerson, G.G., Reinhardt, C.F., 2004. Calculating pesticide sorption coefficients $\left(K_{d}\right)$ using selected soil properties. Chemosphere 55 (2), 157-166.

Zachara, J.M., Ainsworth, C.C., Felice, L.J., Resch, C.T., 1986. Quinoline sorption to subsurface materials: role of $\mathrm{pH}$ and retention of the organic cation. Environmental Science and Technology 20 (6), 620-627. 


\section{Chapter 5}

\section{A new generation of tracers for the characterization of interfacial areas during supercritical carbon dioxide injections into deep saline aquifers: Kinetic interface- sensitive tracers (KIS tracer)}

Mario Schaffer*, Friedrich Maier, Tobias Licha, Martin Sauter

Citation:

Schaffer, M., Maier, F., Licha, T., Sauter, M., 2013. A new generation of tracers for the characterization of interfacial areas during supercritical carbon dioxide injections into deep saline aquifers: Kinetic interface-sensitive tracers (KIS tracer). International Journal of Greenhouse Gas Control 14, 200-208. 


\section{Abstract}

The storage of supercritical carbon dioxide in deep saline aquifers requires new techniques to assess plume spreading, storage efficiencies and operational strategies after and during injections. In this work, a new class of reactive tracers (KIS tracers) planned to be used for the characterization of interfacial areas between supercritical $\mathrm{CO}_{2}$ and formation brine is presented. The implementation of a time-dependent hydrolysis reaction at the interface enables to investigate the development of the $\mathrm{CO}_{2} /$ brine interface. Besides the basic concept for these novel tracers and the methodology for a suitable target molecular design, the desired tracer properties as well as the exemplary synthesis of first promising compounds are presented here. Additionally, the first experimental results of an analog study in a static two-phase batch system are shown and evaluated with a newly developed macroscopic model. Subsequently, the numerical forward modeling of different functions for the interfacial area change is described. The first results are promising and show the potential for new applications of KIS tracers after further research.

\section{Graphical abstract}

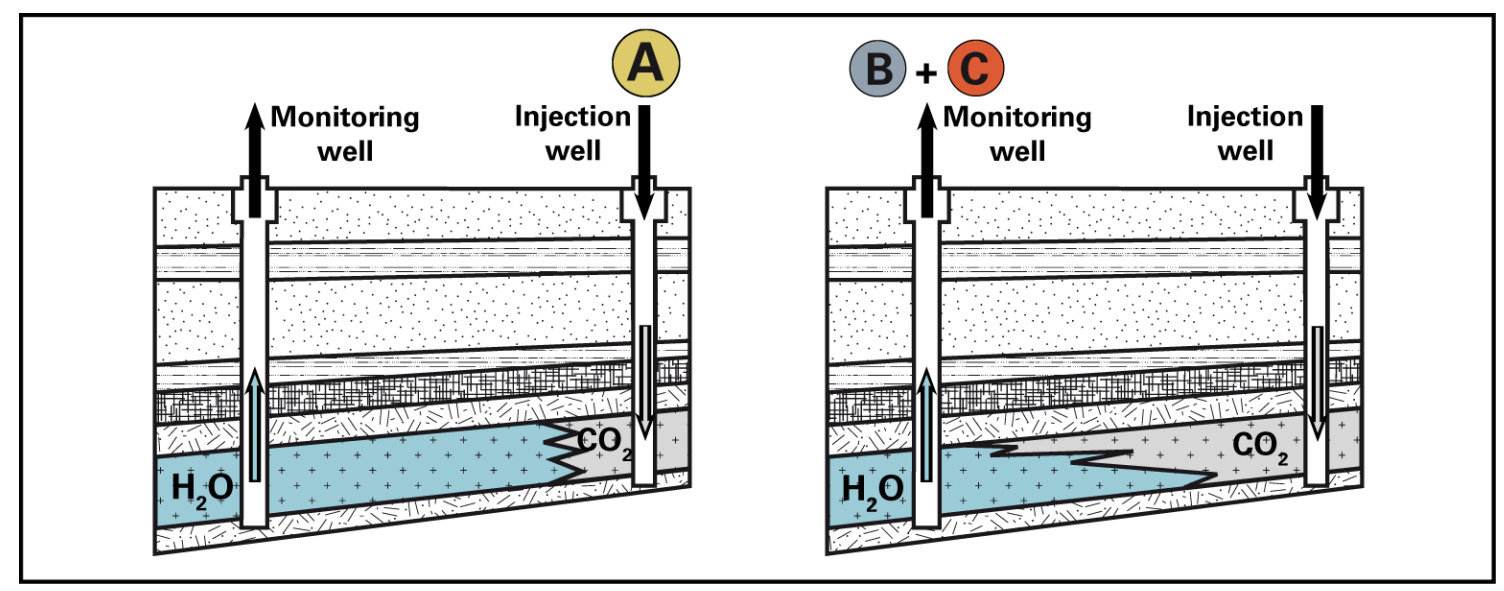




\section{Nomenclature}

c

$c_{0}$

$c_{a}$

$c_{i}$

$C_{i, \max }$

$k_{1}$

$k_{a}$

$m$

$p$

$p_{c}$

$\mathrm{pH}$

$\mathrm{p} K_{a}$

9

$\mathrm{scCO}_{2}$

$t$

A

$A_{\text {eff }}$

$A_{s c \mathrm{CO} 2}$

$B_{\mathrm{H} 2 \mathrm{O}}$

$\mathrm{CH}_{\mathrm{H} 2 \mathrm{O}}$

$D$

$D_{\mathrm{H} 2 \mathrm{O}}$

$D_{s c \mathrm{CO} 2}$

Dow

$E_{T}(30)$

$K_{L}$

Kow

NAPL

$T$

$T_{c}$

V

$\lambda$

concentration of reaction product in water phase

initial concentration of reaction product in water phase

tracer concentration in $\mathrm{scCO}_{2}$

tracer concentration at interface

tracer concentration at saturated interface

hydrolysis reaction rate constant in water (one-phase system)

effective hydrolysis reaction rate constant (two-phase system)

slope of a line

pressure

pressure at critical point

$\mathrm{pH}$ value

logarithmic acid dissociation constant

specific mass flux across interface

supercritical carbon dioxide

time

interfacial area size

effective interfacial area

reactive Tracer in $\mathrm{scCO}_{2}$ phase (reactant)

reaction product 1 in water phase

reaction product 2 in water phase

diffusion coefficient

diffusion coefficient in water

diffusion coefficient in $\mathrm{scCO}_{2}$

$\mathrm{pH}$-dependent $n$-octanol/water distribution coefficient

empirical solvent polarity indicator (based on solvatochromism)

Langmuir sorption coefficient

n-octanol/water distribution coefficient

non-aqueous phase liquid

temperature

temperature at critical point

volume of water phase

fluorescence: excitation wavelength $\rightarrow$ emission wavelength 


\subsection{Introduction}

The storage of $\mathrm{CO}_{2}$ into geological formations, such as unmineable coal beds, depleted oil or gas reservoirs, sedimentary basins and deep saline aquifers is recently one of the most promising technologies to mitigate anthropogenic greenhouse gas emissions into the earth's atmosphere (Lackner, 2003; Bachu and Adams, 2003; IPCC, $2005,2007)$. Deep saline aquifers are considered as the most potential sequestration sites of $\mathrm{CO}_{2}$ due to their large storage capacities and wide presence compared with other geological sequestration alternatives (Lackner, 2003; IPCC, 2005). The global storage capacity of these aquifers is estimated to be in the order of up to 10 teratons (IEA, 2001; Bachu and Adams, 2003).

When $\mathrm{CO}_{2}$ is injected as supercritical fluid $\left(\mathrm{scCO}_{2}\right)$ above its critical point $\left(p_{c}=7.39 \mathrm{MPa}, T_{c}=31.1^{\circ} \mathrm{C}\right)$ it has a lower density than the formation brine. Therefore, it is buoyant with respect to the brine and flows unevenly upwards until it reaches the top of the aquifer, usually represented by overlying and sealing caprocks. At this point the $\mathrm{CO}_{2}$ is able to continue the migration only in lateral direction. Here, four trapping mechanisms play a major role (IPCC, 2005): (1) structural and stratigraphic trapping: hindrance of vertical $\mathrm{CO}_{2}$ migration by impermeable caprock (static trapping) or very slow $\mathrm{CO}_{2}$ migration over long distances in open systems (hydrodynamic trapping); (2) capillary or residual trapping: retention of $\mathrm{CO}_{2}$ by capillary forces as immobile phase in the pore space, disconnection from initial plume at the edges; (3) solubility trapping: dissolution of $\mathrm{CO}_{2}$ in brine, decreasing solubility with increasing temperature and salinity of brine $\left(20-60 \mathrm{~g} \mathrm{~L}^{-1}\right)$; (4) geochemical trapping: reaction of dissolved $\mathrm{CO}_{2}$ in reservoir leads to formation of $\mathrm{HCO}^{3-} / \mathrm{CO}_{3}{ }^{2-}$ species (ionic trapping) or precipitation of carbonate minerals at rock surfaces (mineral trapping) at higher $\mathrm{pH}$.

Due to the different time scales $\left(\mathrm{t}_{(1)}=\mathrm{t}_{(2)}<\mathrm{t}_{(3)}<<\mathrm{t}_{(4)}\right)$ dissolution and mineral trapping processes can be neglected during and shortly after the injection (IPCC, 2005; Juanes et al., 2007; Ide et al., 2007). Therefore, several authors assume sharp interfaces for the existing three-phase system $\mathrm{scCO}_{2} /$ brine/rock in their modeling approaches (Juanes et al., 2007; MacMinn and Juanes, 2009; Dentz and Tartakovsky, 2009). This approximation appears to be plausible from the physicochemical point of view, since as a result of the low solubility between the phases a very high concentration 
gradient exists between them. More concisely, a several angstroms thick interphase is formed due to the diffusion of $\mathrm{scCO}_{2}$ into the brine phase (Tewes and Boury, 2005).

To assess the fate of $\mathrm{CO}_{2}$ during and after injection into these aquifers, an understanding of spreading, mixing and plume migration is fundamental. Particularly, knowledge on the size, the amount, and the shape of the injected $\mathrm{CO}_{2}$ plume is important to provide more information on the trapping effectiveness in the formation.

Dissolution of $\mathrm{scCO}_{2}$ into the brine is limited by the interfacial area. Thus, numerous subsequent chemical processes (e.g., mineral dissolution, precipitation) are also directly affected. Therefore, the extent of the interfacial area between injected $\mathrm{scCO}_{2}$ and brine is of great interest. The larger the interface, the larger is the reacted or dissolved mass. In most cases, it is desired to maximize this area to increase the storage effectiveness in terms of long-term trapping. During injections the interfacial area increases with time due to mixing, spreading and dispersive processes (Dentz and Carrera, 2005; Dentz and Tartakovsky, 2009). Therefore, novel tracers, which are able to describe and to characterize the spatial and temporal development of the plume and its interface in the reservoir, are required.

Up to now, such time-dependent tracers for reservoir studies are not available. Current studies are limited to equilibrium tracers. On the one hand, volume-sensitive partitioning tracers are used to quantify the amount or the saturation of immiscible hydrophobic phases (e.g., NAPLs or $\mathrm{scCO}_{2}$ ) in porous multiphase systems under equilibrium conditions. Frequently used compounds are (Noordman et al., 2000): alcohols (Dwarakanath and Pope, 1998), gases (e.g., SF 6 and Kr; Vulava et al., 2002), fluorinated hydrocarbons (McCallum et al., 2005; Wells et al., 2007) and naturally occurring isotopes (e.g., ${ }^{222} \mathrm{Rn}$; Hunkeler et al., 1997). On the other hand, so-called "interfacial tracers" exist (Saripalli et al., 1998; Setarge et al., 1999; Annable et al., 1998). Anionic surfactants, such as linear alkylbenzenesulfonates (Saripalli et al., 1998; Kim et al., 1999), which adsorb exclusively on the interface between the water and the non-aqueous phase are applied. Hence, these tracers are interface-sensitive. But similarly to conventional partitioning tracers, a thermodynamic equilibrium between water and liquid/liquid-interface is assumed. Therefore, the application is only useful 
in static time-independent systems. Furthermore, these tracers are dissolved in the water phase and cannot be injected together with the $\mathrm{scCO}_{2}$ phase.

The work presented provides first insight into the development of novel reactive tracers, termed as kinetic interface-sensitive tracers (KIS tracer). These tracers have the potential to overcome above-mentioned deficits by describing the plume and interface development with time. This is obtained by the implementation of an intended and well studied hydrolysis reaction of the tracer molecule, which allows an irreversible chemical reaction at the $\mathrm{SCCO}_{2} /$ water interface. Due to the reaction kinetics controlling the phase transfer a time-dependent component is integrated. In $\mathrm{CO}_{2}$ sequestration reservoirs, the tracers may help to provide additional information on the following issues:

- $\quad$ Effect of pressure stimulation on mixing

- $\quad$ Plume spreading, characterization of interfacial area and area change

- Identification of fingering effects

- Estimation of residual $\mathrm{scCO}_{2}$ saturation

- $\quad$ Assessment of storage capacity and effectiveness

- Optimization of operational strategies, management of injection wells

\subsection{Theory-conceptual model}

\subsubsection{Application of KIS tracers during $\mathrm{CO}_{2}$ injections}

Before the $\mathrm{CO}_{2}$ injection, the KIS tracer $\left(A_{s c \mathrm{CO}_{2}}\right)$ is dissolved in supercritical or mixed with liquid $\mathrm{CO}_{2}$. Afterwards, the mixture is injected simultaneously through the injection well into the brine saturated aquifer. The tracer reacts at the brine/scCO interface to highly water soluble reaction products $B_{\mathrm{H} 2 \mathrm{O}}$ and $C_{\mathrm{H} 2 \mathrm{O}}$. Subsequently, these products are measured in the water phase over time (monitoring well). Due to the spreading of the $\mathrm{scCO}_{2}$ plume, the interfacial area increases with time (Fig. 5.1). The larger the interface (reaction surface) between both phases, the higher is the mass of the reaction products in the water phase. The high water solubility leads to negligible back-partitioning of the reaction products into the $\mathrm{sCCO}_{2}$ phase. Because of the implemented interface-sensitive hydrolysis reaction with known kinetic 
parameters, it is possible to establish a correlation between time, concentration in water phase, and interfacial area size for given reservoir conditions $(T, p, \mathrm{pH})$. For the field evaluation and interpretation of the time-dependent interface development, these correlations may be integrated as specific reaction terms into a flow and transport model of the reservoir.
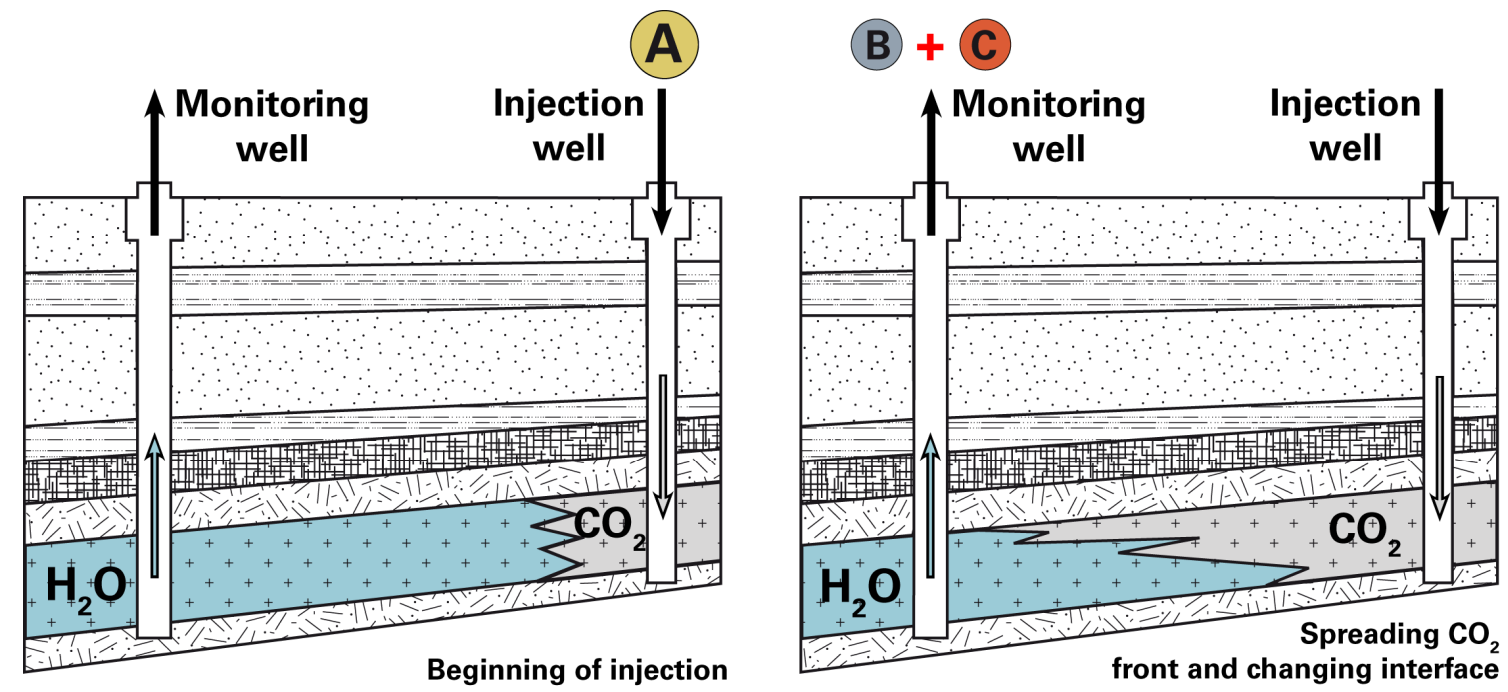

Fig. 5.1 Injection well: Injection and spreading of $\mathrm{SCCO}_{2}$ together with dissolved KIS tracer. Monitoring well: Measurement of KIS tracer reaction products in the brine.

\subsubsection{Underlying processes}

The basis of KIS tracers is an interface-sensitive hydrolysis reaction at the $\mathrm{scCO}_{2} / \mathrm{brine}$ interface. Here, the tracer substance $A_{\text {scCO2 }}$ reacts irreversibly into two reaction products $B_{\mathrm{H} 2 \mathrm{O}}$ and $\mathrm{C}_{\mathrm{H} 2 \mathrm{O}}$ in the presence of water $\left(\mathrm{H}_{2} \mathrm{O}\right)$ at the interface:

$$
A_{\mathrm{scCO}_{2}}+\mathrm{H}_{2} \mathrm{O} \stackrel{k_{1}}{\longrightarrow} B_{\mathrm{H}_{2} \mathrm{O}}+\mathrm{C}_{\mathrm{H}_{2} \mathrm{O}}
$$

The parameter $k_{1}$ depends on the physical and chemical conditions (e.g., $T$ and $\mathrm{pH}$ ) at the point of reaction and expresses the reaction rate constant of the hydrolysis reaction. Due to the presence of two mobile phases, several underlying physicochemical processes influencing the mass transfer from $\mathrm{scCO}_{2}$ to the brine phase and the reaction speed have to be taken into account as well (Fig. 5.2):

(1.) Dissolution of tracer in $\mathrm{scCO}_{2}$ and diffusion toward the interface. $A_{s c \mathrm{CO}}$ is dissolved and evenly distributed into the $\mathrm{sCCO}_{2}$ phase. This assumption is reasonable because 
the diffusion coefficients in $\mathrm{scCO}_{2}$ are one order of magnitude higher than in water (e.g., for phenol $T=35-55^{\circ} \mathrm{C}: D_{\text {scCO2 }}=1-3 \mathrm{E}-08 \mathrm{~m}^{2} \mathrm{~s}^{-1}$ (Lai and Tan, 1995) and $D_{\text {H2O }}=0.5-2 \mathrm{E}-09 \mathrm{~m}^{2} \mathrm{~s}^{-1}$ (Niesner and Heintz, 2000)). Thus, a fast transport without limitations (small transport resistance) to the interface is expected.

(2.) Adsorption at the interface. The surface active tracer molecules $A_{s c \mathrm{CO}}$ are assumed to accumulate at the interface (energy minimization) and saturate the interface after an initial time. This adsorption process normally follows a non-permeable monolayer isotherm type, such as a Langmuir or Frumkin isotherm (Benjamin, 1997). The absolute amount of adsorbed molecules depends linearly on the interfacial area. Due to an excess of dissolved $A_{s c \mathrm{CO}}$ in the supercritical phase, the interface is assumed to be permanently saturated. Therefore, the concentration of $A_{s c \mathrm{CO}}$ at the interface can be expected to remain constant.

(3.) Reaction at the interface. After adsorption at the interface, $A_{s c \mathrm{CO}}$ reacts in contact with water. The envisaged hydrolysis reaction (see Section 5.3.1) of an ester with water follows a (pseudo)-first order kinetics (Nottebohm et al., 2012). Due to the constant interface concentration, the reaction kinetics simplifies to (pseudo)-zero order kinetics with linear behavior. Thus, the reaction kinetics is the limiting step for phase transfer across the interface.

(4.) Phase transfer. The highly water soluble reactions products $B_{\mathrm{H} 2 \mathrm{O}}$ and $C_{\mathrm{H} 2 \mathrm{O}}$ are distributed into the brine due to diffusion and thus away from the interface. Therefore, the concentrations of $B_{\mathrm{H} 2 \mathrm{O}}$ and $C_{\mathrm{H} 2 \mathrm{O}}$ increase proportionally to the decrease of $A_{\text {scCO2 }}$ and can be measured in the water phase.

In addition to the interface-sensitive part of mass transfer across the interface, partitioning between both phases also has to be taken into account. Despite the low polarity and water solubility of $A_{s c \mathrm{CO}}$ small amounts of $A_{s c \mathrm{CO}}$ may partition into the brine phase. The resulting reaction in the water phase follows first order kinetics and would lead to an exponential increase of $B_{\mathrm{H} 2 \mathrm{O}}$ and/or $C_{\mathrm{H} 2 \mathrm{O}}$ in the water phase. Hence, the superposition of interface reaction and partitioning results in a non-linear function. Vice versa, a low back-partitioning of the polar and highly water soluble reaction products $B_{\mathrm{H} 2 \mathrm{O}}$ and $\mathrm{C}_{\mathrm{H} 2 \mathrm{O}}$ into the $\mathrm{sCCO}_{2}$ phase may also occur. Because of the increasing complexity, it is desirable to be able to neglect or to minimize partitioning effects within the data evaluation. To estimate and compare the tendency for 
partitioning between both phases at reservoir conditions the $n$-octanol/water distribution coefficient $K_{\text {ow }}$ was used as a model parameter due to similar solvent hydrophobicities of $n$-octanol and $\mathrm{scCO}_{2}\left(\log K_{\text {ow }(s c C O 2)}=2.85\left(50{ }^{\circ} \mathrm{C}, 143\right.\right.$ bar; Nakaya et al., 2001), $\log K_{\text {ow(n-octanol })}=2.88\left(25^{\circ} \mathrm{C}, 1\right.$ bar; SciFinder, 2012). Furthermore, Timko et al. (2004) showed for non-acidic compounds, such as the KIS tracers, that the log Kow is correlated to the $\mathrm{scCO}_{2}$ /water partitioning behavior.

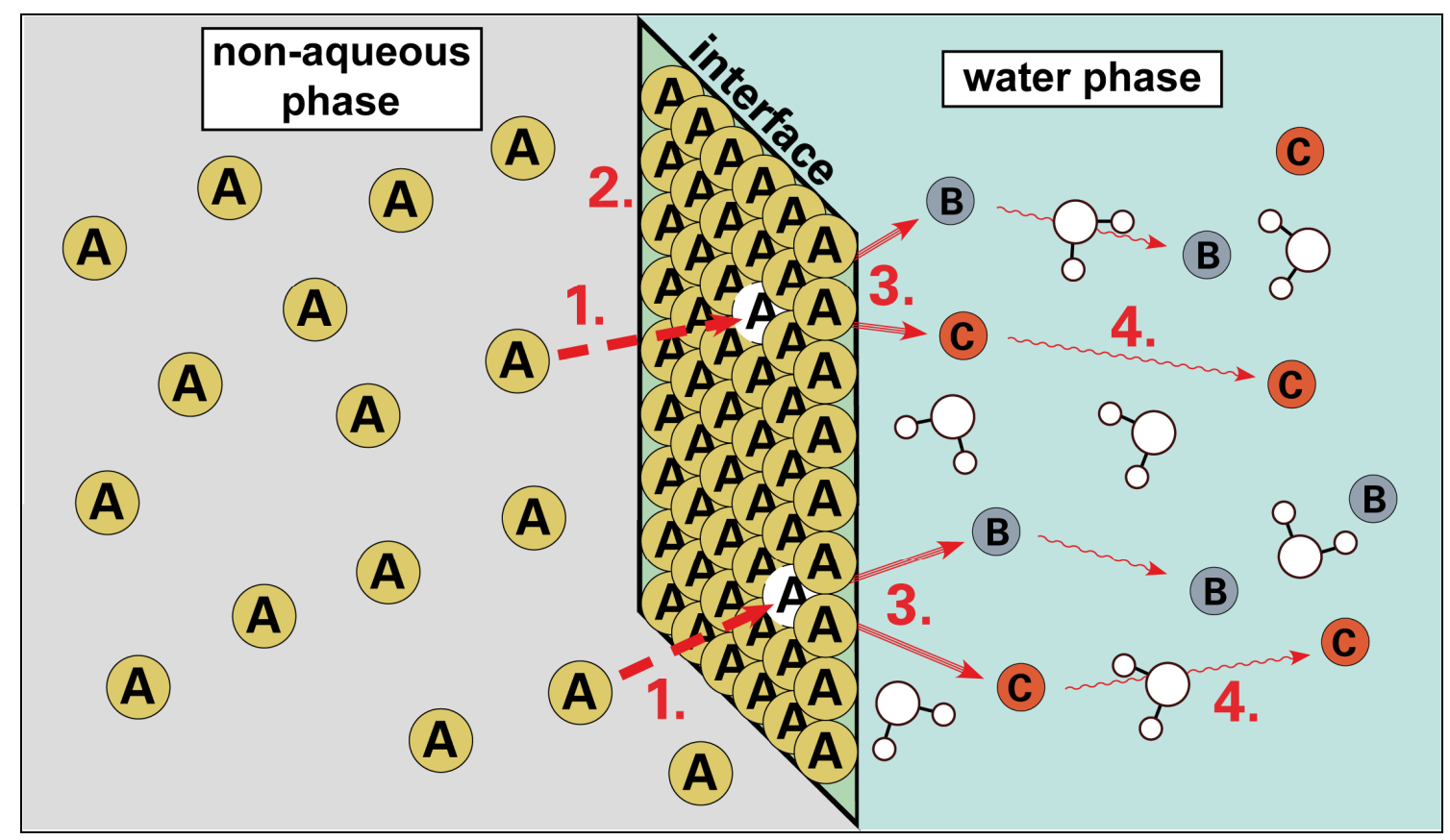

Fig. 5.2 Schematic representation of all involved processes at the $\mathrm{scCO}_{2} /$ water interface during KIS tracer application.

\subsection{KIS tracer design}

Molecular target design has been established as a methodology for producing molecules with desired properties or effects especially in the field of pharmaceutical, biochemical (Kuntz et al., 1994) and material sciences (Kang and Zhang, 2000). Due to the exploitation and combination of well studied structural elements and molecular properties (e.g., functional groups, substructures, and homologs) novel tailor-made compounds with controlled structures and properties are conceivable and can be synthesized for a magnitude of applications. During the molecular design quantitative structure-property relationships (QSPR) can be used as a tool for predicting molecule properties for the molecule selection/modification and to 
transfer their chemical behavior to unknown systems. In this work for instance, the relation of the molecule structure to the $\log K_{\text {ow }}$ value was used to estimate the water/ $\mathrm{sCCO}_{2}$ partitioning behavior of the synthesized esters (see Section 5.3.2).

Up to now, the molecular design of tracer substances for environmental studies has not yet been considered. This also applies to challenging tracer tests in $\mathrm{CO}_{2}$. Published tracer tests are limited to classical hydrogeological and thus commercially available tracer compounds. For example, Freifeld et al. (2005) and McCallum et al. (2005) applied several perfluorocarbons and noble gases $\left(\mathrm{Kr}, \mathrm{SF}_{6}\right)$ for the determination of $\mathrm{CO}_{2}$ travel times and the $\mathrm{CO}_{2}$ saturation within the formation. Identical compounds were used from Wells et al. (2007) and Hortle et al. (2011) to detect $\mathrm{CO}_{2}$ leakage. For the same purpose, Bachelor et al. (2008) proposed the spiking of injected $\mathrm{CO}_{2}$ with radioactive isotopes $\left({ }^{14} \mathrm{C}\right.$ and $\left.{ }^{222} \mathrm{Rn}\right)$.

Due to the limitations of conventional tracers, the general applicability of molecular design for geoscientific problems is shown here with KIS tracers as an example, especially developed for $\mathrm{CO}_{2}$ injections into deep saline aquifers.

\subsubsection{Tracer requirements}

A prior consideration of the KIS tracer requirements is essential for a successful target design of potential tracer substances. For describing interfacial areas between $\mathrm{scCO}_{2}$ and brine a defined reaction of the tracer with water is required. Splitting reactions with water as nucleophilic reagent belong to hydrolysis reactions as a subgroup of solvolysis. Hydrolysable substances are alcoholic and phenolic esters, acid chlorides, acid amides, and nitriles. Due to the comparably easy synthesis, different phenol esters were suggested and used in this work. The simplified hydrolysis reaction scheme is the following:

$$
\operatorname{Ester}\left(A_{\mathrm{scCO}_{2}}\right)+\mathrm{H}_{2} \mathrm{O} \stackrel{k_{1}}{\longrightarrow} \operatorname{Acid}\left(B_{\mathrm{H}_{2} \mathrm{O}}\right)+\operatorname{Alcohol} / \text { Phenol }\left(\mathrm{C}_{\mathrm{H}_{2} \mathrm{O}}\right)
$$

The esters are dissolved in $\mathrm{scCO}_{2}\left(A_{s c O_{2}}\right)$ and should show minimal partitioning into the polar water phase. Since $\mathrm{scCO}_{2}$ is an excellent solvent for non-polar compounds (Luque de Castro and Tena, 1996), the applied esters should also have non-polar substructures (e.g., linear $n$-alkyl chains, aromatic rings) with corresponding high $\log$ Kow values. 
In contrast, at least one of the hydrolysis reaction products has to be highly polar, water soluble and mobile in order to determine it in the water phase. For this purpose, the formed acids can be exploited $\left(B_{\mathrm{H}_{2} \mathrm{O}}\right)$. Their ability of deprotonation is very convenient, since anions are formed depending on $\mathrm{pH}$. Thus, especially the esters of strong organic acids with very low logarithmic acid dissociation constants $\mathrm{p} K_{a}$ seem to be the most promising compounds.

The requirements for the second reaction product $\left(C_{\mathrm{H} 2 \mathrm{O}}\right)$ are not so strict. The formed alcohols or phenols can be polar or even non-polar. If the product is medium polar with suitable distribution coefficients between the brine and $\mathrm{scCO}_{2}$ phase, it may even be used as additional partitioning tracer. However, the major task of the alcohol or phenol, respectively, is the adjustment of the KIS tracer properties during the molecular design. Beside the modification of the tracer polarity, the alcohols or phenols used for esterification have a large influence on the hydrolysis reaction rate constant $k_{1}$. This rate constant can be modified and adapted to reservoir conditions $(T, \mathrm{pH})$ as well as for experimental durations. Steric hindrance, mesomeric and inductive effects are only some reasons for different hydrolysis kinetics and can be considered during synthesis (Nottebohm et al., 2012).

Regarding the practicability for field applications, the concentrations of reaction products should preferably be measured with standard equipment in a high temporal resolution, a high selectivity, and with a low detection limit. Therefore, the synthesis of the target compounds was focused on compounds with fluorescence properties.

\subsubsection{Tracer design / synthesis}

As a consequence of the prior emphasized requirements, the esterification of naphthalenesulfonic acids is most promising. Because of $\mathrm{p} K_{a}<1$, these acids are deprotonated at even very low $\mathrm{pH}$ levels and therefore, very water soluble permanent anions are formed. Thus, no significant retardation can be expected for organic acids at $\mathrm{pH}>\mathrm{p} K_{a}+2$ (Schaffer et al., 2012). This also applies for naphthalenesulfonates, which are established conservative, non-sorptive tracers for geothermal applications, very stable at high temperatures and anaerobic conditions 
(Rose et al., 2001; Rose et al., 2002; Nottebohm et al., 2010). Furthermore, a backpartitioning of the anions into the $\mathrm{SCCO}_{2}$ phase can be excluded. For reservoirs, which are already contaminated with these compounds different constitutional isomers can be prepared to make the identification of the tracer unique. Furthermore, naphthalenesulfonates are highly fluorescent with a detection limit in the low $\mathrm{\mu g} \mathrm{L}^{-1}$ range. Pre-concentration and subsequent chromatographic separation lowers the detection limit by around one order of magnitude and enables the determination of different isomers even in highly saline matrices (Nottebohm and Licha, 2012).

Additional analytical problems might occur in sequestration reservoirs that contain significant residuals of hydrophobic aromatic compounds (e.g., depleted petroleum reservoirs), such as polycyclic aromatic hydrocarbons, since the dissolution of these substances in $\mathrm{scCO}_{2}$ can be expected during the injection. The leached compounds accumulate at the $\mathrm{scCO}_{2} /$ brine interface and might cause fluorescence interferences with the tracer reaction products. Thus, online measurements would be no longer possible and chromatographic systems have to be used again for sample clean-up and compound separation prior to fluorescence analysis.

If mononaphthalenesulfonic acids are applied, the esterification of the sulfo group leads to non-polar esters. In dependence of the deployed alcohol or phenol the ester properties can further be modified. For example, the esterification with linear aliphatic alcohols leads to non-polar but also non-fluorescent esters whereby the measurement of these compounds is more complicated. For this reason, aromatic alcohols (phenols, naphthols) can be used for the esterification of the naphthalenesulfonic acids (Fig. 5.3). The resulting fluorescent esters are hydrophobic $\left(\log K_{o w}>4\right)$.

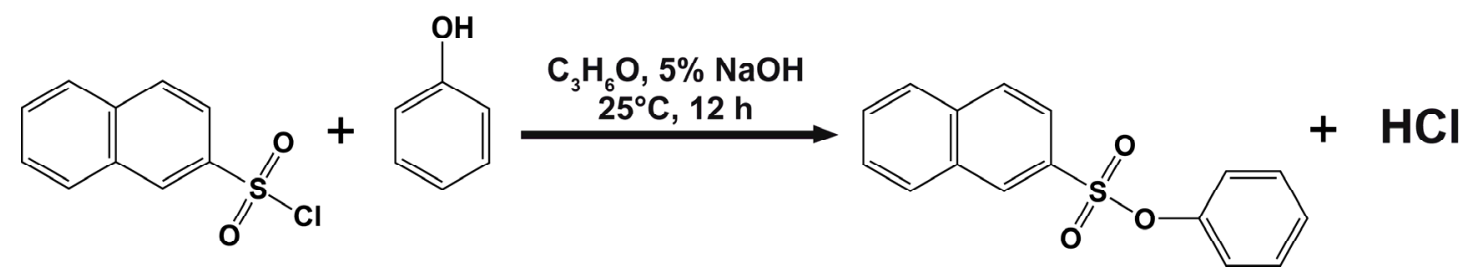

Fig. 5.3 Synthesis of phenyl naphthalene-2-sulfonate from naphthalene-2-sulfonyl chloride and phenol.

For the modification of the hydrophobic properties, different esters were synthesized by esterification of naphthalene-2-sulfonic acid (2-NSA) with different methyl 
substituted phenols. The more non-polar the employed phenol, the more non-polar is the resulting ester (Table 5.1). The esterification of chlorophenols therefore leads to more hydrophobic esters. However, the higher toxicity of these compounds should be also taken into account when used in field studies.

Table 5.1 Properties of synthesized KIS tracer compounds, phenyl acetate and their respective reaction products.

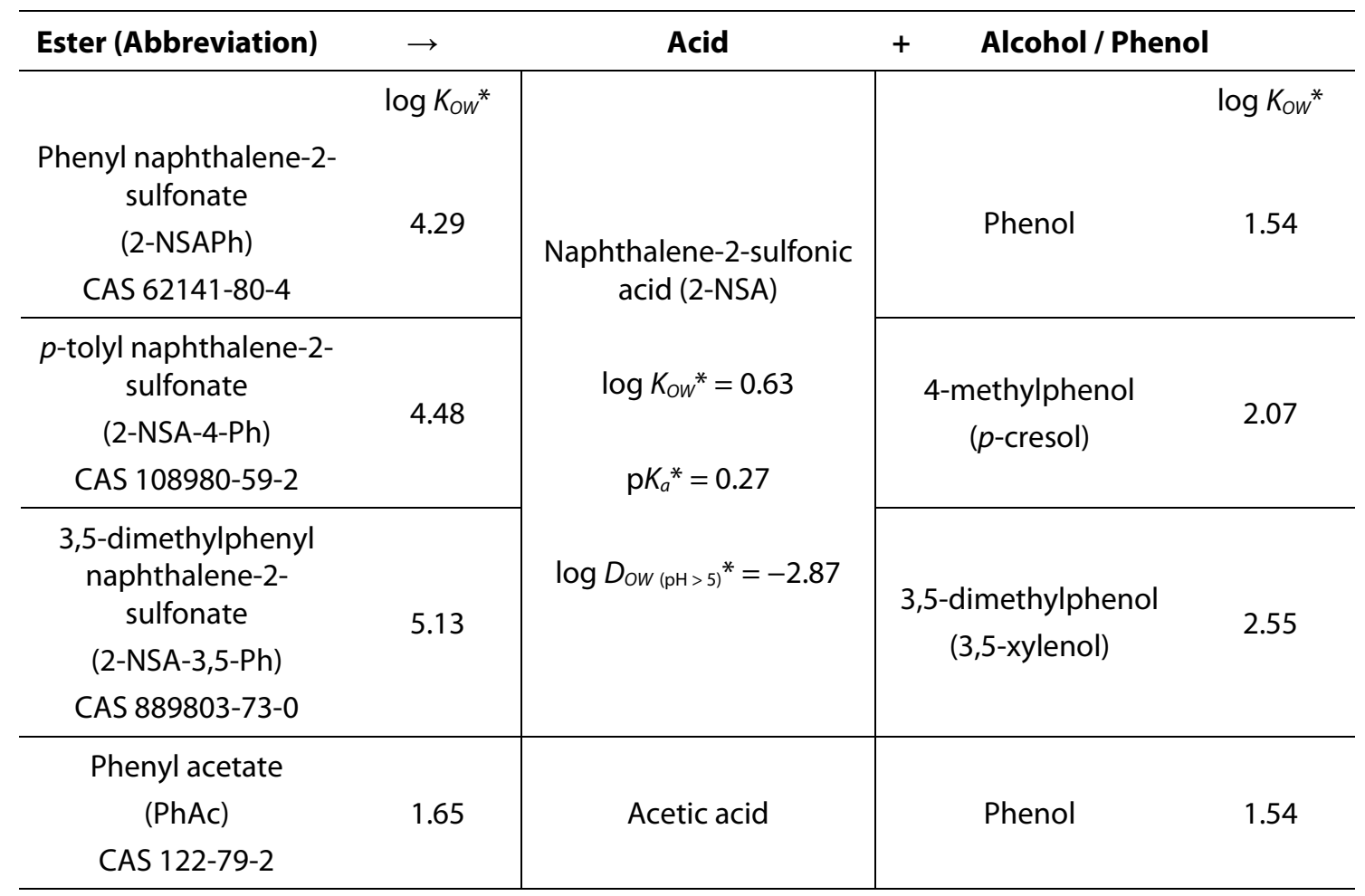

* SciFinder predicted values, calculated using Advanced Chemistry Development (ACD/Labs) Software (1994-2012).

The ester compounds were synthesized on the basis of naphthalene-2-sulfonyl chloride and the respective phenol under alkaline catalyzed conditions (Fig. 5.3) in a slightly modified procedure according to Vennila et al. (2008). Instead of $4 \mathrm{~mL}$ acetone $6 \mathrm{~mL}$ were used. The identity and purity of the esters were confirmed by ${ }^{1} \mathrm{H}$-Nuclear Magnetic Resonance ('H-NMR) spectroscopy. The purity was $>95 \%$. The hydrolysis reaction results in 2-NSA and the respective phenol homologues (Table 5.1). The reaction scheme and the fluorescent properties for the phenyl ester are shown in Figure 5.4. 


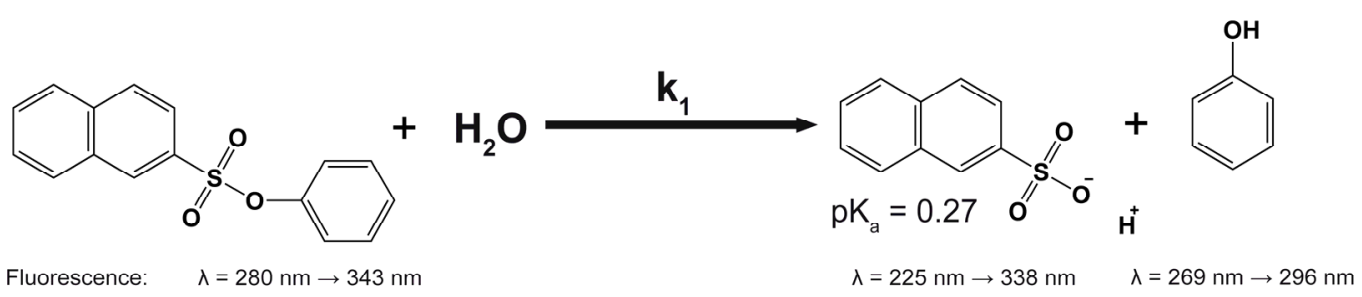

Fig. 5.4 Hydrolysis reaction of phenyl naphthalene-2-sulfonate with water and the fluorescent properties of the reagent and the reaction products.

\subsection{Experiments and modeling}

\subsubsection{Lab experiments}

\subsubsection{Analog approach}

Due to the necessity of high pressure cells to generate $\mathrm{scCO}_{2}$ for identifying and quantifying the expected involved processes the new tracers cannot be tested easily under reservoir conditions. Available pressure cells and $\mathrm{scCO}_{2}$ reactors are limited in size and in their setup variability. Furthermore, direct online measurements in the water phase cannot easily be employed and a sampling over time is not possible due to small cell volumes of only a few milliliters. Therefore, the use of pressure cells seems to be feasible only for a limited number of fundamental static batch experiments, such as the determination of solubilities, partitioning coefficients, further thermodynamic equilibrium parameters, and the inertness of the tracer in mixture with other compounds.

In order to overcome these limitations, to investigate and to interpret the tracer behavior in defined systems at larger scale, the $\mathrm{scCO}_{2}$ was replaced with another solvent. Particularly, organic solvents, which are immiscible with water, are expected to show a similar behavior and allow the process identification and separation at the interface on a larger scale without special equipment. For this purpose, different nonpolar solvents were selected and tested with respect to density, polarity, inertness, and solubility in water.

The alkane $n$-octane has proven most suitable as $\mathrm{scCO}_{2}$ analog. Table 5.2 compares some selected properties of $\mathrm{scCO}_{2}$ at reservoir conditions with $n$-octane at atmospheric conditions. Density of $\mathrm{ScCO}_{2}$ depends strongly on temperature. In contrast, the density of $n$-octane is almost constant but lies in the same range. The 
solubility of $\mathrm{scCO}_{2}$ in water under equilibrium conditions is higher than that of $n$ octane. Due to the timescale of $\mathrm{scCO}_{2}$ dissolution (non-equilibrium), the salinity of the brine, and the presence of further dissolved gases (e.g., methane) a significantly lower water solubility can be assumed (IPCC, 2005). Therefore, $n$-octane develops analogously to $\mathrm{scCO}_{2}$ a sharp interface to the water phase (see Section 5.1). For the comparison of the solvent polarity, which influences the tracer solubility and the partitioning between both phases, two different parameters were selected. On the one hand the log $K_{\text {ow }}$ value, which depends for $\mathrm{scCO}_{2}$ strongly on the pressure (Nakaya et al., 2001), and on the other hand the $E_{T}(30)$ value as empirical solvent polarity indicator (Reichardt, 1994) were used. As desired, these values lie for $n$-octane in the same range as for $\mathrm{ScCO}_{2}$. Additional advantages of $n$-octane are the low cost as well as the comparable low toxicity and vapor pressure. Therefore, the handling is uncomplicated and the compound can be used in larger amounts. All obtained values for kinetic rate constants, interface adsorption parameters, mass fluxes and mass transfer coefficients in the $n$-octane/water system can be transferred and adapted later to $\mathrm{scCO}_{2}$ based on calibrated process models.

Table 5.2 Comparison of physical and chemical properties between $\mathrm{scCO}_{2}$ with $n$-octane as analog compound.

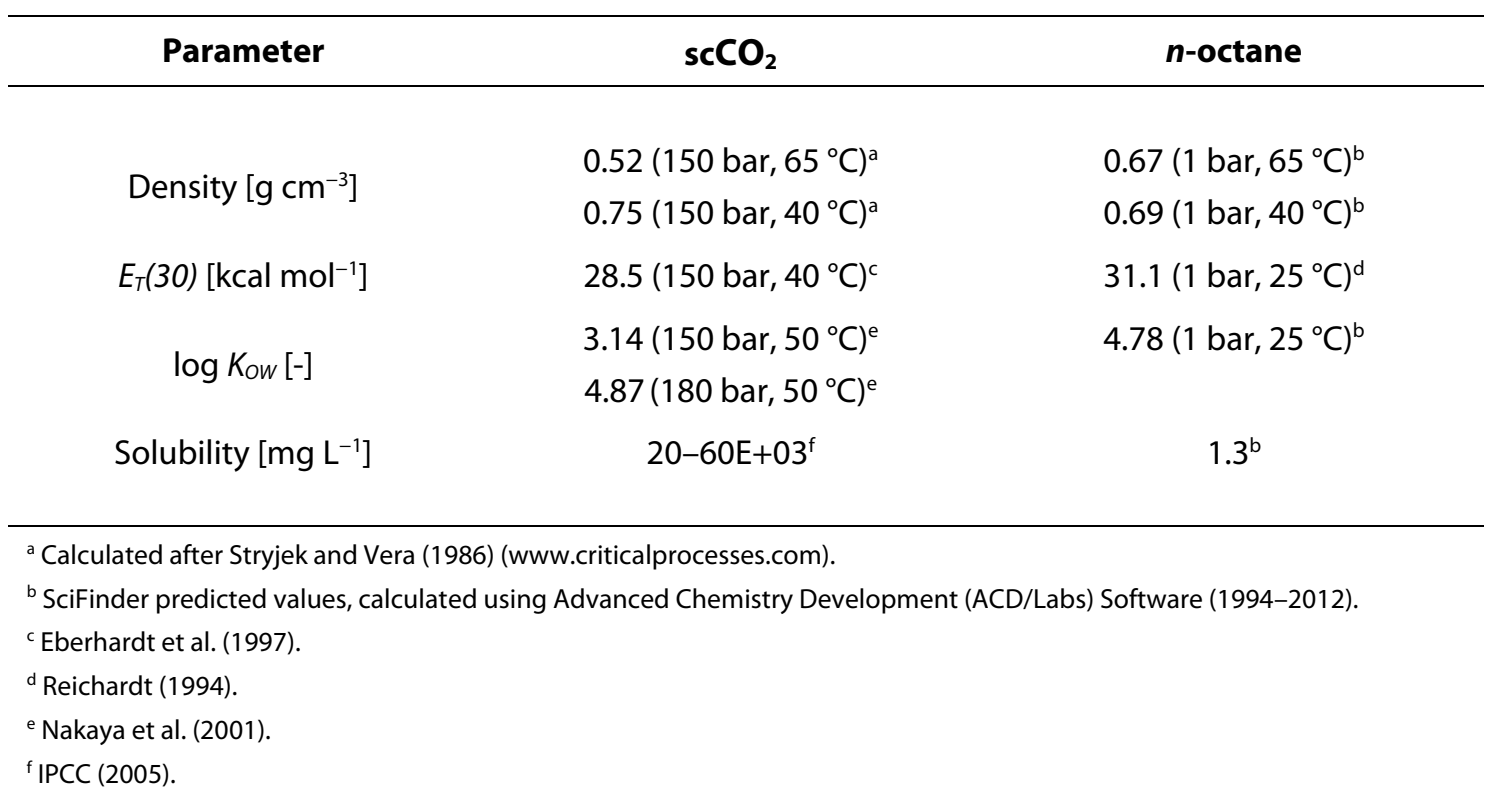

As an analog for the aqueous brine phase (buffer) solutions with different $\mathrm{pH}$ values can be used. This allows investigating the effects of different hydrolysis rate 
constants due to their direct relation to the $\mathrm{pH}$ value. The hydrolysis rate changes by about one order of magnitude per one $\mathrm{pH}$ unit increase (Nottebohm et al., 2012).

\subsubsection{Experimental setup}

For identifying, verifying, and separating the processes relevant for the developed novel KIS tracer application, major effort was made to simplify the experimental setup. The reason is that a profound knowledge of processes controlling the tracer interface sensitivity is fundamental to all consecutive investigations and the process modeling. Thus, an undisturbed (closed) system with fixed boundary conditions (constant interfacial area size, phase volume ratio, $T, \mathrm{pH}$ ) and high temporal resolution measurements are necessary.

For this reason, static batch experiments were conducted directly in sealed smallvolume fluorescence spectroscopy cuvettes $(V=4 \mathrm{~mL})$. This approach has the advantage that the concentrations of the reaction products and the possibly partitioned tracer can be measured in short time intervals without mass loss and without disturbing the closed system by sampling. Furthermore, it is possible to adjust certain temperatures and stirring rates in the cells to avoid unwanted temperature changes and diffusive effects.

After providing $3 \mathrm{~mL}$ deionized or buffered and degassed water in the cuvette, $1 \mathrm{~mL}$ of $n$-octane containing the dissolved (KIS) tracer (2-NSAPh or PhAc) was carefully added above the water phase. The interfacial area was constant $\left(A=1 \mathrm{~cm}^{2}\right)$. Consecutively, the concentration increase of the respective reaction products (2-NSA or phenol) in the water phase was recorded every minute for several thousand minutes by using fluorescence spectroscopy.

The resulting concentration curves of the measured compounds were used to determine the mass flux across the interface and to calibrate the numerical model that was developed in parallel to the experiments. 


\subsubsection{Numerical modeling}

To understand the relationship between interface development and resulting concentration curves of the reaction products in the water phase, a numerical modeling approach using the finite element method was implemented. The problem can be described as a heterogeneous reaction of the KIS tracer at the $\mathrm{scCO}_{2} /$ water interface. The $\mathrm{KIS}$ tracer in the $\mathrm{scCO}_{2}$ migrates to the interface and reacts here with the water in a hydrolysis reaction. In this study, a macroscopic model with averaged quantities was developed.

\subsubsection{Model description}

The comprehensive problem consists of the two different immiscible phases $\left(\mathrm{scCO}_{2}\right.$ or analog solvent and water) and of the allocation of the KIS tracer with its reaction products. Since the reaction at the interface is the limiting step in the mass transfer across the interface and due to high diffusion rates and the excess of tracer in the $\mathrm{ScCO}_{2}$ phase, the interface is permanently saturated. Here, a Langmuir (Langmuir, 1918 ) isotherm is assumed for the adsorption process onto the interface:

$C_{i}=\frac{K_{L} \cdot C_{i, \max } \cdot C_{a}}{1+K_{L} \cdot c_{a}}$

$K_{L}$ is the Langmuir sorption coefficient. For high tracer concentrations $C_{a}$ in the $\mathrm{scCO}_{2}$ phase the interface concentration $c_{i}$ is approximately equal to the maximum concentration of the saturated interface $c_{i, \max }$. The assumption includes that the hydrolysis at the interface and the migration of the reaction products into the water phase take place within one time step. It is additionally assumed that the reacted small fraction of tracer $\Delta c_{i}$ at the interface is instantaneously replaced from the $\mathrm{scCO}_{2}$ bulk due to large diffusion coefficients. Consequently, due to the interface limited transfer the KIS tracer decay in the non-aqueous phase follows the linear zero order reaction kinetics of the hydrolysis reaction. The effective reaction rate constant $k_{a}$ of the limiting step can be expressed as a specific constant mass flux $q$ of the reaction products into the water phase:

$$
q=k_{a}=\frac{\Delta c_{i}}{\Delta t}
$$


This allows the reduction of the numerical model to a single-phase problem. The model geometry follows the cuvette used in the lab experiment (see Section 5.4.1.2) with a base area $A=1 \mathrm{~cm}^{2}$. The height depends on the volume and therefore the filling level of water. The upper model boundary is equal to the interfacial area. The constant $q$ of tracer products into the water phase, which is represented by the model domain, is defined as boundary condition. All other boundaries are no-flow boundaries (Fig. 5.5).

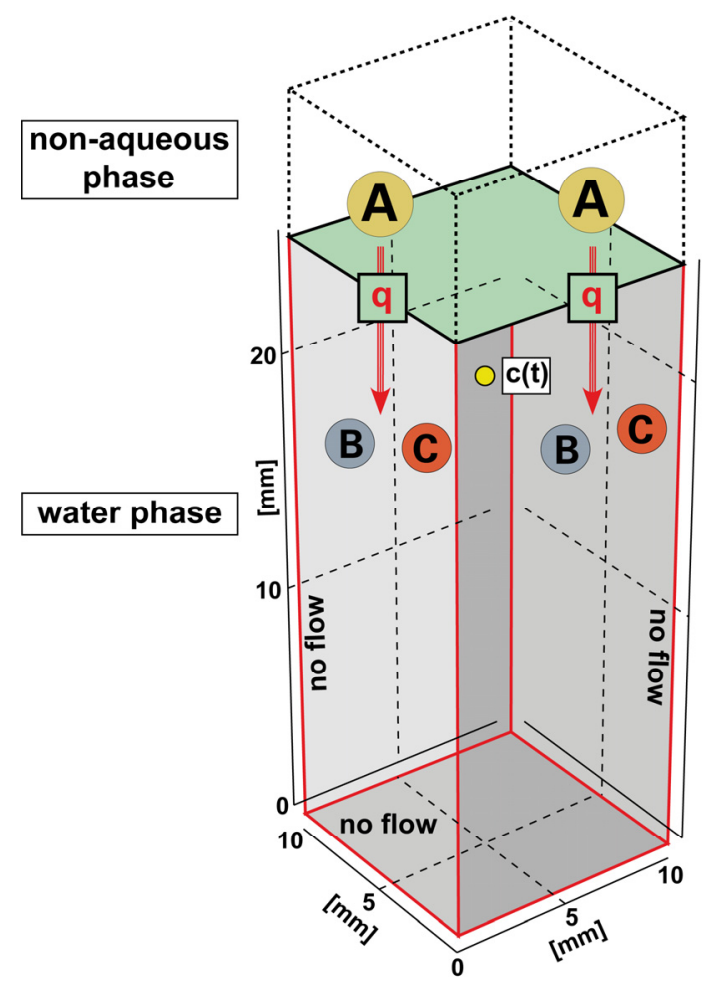

Fig. 5.5 Sketch of the numerical model domain: The yellow dot at $20 \mathrm{~mm}$ height represents the observation point where the fluorescence signal is measured. Red boundaries are no flow boundaries. On the upper green boundary the flux $q$ is defined, where the reaction products flow into the water.

For the ionic tracer reaction product 2-NSA no back-partitioning into the $\mathrm{scCO}_{2}$ phase is assumed. Hence, the concentration curve is only allowed to rise or to level at a constant value. The distribution of the product across the water volume is described through a diffusion process:

$$
\frac{\partial c}{\partial t}=-D \frac{\partial^{2} c}{\partial x^{2}}
$$

Therefore, a steady-state concentration increase establishes in the model region (observation point) for a given constant interfacial area size. 


\subsubsection{Relation between concentration curve and interfacial area size}

As stated above, the concentration of KIS tracer reaction product depends only on the interface size and time. The zero order kinetics of the hydrolysis reaction results for a constant interfacial area in a linear concentration curve $c(t)$ :

$$
c(t)=c_{0}+q \frac{A}{V} t
$$

Where $A$ is the interfacial area, $V$ the volume and $c_{0}$ the initial concentration in the water phase. From linear regression analysis the mass transfer rate $q$ can be determined with:

$$
q=m \frac{V}{A}
$$

Here, $m$ is the slope of the concentration curve. For the case of a time-dependent variable interfacial area $A(t)$ a decomposition ansatz is applied:

$$
A(t)=f_{A}(t) \cdot A_{\max }
$$

A dimensionless time-dependent function $f_{A}(t)$ is used to scale a constant maximum area $A_{\max }$. The function $f_{A}(t)$ must be equal to one when $A_{\max }$ establishes and has some additional properties:

$$
f_{A}(t) \in[01] \quad \text { and } \quad \exists \hat{t} \in\left[0 t_{\max }\right] \text { with } \quad f_{A}(\hat{t})=1
$$

The application of the ansatz in Eq. (5.8) in Eq. (5.6) leads to:

$$
\begin{aligned}
& \frac{d c}{d t}=\frac{A_{\max }}{V} q \cdot f_{A}(t) \quad \text { and } \\
& c(t)=c_{0}+\frac{A_{\max }}{V} q \cdot \int f_{A}(t) d t
\end{aligned}
$$

For the determination of $A_{\max }$ a case-by-case analysis of $c(t)$ has to be carried out:
(1) $\quad \exists \ddot{c}(\hat{t})=0 \quad \Rightarrow \quad f(\hat{t})=1 \quad$ if $\quad c(\hat{t})=\max \{\dot{c}(\hat{t})\}$
(2) $\quad \exists ! \ddot{c}(\hat{t})=0 \quad \Rightarrow \quad f(\hat{t})=1 \quad \wedge \quad A(\hat{t})=A_{\max }$
(3) $\neg \exists \ddot{c}(\hat{t})=0 \quad \Rightarrow \quad f\left(t_{\max }\right)=1 \quad \vee \quad f(0)=1 \quad$ with

$$
A(T)=A_{\max } \quad \vee \quad A(0)=A_{\max }
$$


Hence, $A_{\max }$ can be calculated with:

$$
A_{\max }=\frac{\left(c(\hat{t})-c_{0}\right) \cdot V}{q} \cdot \frac{1}{\int_{0}^{\hat{t}} f_{A}(t) d t}
$$

At this point it can clearly be seen that the time-dependent function $f_{A}(t)$ and consequently $A_{\max }$ are highly dependent on the sampling rate and detection limit of the reaction products.

\subsubsection{First results from static batch experiments}

Initially, the lab experiments were conducted with phenyl acetate (PhAc) as well as with the potential KIS tracer compound phenyl naphthalene-2-sulfonate (2-NSAPh) (Table 5.1). PhAc is the phenyl ester of acetic acid. Due to the significantly lower $\log K_{\text {ow, }}$ the KIS tracer can be compared with a more hydrophilic compound as a reference. Thus, it is more likely that PhAc shows a stronger partitioning into the water phase than the more hydrophobic 2-NSAPh. The resulting concentration curves of the respective hydrolysis reaction products phenol (reactant: PhAc) and naphthalene-2-sulfonate (reactant: 2-NSAPh) are shown in Figure 5.6.

As expected, the desired hydrolysis reactions went on and both products could be measured online in the water phase by fluorescence spectroscopy. But obviously, both compounds developed a completely different curve shape. As mentioned above, a considerable partitioning additional to the interface sensitive part of mass transfer across the interface leads to an exponential increase of the phenol concentration curve for PhAc. Therefore, the interface sensitivity is lost and the compound is not suitable as KIS tracer. In contrast, 2-NSA showed a very promising curve shape. After an initial startup phase of around 2,000 min, a steady state condition established in the concentration change and the concentration increase became linear. The start-up phase might be caused by the initial saturation of the interface, partitioning of ester impurities (2-NSA) and the final establishment of constant diffusion gradients. Furthermore, the linear slope of the concentration curve seems to confirm the expected reduction of first order to zero order kinetics and indicates a negligible partitioning of the ester between both phases. 


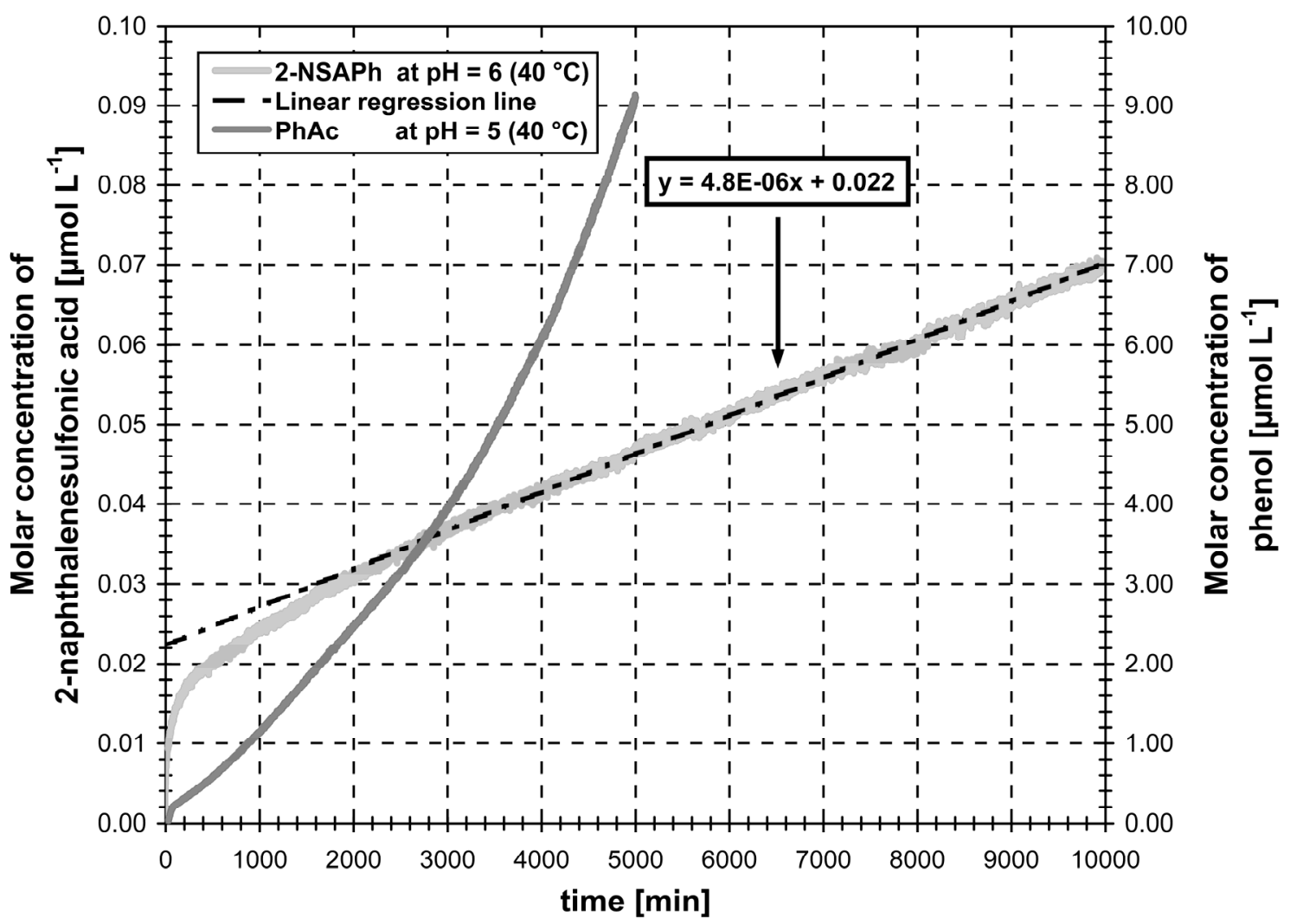

Fig. 5.6 Comparison of measured concentration curves for the hydrolysis reaction products of phenyl acetate (PhAc) and phenyl naphthalene-2-sulfonate (2-NSAPh).

For the evaluation of the interface sensitivity, a linear regression analysis was carried out for the values $t>2,000 \mathrm{~min}$ (Fig. 5.6, $\mathrm{R}^{2}=0.99$ ). By applying the obtained slope $m=4.8 \mathrm{E}-06 \mu \mathrm{mol} \mathrm{L}^{-1} \mathrm{~min}^{-1}$, and the given values $A=1 \mathrm{~cm}^{2}, V=3 \mathrm{~mL}$ for the cuvette in Eq. (7), $q$ was calculated with $2.4 \mathrm{E}-06 \mu \mathrm{mol} \mathrm{m} \mathrm{m}^{-2} \mathrm{~s}^{-1}$. The fitted $m$ depends directly on $k_{1}$ of the hydrolysis reaction and is only valid for the given conditions. Conceivable changes in $T, \mathrm{pH}$ and the molecule structure would lead to different $k_{1}$ and thus to different $m$ and $q$, respectively (see Sections 5.3.1 and 5.4.1.1). During $\mathrm{CO}_{2}$ injections, the $\mathrm{pH}$ is lower in the vicinity of the $\mathrm{scCO}_{2} /$ water interface than for the experiments conducted in this study. Therefore, $k_{1}$ and $q$ are also expected to be lower under field conditions.

The numerical model was calibrated using the observed $m$ from the static batch experiment and a constant interfacial area of $A=1 \mathrm{~cm}^{2}$ (Fig. 5.7). Additionally, three different classical test functions $A(t)$ with properties according to Eq. (5.8) were applied and the resulting concentration curves were modeled to gain further insight 
into the behavior of KIS tracers. The concentrations are proportional to the integrated $A(t)$ which represents an effective area $A_{\text {eff: }}$

$c(t) \propto \int_{0}^{t} A(t) d t=A_{\text {eff }}$

Furthermore, the model allows the distinction between different functions for $A(t)$ even when $A_{\text {eff }}$ and thus also the total amount of reacted tracer is equal (Fig. 5.7). Hence, $A_{\text {eff }}$ is one of the main target parameters for proving the effectiveness of $\mathrm{scCO}_{2}$ injections.

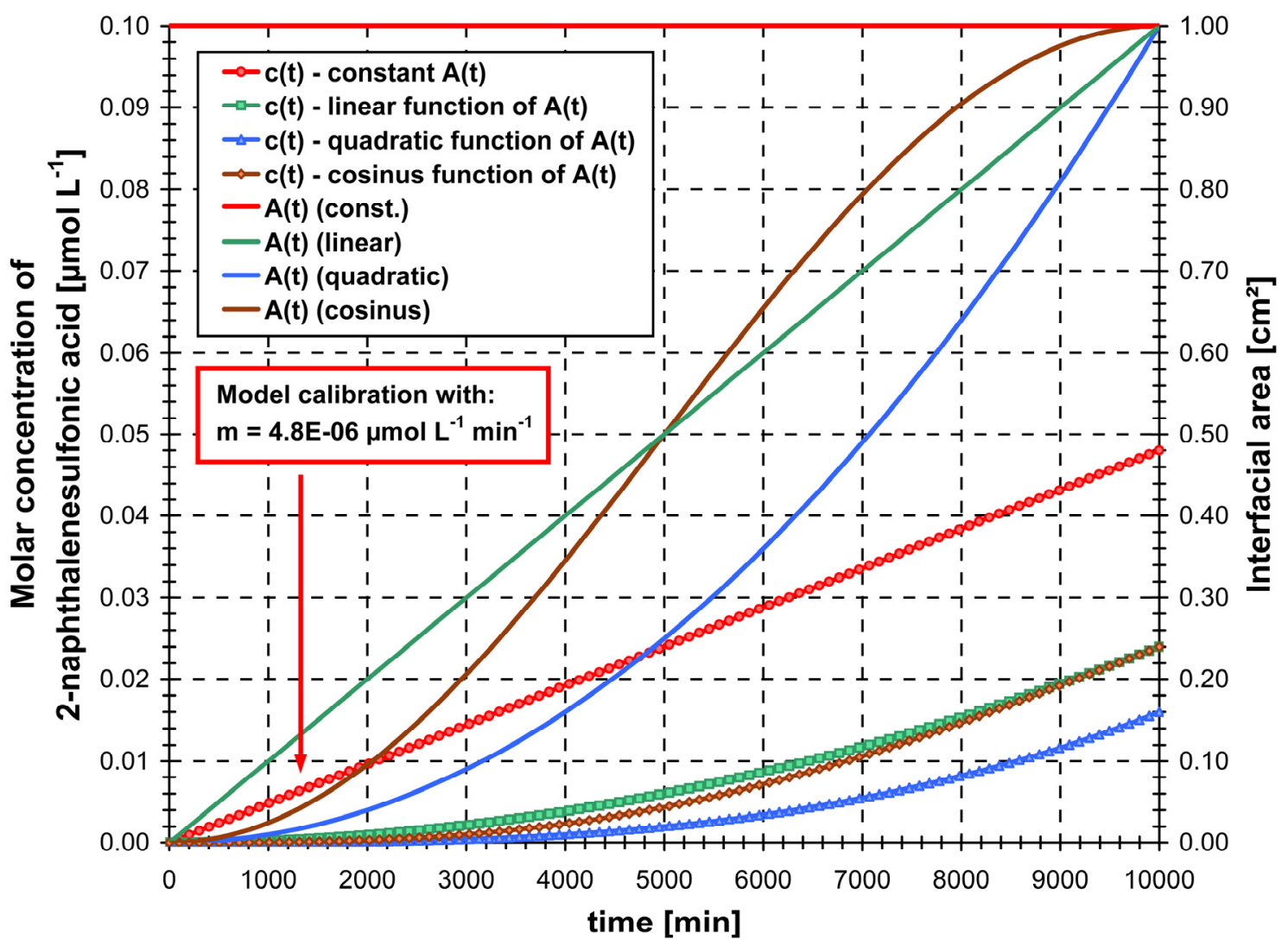

Fig. 5.7 Comparison of different modeled scenarios: Concentration curves are modeled based on different functions for $A(t)$. For the model calibration (red line) the constant $A$ from the experiment was used.

\subsection{Summary and conclusions}

The interfacial area between $\mathrm{scCO}_{2}$ and brine is an important parameter for the evaluation of $\mathrm{CO}_{2}$ storage in deep saline aquifers, since numerous relevant trapping mechanisms and physicochemical processes are directly dependent on this reactive 
interface. Up to now, these interfacial areas and their development during injection cannot be studied directly. In this work, a methodology for the design of kineticinterface sensitive tracers (KIS tracers) was presented. These tracers are believed to have the potential to close the existing gaps for field experimental interpretation by implementing an interface-sensitive reaction. Here, the idea and the theoretical concept for these novel tracers were presented. After defining the tracer requirements and showing possibilities for a tailor-made molecular design, several compounds were successfully synthesized. An analog approach was proposed for testing the tracer behavior by replacing the non-aqueous $\mathrm{ScCO}_{2}$ phase with organic solvents. Additionally, a relationship between measured concentration curves and interfacial area was derived and a first model for the tracer evaluation in static batch systems was presented.

The results show, that molecular target design is a suitable method to develop these kinds of new tracers. As expected, the tested esters 2-NSAPh and PhAc confirmed the combination of mass transfer across the interface and hydrolysis reaction. The respective reaction products $2-N S A$ and phenol were detected in the water phase by fluorescence spectroscopy. However, in contrast to the newly synthesized potential KIS tracer compound 2-NSAPh, which demonstrated the expected linear increase of the reaction product 2-NSA in the water phase and thus interface sensitivity, PhAc showed no interface sensitivity due to a too strong partitioning behavior. The linear concentration increase of 2-NSA is very promising and supports the theoretically derived zero order reaction kinetics at the interface. Thus, a constant mass flux across the interface could be determined. Based on this flux, the new macroscopic numerical model was calibrated and different scenarios were calculated. The model demonstrated the interface sensitivity of KIS tracers and showed the possibility for evaluating the from lab experiments obtained concentration curves. In contrast to conventional equilibrium tracers (partitioning or interfacial tracers), KIS tracers are injected together with the non-aqueous phase and their reaction kinetics (nonequilibrium) is exploited to gain information on the temporal interface or plume development.

Future works will include additional process studies and modeling to describe the relevant processes, dependencies and mechanisms. Furthermore, the experiments 
will be extended to dynamic systems with a variable interface as well as repeated with additional compounds with regard to their possible application as KIS tracer. The influence of a third phase (rock material) on the tracer behavior will also be investigated.

In parallel, the existing model will be extended and adapted according to the experimental progress. Hence, it is planned to use the model as forecast tool for more complex dynamic systems. Finally, when all relevant physicochemical processes are completely understood, it should be possible to implement the model in a reservoir simulator.

\subsection{Acknowledgment}

The research leading to these results has received funding from the European Community's $7^{\text {th }}$ Framework Programme FP7/2007-2013, within the MUSTANG project (grant agreement no. 227286).

\subsection{References}

Annable, M.D., Jawitz, J.W., Rao, P.S.C., Dai, D.P., Kim, H., Wood, A.L., 1998. Field evaluation of interfacial and partitioning tracers for characterization of effective NAPL-water contact areas. Ground Water 36 (3), 495-502.

Bachelor, P.P., McIntyre, J.I., Amonette, J.E., Hayes, J.C., Milbrath, B.D., Saripalli, P., 2008. Potential method for measurement of $\mathrm{CO}_{2}$ leakage from underground sequestration fields using radioactive tracers. Journal of Radioanalytical and Nuclear Chemistry 277 (1), 85-89.

Bachu, S., Adams, J.J., 2003. Sequestration of $\mathrm{CO}_{2}$ in geological media in response to climate change: capacity of deep saline aquifers to sequester $\mathrm{CO}_{2}$ in solution. Energy Conversion and Management 44 (20), 3151-3175.

Benjamin, I., 1997. Molecular structure and dynamics at liquid-liquid interfaces. Annual Review of Physical Chemistry 1997 (48), 407-451.

Dentz, M., Carrera, J., 2005. Effective solute transport in temporally fluctuating flow through heterogeneous media. Water Resources Research 41 (8), 1-20.

Dentz, M., Tartakovsky, D.M., 2009. Abrupt-interface solution for carbon dioxide injection into porous media. Transport in Porous Media 79 (1), 15-27.

Dwarakanath V., Pope, G.A., 1998. New approach for estimating alcohol partition coefficients between nonaqueous phase liquids and water. Environmental Science and Technology 32 (11), 16621666. 
Eberhardt, R., Löbbecke, S., Neidhart, B., Reichardt, C., 1997. Determination of $E_{T}(30)$ values of supercritical carbon dioxide at various pressures and temperatures. Liebigs Annalen 1997 (6), 1195-1199.

Freifeld, B.M., Trautz, R.C., Kharaka, Y.K., Phelps, T.J., Myer, L.R., Hovorka, S.D., Collins, D.J., 2005. The Utube: A novel system for acquiring borehole fluid samples from a deep geologic $\mathrm{CO}_{2}$ sequestration experiment. Journal of Geophysical Research B: Solid Earth 110, B10203.

Hortle, A., de Caritat, P., Stalvies, C., Jenkins, C., 2011. Groundwater monitoring at the Otway Project site, Australia. Energy Procedia 4, 5495-5503.

Hunkeler, D., Hoehn, E., Höhener, P., Zeyer, J., 1997. ${ }^{222} \mathrm{Rn}$ as a partitioning tracer to detect diesel fuel contamination in aquifers: Laboratory Study and Field Observations. Environmental Science and Technology 31 (11), 3180-3187.

Ide, S.T., Jessen, K., Orr, F.M., 2007. Storage of $\mathrm{CO}_{2}$ in saline aquifers: Effects of gravity, viscous, and capillary forces on amount and timing of trapping. International Journal of Greenhouse Gas Control 1 (4), 481-491.

IEA Greenhouse Gas R\&D Programme: Davison, J., Freund, P., Smith, A. (Eds.), 2001. Putting carbon back into the ground, http://www.ieaghg.org/docs/general_publications/putcback.pdf. Accessed $10^{\text {th }}$ October 2011.

IPCC: Metz, B., Davidson, O.R., de Coninck, H. C., Loos, M., Meyer, L.A. (Eds.), 2005. IPCC special report on carbon dioxide capture and storage, Cambridge University Press, Cambridge and New York.

IPCC: Metz, B., Davidson, O.R., Bosch, P.R., Dave, R., Meyer, L.A. (Eds.), 2007. Summary for policymakers. In: Climate change 2007: Mitigation, Cambridge University Press, Cambridge and New York.

Juanes, R., MacMinn, C.W., Szulczewski, M.L., 2010. The footprint of the $\mathrm{CO}_{2}$ plume during carbon dioxide storage in saline aquifers: storage efficiency for capillary trapping at the basin scale. Transport in Porous Media 82 (1), 19-30.

Kang, E.T., Zhang, Y., 2000. Surface modification of fluoropolymers via molecular design. Advanced Materials 12 (20), 1481-1494.

Kim, H., Suresh, P., Rao, P.S.C., Annable, M.D., 1999. Consistency of the interfacial tracer technique: experimental evaluation. Journal of Contaminant Hydrology 40 (1), 79-94.

Kuntz, I.D., Meng, E.C., Shoichet, B.K., 1994. Structure-based molecular design. Accounts of Chemical Research 27 (5), 117-123.

Lackner, K.S., 2003. A guide to $\mathrm{CO}_{2}$ sequestration. Science 300 (5626), 1677-1678.

Lai, C.-C., Tan, C.-S., 1995. Measurement of molecular diffusion coefficients in supercritical carbon dioxide using a coated capillary column. Industrial and Engineering Chemistry Research 34 (2), 674-680.

Langmuir, I., 1918. The adsorption of gases on plane surfaces of glass, mica, and platinum. Journal of the American Chemical Society 40 (9), 1361-1403.

Luque de Castro, M.D., Tena, M.T., 1996. Strategies for supercritical fluid extraction of polar and ionic compounds. TrAC Trends in Analytical Chemistry 15 (1), 32-37.

McCallum, S.D., Riestenberg, D.E., Cole, D.R., Freifeld, B.M., Trautz, R.C., Hovorka, S.D., Phelps, T.J., 2005. Monitoring geologically sequestered $\mathrm{CO}_{2}$ during the Frio Brine pilot test using perfluorocarbon tracers. In: Proceedings of the $4^{\text {th }}$ Annual Conference on Carbon Capture and Sequestration, Alexandria, USA. 
MacMinn, C.W., Juanes, R., 2009. Post-injection spreading and trapping of $\mathrm{CO}_{2}$ in saline aquifers: impact of the plume shape at the end of injection. Computational Geosciences 13 (4), 483-491.

Nakaya, H., Miyawaki, O., Nakamura, K., 2001. Determination of $\log P$ for pressurized carbon dioxide and its characterization as a medium for enzyme reaction. Enzyme and Microbial Technology $28(2-3), 176-182$.

Niesner, R., Heintz, A., 2000. Diffusion coefficients of aromatics in aqueous solution. Journal of Chemical and Engineering Data 45 (6), 1121-1124.

Noordman, W.H., de Boer, G.J., Wietzes, P., Volkering, F., Janssen, D.B., 2000. Assessment of the use of partitioning and interfacial tracers to determine the content and mass removal rates of nonaqueous phase liquids. Environmental Science and Technology 34 (20), 4301-4306.

Nottebohm, M., Licha, T., Ghergut, I., Nödler, K., Sauter, M., 2010. Development of thermosensitive tracers for push-pull experiments in geothermal reservoir characterization. In: Proceedings of the World Geothermal Congress, Bali, Indonesia.

Nottebohm, M., Licha, T., Sauter, M., 2012. Tracer design for tracking thermal fronts in geothermal reservoirs. Geothermics 43, 37-44.

Nottebohm, M., Licha, T., 2012. Detection of naphthalene sulfonates from highly saline brines with high-performance liquid chromatography in conjunction with fluorescence detection and solid-phase extraction. Journal of Chromatographic Science 50 (6), 477-481.

Reichardt, C., 1994. Solvatochromic dyes as solvent polarity indicators. Chemical Reviews 94 (8), 23192358.

Rose, P.E., Benoit, W.R., Kilbourn, P.M., 2001. The application of the polyaromatic sulfonates as tracers in geothermal reservoirs. Geothermics 30 (6), 617-640.

Rose, P.E., Johnson, S.D., Kilbourn, P.M., Kasteler, C., 2002. Tracer testing at Dixie Valley, Nevada using 1-naphthalene sulfonate and 2,6-naphthalene disulfonate. In: Proceedings of the $27^{\text {th }}$ Workshop on Geothermal Reservoir Engineering, Stanford, USA, SGP-TR-171.

Saripalli, K.P., Rao, P.S.C., Annable, M.D., 1998. Determination of specific NAPL-water interfacial areas of residual NAPLs in porous media using the interfacial tracers technique. Journal of Contaminant Hydrology 30 (3-4), 375-391.

Schaffer, M., Boxberger, N., Börnick, H., Licha, T., Worch, E., 2012. Sorption influenced transport of ionizable pharmaceuticals onto a natural sandy aquifer sediment at different $\mathrm{pH}$. Chemosphere 87 (5), 513-520.

Setarge, B., Danzer, J., Klein, R., Grathwohl, P., 1999. Partitioning and interfacial tracers to characterize non-aqueous phase liquids (NAPLs) in natural aquifer material. Physical Chemistry of the Earth, Part B: Hydrology, Oceans and Atmosphere 24 (6), 501-510.

Stryjek, R., Vera, J.H., 1986. PRSV: An improved Peng-Robinson equation of state for pure compounds and mixtures. The Canadian Journal of Chemical Engineering 64 (2), 323-333.

Timko, M.T., Nicholson, B.F., Steinfeld, J.I., Smith, K.A., Tester, J.W., 2004. Partition coefficients of organic solutes between supercritical carbon dioxide and water: experimental measurements and empirical correlations. Journal of Chemical and Engineering Data 49 (4), 768-778.

Tewes, F., Boury, F., 2005. Formation and rheological properties of the supercritical $\mathrm{CO}_{2}$-water pure interface. The Journal of Physical Chemistry B 109 (9), 3990-3997.

Vennila, J.P., Kavitha, H.P., Thiruvadigal, D.J., Manivannan, V., 2008. Phenyl naphthalene-2-sulfonate. Acta Crystallographica Section E 64, 02304. 
Vulava, V.M., Perry, E.B., Romanek, C.S., Seaman, J.C., 2002. Dissolved gases as partitioning tracers for determination of hydrogeological parameters. Environmental Science and Technology 36 (2), 254-262.

Wells, A., Diehl, J., Bromhal, G., Strazisar, B., Wilson, T., White, C., 2007. The use of tracers to assess leakage from the sequestration of $\mathrm{CO}_{2}$ in a depleted oil reservoir, New Mexico, USA. Applied Geochemistry 22 (5), 996-1016. 


\section{Chapter 6}

\section{General conclusions and perspectives}

Tracer techniques are able to provide valuable insights into aquifer systems that are not accessible with other conventional characterization methods. Due to the large number of molecules with individual properties, which can be selected or adapted to specific problems, the application of organic substances as groundwater tracers opens up the chance for gaining further information on processes influencing the tracer transport. For this purpose, however, the sufficient understanding of all involved and the awareness of potentially possible transport-relevant processes are required. Especially in the case of non-conservative compounds, which intentionally interact chemically, biochemically, or physicochemically in the aquifer, this understanding is vital. This work focused on geosorption as one of the most decisive physicochemical processes affecting the solute transport in the subsurface. Knowledge on the underlying interactions and mechanisms causing tracer retardation in a considered system is a promising key to derive process-specific information and related aquifer parameters. However, the sorption-influenced transport, especially for positively charged organic species, is rather complex and not yet fully understood. As a consequence, no resilient prognoses are possible at this time. Therefore, the identification and adequate description of relevant sorption processes including the relation to the molecular characteristics and to further influencing factors are essential in the potential use of any organic substance as hydrogeological tracer. Based on this knowledge, tailor-made tracer molecules for manifold applications could be selected or individually synthesized. 


\subsection{Sorption of organic molecules onto aquifer materials}

Sorption onto aquifer materials is a fundamental process leading to the retardation (and/or removal) of organic compounds in natural aquatic systems. The comprehensive understanding of sorption processes is important for the successful realization and evaluation of field tracer experiments as well as for several naturerelated water treatment processes, such as river bank filtration or soil aquifer treatment. Different molecular structures lead to specific properties of organic compounds. Therefore, a strong influence of the molecular character on sorption and, thus, the transport behavior can be anticipated. Evaluating the applicability of existing model approaches, identifying relevant sorption mechanisms, and studying their main influencing factors is necessary for a meaningful prediction of the subsurface transport of organic solutes.

Column experiments conducted with several ionizable pharmaceuticals and one aquifer sediment showed a strong influence of $\mathrm{pH}$ on sorption. Compounds with $\mathrm{p} K_{a}$ values in the considered $\mathrm{pH}$ range showed the strongest $\mathrm{pH}$-dependence. This is because several species with different charge are formed in the aqueous phase. The comparison between measured and predicted data using a simple $\log K_{o w}-\log K_{o c}$ regression gave confident results only for neutral compounds. The use of $\log D$ instead of $\log K_{\text {ow }}$ within these correlations enabled the prediction for acids and, thus, led also to acceptable results. Hence, the prediction for neutral and acidic molecules with existing classical or slightly modified concepts considering the speciation is reasonable. In contrast, the sorption of organic cations was generally underestimated, since only hydrophobic interactions are considered in these simple one-parameter correlation approaches. However, aquifer materials possess usually negative net surface charges, which induce additional electrostatic attractions between the sorbent and the positively charged sorbate. Hence, polar sorption mechanisms (e.g., cation exchange, hydrogen bonding) also have to be considered. Additionally, awareness is required that the relative role may change dramatically depending on the boundary conditions (e.g., solute speciation and variable surface charges of the sorbent are $\mathrm{pH}$ - dependent).

In order to predict the sorption of organic cations, the relevant sorption mechanisms have to be separated a priori and investigated independently. For this purpose, the 
systematic study and comparison of the sorption behavior of further selected, but structurally related organic cations (e.g., homologues) under varying conditions is suggested. By using additionally defined sorbents with different surface properties, certain sorptive interactions may be excluded or emphasized and studied separately. Consecutively, it should be attempted to relate or to normalize observed sorption data with measured solution and sorbent properties.

For assessing the extent of ionic contributions to the whole sorption process of organic cations, the sorption/desorption behavior of two structurally similar cationic beta-blockers was investigated and compared for two sediments. Dramatically changing retardations due to varying concentrations of inorganic cations were observed. That means organic and inorganic cations compete for the negatively charged surface sites of the sorbent. Consequently, an important role of cation exchange processes under the applied conditions was derived. By comparing the predicted hydrophobic proportion with the observed overall sorption, the contribution of polar interactions could be quantified with more than $99 \%$. Thus, a high relevance of non-hydrophobic sorption mechanisms for the transport of cationic beta-blocker species and most likely for the transport of further cationic compounds in aquifers can be concluded. Since the relative role and extent of all cation exchange processes generally depends on the water chemistry (e.g., pH, ionic strength, type of competing cations, dissolved organic matter) as well as the sorbent properties (e.g., cation exchange capacity, specific surface area, clay content, point of zero charge, solid organic matter), the individual influence of these factors in addition to the influence of the sorbate (molecule) properties have to be known.

As a consequence, measured sorption coefficients given in the literature cannot be directly compared for the protonated organic cation species, since the boundary conditions are most probably unequal. Therefore, a mechanistic understanding is necessary in order to compare and sufficiently predict the sorption of organic cations. For doing so, the stepwise and thorough study of relevant boundary conditions influencing polar sorbent/sorbate interactions is strongly recommended.

First systematic experiments in this context were carried out within this work. By means of batch equilibrium experiments, the influence of the background electrolyte (concentration and type of inorganic cations) on the sorption of the monovalent 
organic cation metoprolol onto an aquifer sediment was studied. All competitive sorption isotherms were non-linear indicating the existence of energetically heterogeneous sorption sites. Nevertheless, constant Freundlich exponents indicated that the sorption mechanisms are not changing dramatically over a wide concentration range. Due to decreasing sorption of the organic cation with increasing concentrations of the inorganic cations $\mathrm{Na}^{+}$and $\mathrm{Ca}^{2+}$ the dominating role of cation exchange processes could be confirmed. A first simple logarithmic correlation between the sorption coefficient and the competing electrolyte concentration was found allowing the prediction of metoprolol sorption on the investigated sediment. In contrast to other authors, however, these correlations show an opposite curve shape. This difference cannot yet be explained and requires further research on the controlling influence factors. Thus, the application field of the relationships found is currently still vague.

Before general conclusions for other organic/inorganic cations and sorbents can be drawn, all sorption mechanisms and further influence factors have to be investigated and understood in more detail. The first step was done in this work. In further steps, the detected relations have to be described with effective parameters, which allow the conjunction of all system relevant factors in one model. The directly following work could include the study the sorption behavior of organic cations in mixtures of inorganic cations as well as the study of the influence of further not yet investigated competing inorganic cations under otherwise constant conditions. Subsequently, the sorbate and sorbent properties should be changed systematically.

\subsection{Development of reactive organic tracers for the characterization of $\mathrm{CO}_{2}$ plume spreading}

The target synthesis of molecules with desired properties has been successfully established in many scientific disciplines. Especially in the field of life sciences (e.g., pharmacology, biochemistry, medicine) and material sciences, this methodology is used. The conscious combination of structural elements and molecular features allows the creation of novel compounds with defined properties. To date, molecular 
design of hydrogeological tracers for reservoir studies, however, has not yet been considered.

The interfacial area size between supercritical $\mathrm{CO}_{2}\left(\mathrm{scCO}_{2}\right)$ and brine is an important parameter for characterizing $\mathrm{CO}_{2}$ spreading during $\mathrm{CO}_{2}$ sequestration into deep saline aquifers. In this work, the concept and methodology for the target design of a new reactive tracer type (KIS tracer), which may be able to detect these interfaces, were proposed. Based on the tracer concept, it is required that one of the tracer hydrolysis reaction products has to show a conservative transport behavior in the water phase. For this reason, naphthalenesulfonate was selected as base structure, because several physicochemical attributes make it convenient for the modification to a KIS tracer via esterification. Naphthalenesulfonic acids are strong acids with corresponding low $\mathrm{p} K_{a}$ values of $<1$. Hence, these compounds are anionic over the entire $\mathrm{pH}$ range. Based on the previous sorption studies, a non-sorptive behavior and a high mobility in aquifer systems can be expected. Furthermore, a partitioning to the non-aqueous $\mathrm{scCO}_{2}$ phase can be neglected due to the high affinity of these molecules to the water phase (water solubility $>1,000 \mathrm{~g} \mathrm{~L}^{-1}$ ). The lab experiments confirmed that the mass transfer through the interface is limited by the hydrolysis reaction. As intended, the combined process follows zero-order kinetics. Thus, a constant mass flux through the interface could be determined. Furthermore, first modeling results demonstrated the interface sensitivity of the synthesized compound.

In the next steps, the modeling has to be extended for predicting suitable reaction rates of the hydrolysis in order to resolve the plume development. Afterwards, the hydrolysis kinetics needs to be adapted by molecular design to the required time and space scales in lab or field applications. For this purpose, the need may also arise to use other compounds than naphthalenesulfonates as base structures for the KIS tracer development. For instance, it might be suitable to use acid chlorides or acid amides instead of esters as KIS tracer, since their hydrolysis rates are very different to the aforementioned. In the case of acid amides, however, organic cations (amines) that do not have a conservative sorption behavior would also be formed during the reaction. Eventually, the findings from the previous sorption studies might be exploited for the tracer interpretation. 
Appendix 


\section{Appendix A}

\section{A1 Liquid chromatography}

The samples were analyzed by UV absorption using a high pressure liquid chromatograph (HPLC, Merck-Hitachi) with a diode array detector (DAD L-4500, Merck-Hitachi). A $150 \times 3 \mathrm{~mm}$ C18-HPLC reversed phase column (Gemini-NX $3 \mu \mathrm{m}$ C18 110A, Phenomenex) was used for chromatographic separation. The separation was operated at $29^{\circ} \mathrm{C}$, a constant flow rate of $0.5 \mathrm{~mL} \mathrm{~min}^{-1}$, and an injection volume of $100 \mu \mathrm{L}$. Eluent A was acetonitrile (HPLC grade, Mallinckrodt Baker, Griesheim, Germany) and eluent B was a $10 \mathrm{mM} \mathrm{NH} \mathrm{HCO}_{3}$ (p.a., Mallinckrodt Baker, Griesheim, Germany) buffer with $\mathrm{pH}=9.5$. The elution started isocratically with $20 \% \mathrm{~A}$ and $80 \%$ $B$ for 1 min. This step was followed by 9-minute different linear gradients to $84 \%$ of $A$ with steps of $50 \% \mathrm{~A}$ after $4 \mathrm{~min}$ and $78 \% \mathrm{~A}$ after $6 \mathrm{~min}$. This was held for $6 \mathrm{~min}$ followed by a linear gradient back to $20 \%$ of $A$. In the last 8 min of the procedure the system was equilibrated by holding these conditions. Thus, the measurement per sample takes $30 \mathrm{~min}$. The determination limit (DIN 32645, 2008) derived from a linear calibration curve was for all compounds in the range of $5-35 \mu_{\mathrm{g} \mathrm{L}}^{-1}$ (significance level 0.05).

\section{A2 Sediment analysis}

The specific surface area of the sediment was determined with the $\mathrm{N}_{2}$ adsorption/desorption BET method (Brunauer et al., 1938; DIN ISO 9277, 2003) by the use of Autosorb-1-C (Quantachrome) surface analyzer. Sediment $\mathrm{pH}$ was measured according to DIN ISO 10390, 2003 with ultrapure water as well as with a $0.01 \mathrm{M} \mathrm{CaCl}_{2}$ solution. The determination of the total organic carbon TOC content was carried out by dry combustion of the priorly with $4 \mathrm{M} \mathrm{HCl}$ treated sediment at $900^{\circ} \mathrm{C}$ in a total organic carbon analyzer (Dohrmann Boat Sampler $184 \mathrm{~S}$ / Rosemount Dohrmann DC 70). The effective (at sediment $\mathrm{pH}$ ) and the potential (at $\mathrm{pH}=8.1$ ) cation exchange capacity CEC was measured in accordance with DIN ISO 11260, 1997 and DIN ISO 13536, 1997, respectively. The mineralogical constitution of the sediment was 
characterized by macroscopic observation and combined X-ray diffractometrythermoanalysis (Siemens diffractometer D5000, Netzsch STA 409 PG Luxx).

\section{A3 Comparison of applied correlations}

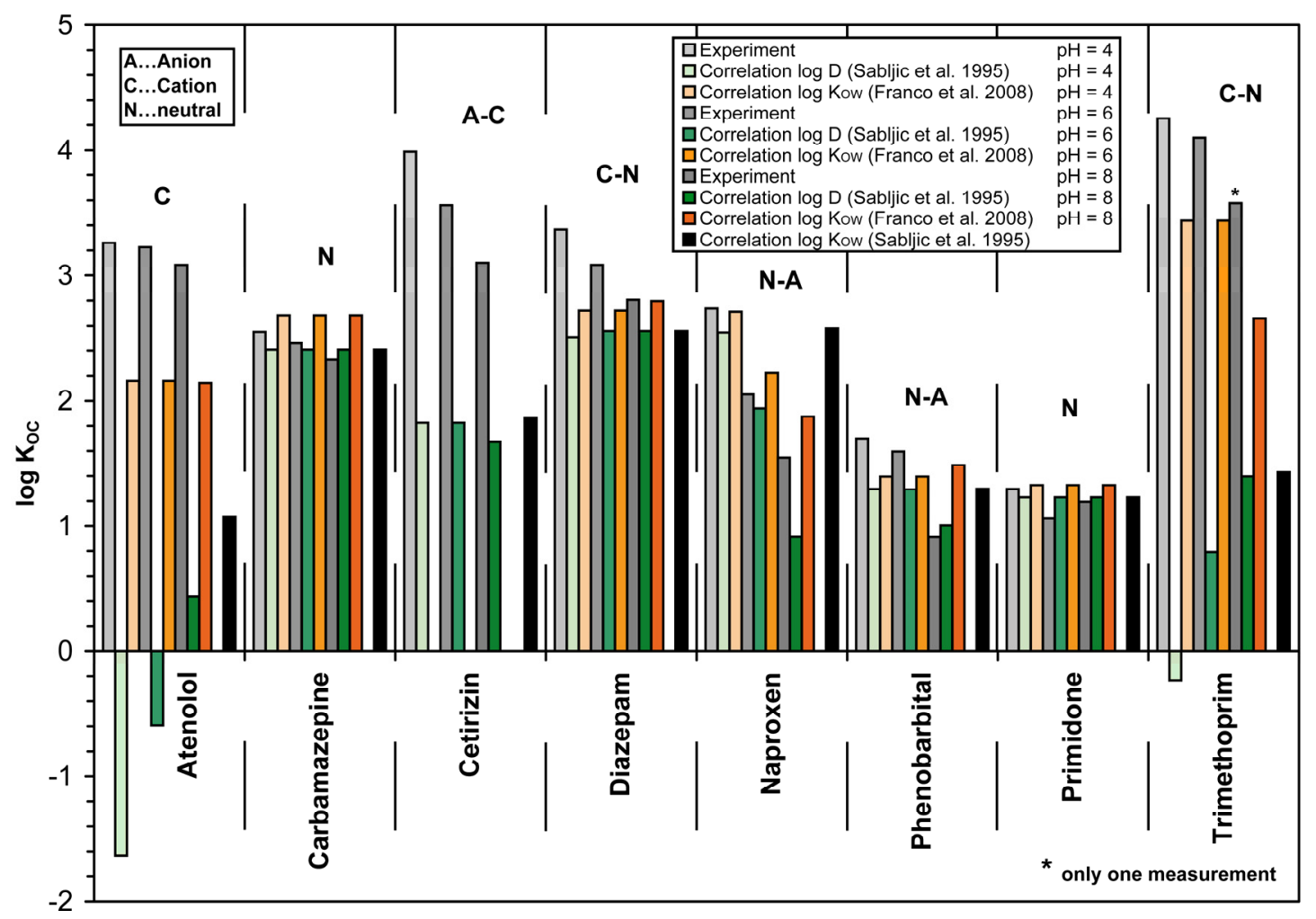

Fig. A1 Average from column experiments derived log $K_{o c}$ values (grey columns) compared with estimated $\log K_{o c}$ values calculated with the modified $\log K_{o w}-\log K_{o c}$ correlation after Sabljic et al. (1995) (green columns) and the correlations of Franco et al. (2008) (orange columns) for all compounds at $\mathrm{pH}=4, \mathrm{pH}=6$, and $\mathrm{pH}=8$. The correlation from Franco et al. (2008) could not be applied for the zwitter-ionic cetirizine.

\section{A4 References}

Brunauer, S., Emmett, P.H., Teller, E., 1938. Adsorption of gases in multimolecular layers. Journal of the American Chemical Society 60 (2), 309-319.

DIN ISO 9277, 2003. Determination of the specific surface area of solids by gas adsorption using the BET method. Deutsches Institut für Normung e. V., Beuth, Berlin, Germany.

DIN ISO 10390, 2003. Soil quality - Determination of pH. Deutsches Institut für Normung e. V., Beuth, Berlin, Germany.

DIN ISO 11260, 1997. Soil quality - Determination of effective cation exchange capacity and base saturation level using barium chloride solution. Deutsches Institut für Normung e. V., Beuth, Berlin, Germany. 


\section{Appendix A}

DIN ISO 13536, 1997. Soil quality - Determination of the potential cation exchange capacity and exchangeable cations using barium chloride solution buffered at $\mathrm{pH}=8.1$. Deutsches Institut für Normung e. V., Beuth, Berlin, Germany.

DIN 32645, 2008. Chemical analysis - Decision limit, detection limit and determination limit under repeatability conditions - Terms, methods, evaluation. Deutsches Institut für Normung e. V., Beuth, Berlin, Germany.

Franco, A., Trapp, S., 2008. Estimation of the soil-water partition coefficient normalized to organic carbon for ionizable organic chemicals. Environmental Toxicology and Chemistry 27 (10), 19952004.

Sabljic, A., Guesten, H., Verhaar, H., Hermens, J., 1995. QSAR modelling of soil sorption. Improvements and systematics of log $K_{o c}$ vs. log Kow correlations. Chemosphere 31 (11-12), 4489-4514. 


\section{Appendix B}

\section{B1 Tracer tests}

Table B1 Column experimental conditions and modeled parameters of the tracer tests.

\begin{tabular}{|c|c|c|c|c|}
\hline 岁 $匚$ & 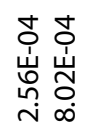 & 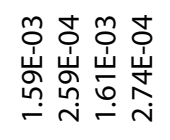 & 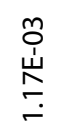 & 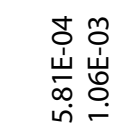 \\
\hline$\approx \Xi$ & 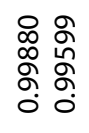 & 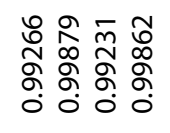 & 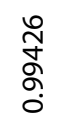 & $\begin{array}{l}\text { oे } \\
\text { o. } \\
\text { o. } \\
\text { ôे } \\
0\end{array}$ \\
\hline $\begin{array}{ll}\frac{2}{ \pm} & \bar{\xi} \\
\frac{0}{3} & \frac{5}{\sigma}\end{array}$ & 总 & 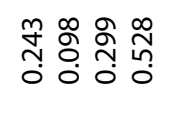 & $\sum_{n}^{m}$ & 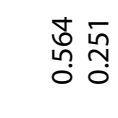 \\
\hline 㐫 & 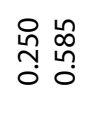 & 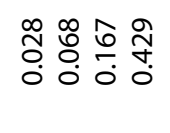 & $\stackrel{\substack{m \\
0}}{o}$ & 究 \\
\hline$\circ \overline{\underline{E}}$ & 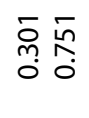 & 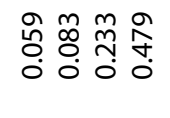 & $\stackrel{\stackrel{n}{\vartheta}}{0}$ & 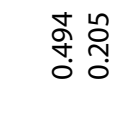 \\
\hline$<\xi$ & \&: & 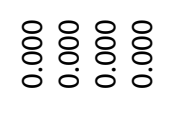 & ষ & : \\
\hline$\propto \Xi$ & -- & ---- & - & -- \\
\hline$>^{3} \frac{\vec{E}}{\underline{\underline{\xi}}}$ & $\frac{+0}{0}$ & $\stackrel{n}{\circ} \frac{t}{0} \frac{t}{0} \frac{t}{0}$ & $\frac{0}{0}$ & $\stackrel{\square}{\circ} \frac{m}{0}$ \\
\hline$\Xi \Xi$ & 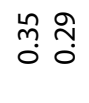 & mị & ?̣̊ & f. ఫ. \\
\hline$\approx \overline{\frac{\pi}{\underline{\xi}}}$ & 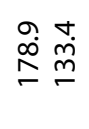 & 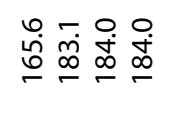 & 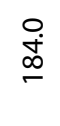 & $\begin{array}{l}\stackrel{0}{0} \\
\stackrel{\infty}{\infty} \underset{\infty}{\infty} \stackrel{\infty}{\infty}\end{array}$ \\
\hline$s \frac{\overrightarrow{\bar{E}}}{\underline{\underline{\xi}}}$ & 능 & 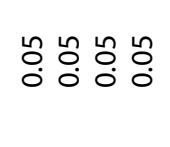 & $\stackrel{n}{0}$ & 눙 \\
\hline $0 \underset{\underline{\underline{\xi}}}{\stackrel{\overrightarrow{\underline{\xi}}}{\underline{\xi}}}$ & 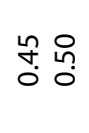 & 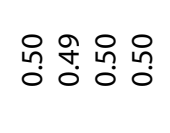 & in & 융ํำ \\
\hline 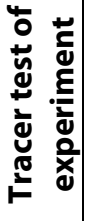 & 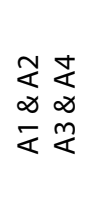 & ๘ ৩ & $\overline{0}$ & 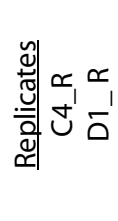 \\
\hline
\end{tabular}


Table B2 CXTFIT modeled parameters and fit quality for all column experiments.

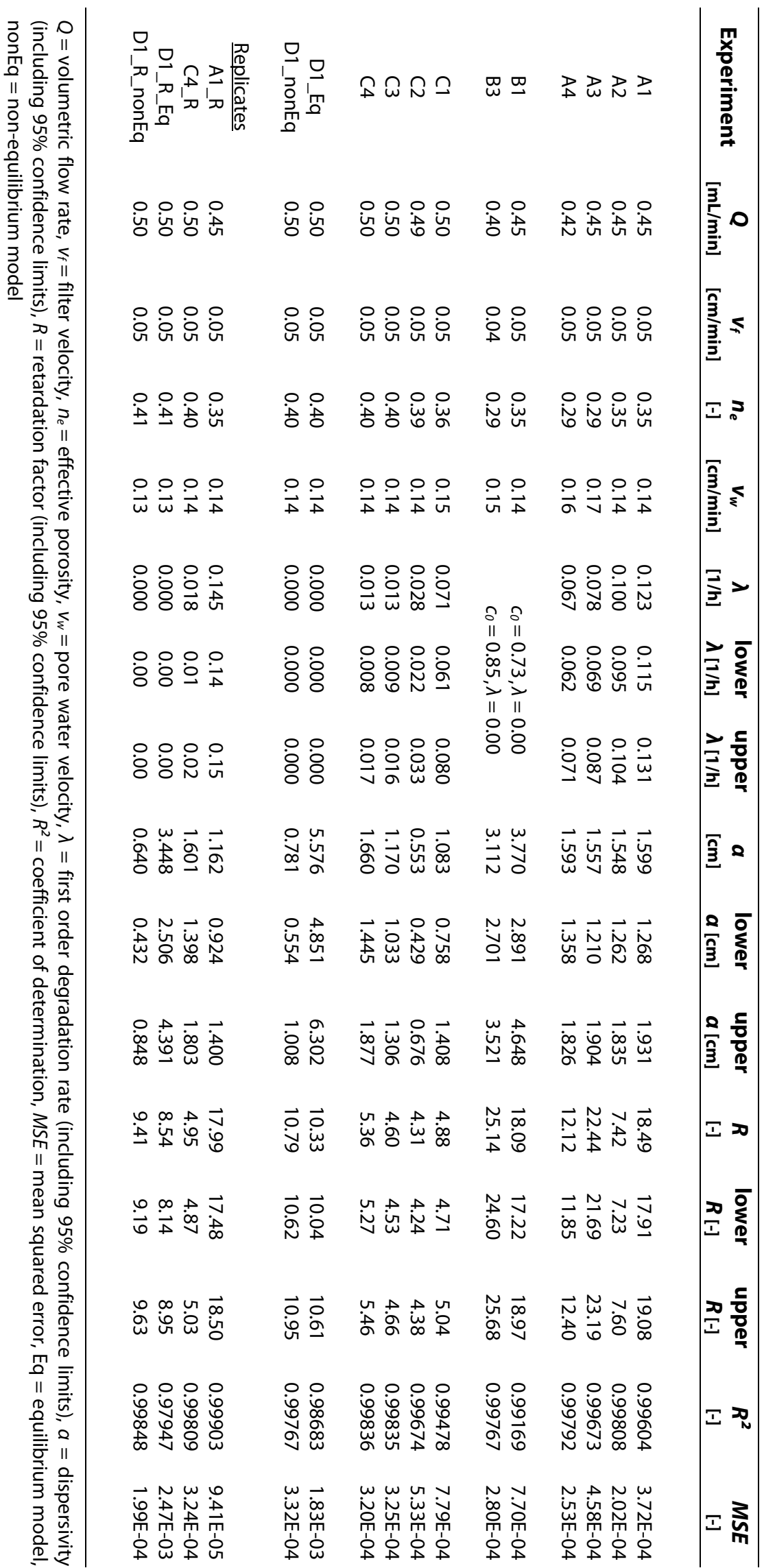


B3 Exemplary replicates of the experiments

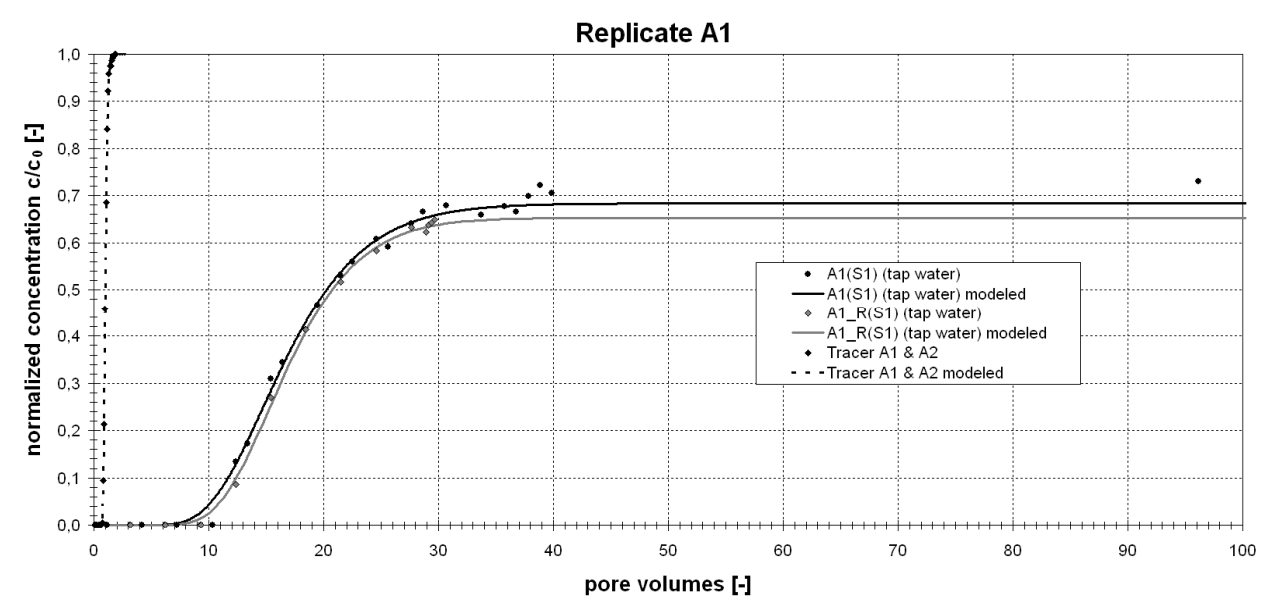

Fig. B1 Replicate of experiment A1.

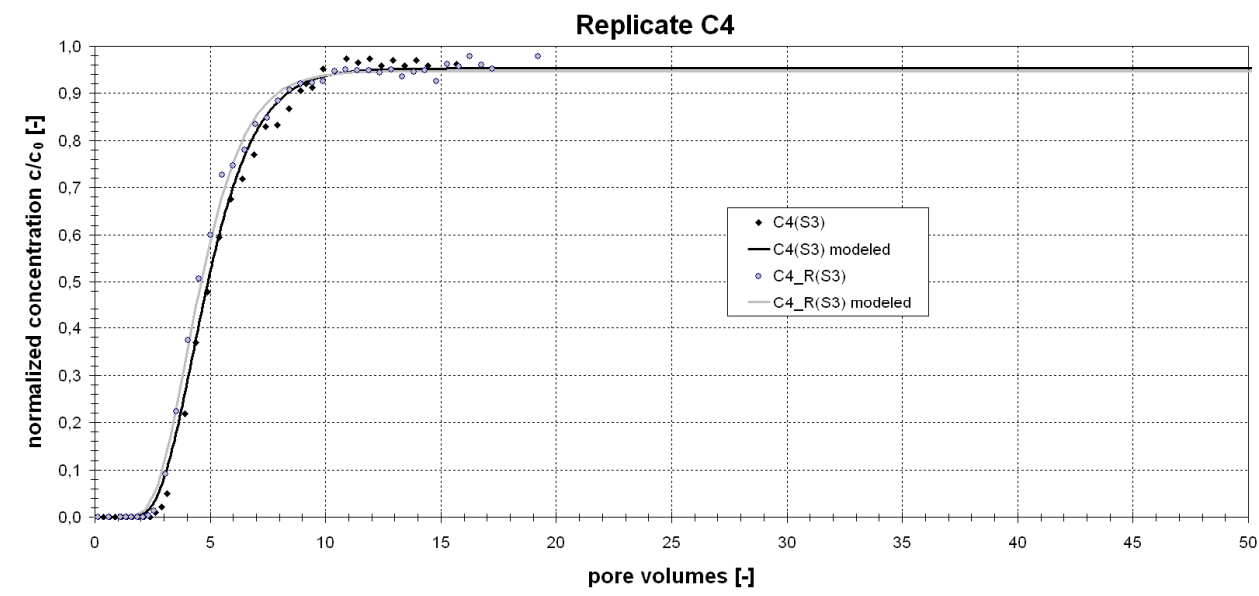

Fig. B2 Replicate of experiment C4.

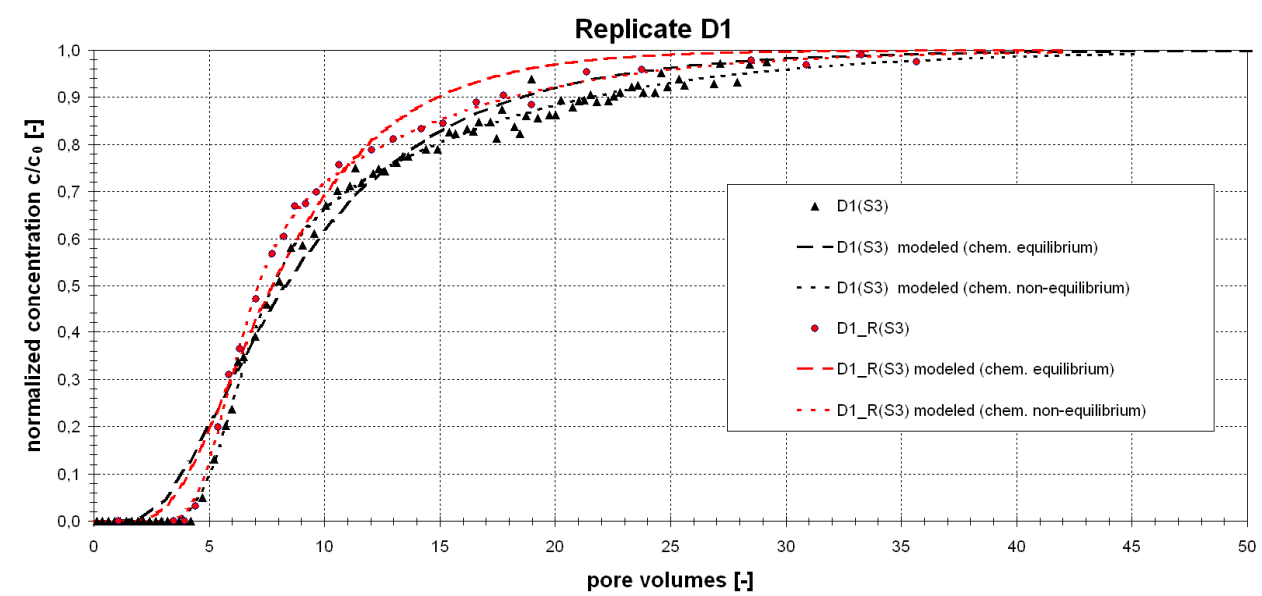

Fig. B3 Replicate of experiment D1. 


\section{Appendix C}

\section{C1 Sorption capacity of the different grain size fractions}

The particle size distribution of the sediment is an important factor, which has to be considered in sorption experiments. For this reason, preliminary experiments were conducted with separated grain size fractions to prove which fractions provide the highest sorption capacities or whether the main experiments can be conducted with sediment bulk.

The particle size distribution of the sediment was analyzed with the Laser Diffraction Particle Size Analyzer LS 13320 (Beckman \& Coulter Inc., Fullerton, USA), in line with the U.S.D.A. classification in a range of $0.04 \mu \mathrm{m}$ to $2,000 \mu \mathrm{m}$. The sediment was divided into ten subsamples and subsequently averaged. An amount of $5-10 \mathrm{~g}$ of each subsample was analyzed by the ultrasonic device Sonoplus HD 2070 (Bandelin electronic, Berlin, Germany) in a suspending fluid three times. The region from $0.04 \mu \mathrm{m}$ to $0.4 \mu \mathrm{m}$ is covered by Polarization Intensity Differential Scattering (PIDS) technology. Afterwards, the mean was calculated.

Although the particle size distribution revealed rather well sorted sediment, different particle size fractions were tested for their sorption capacity towards metoprolol. The aquifer material was separated into five fractions representing the main size distributions. These fractions were received due to mechanical dry sieving with an even distribution over the whole particle size range. A set of five sieves in a range from $63 \mu \mathrm{m}$ up to $1,000 \mu \mathrm{m}$ were used. For each sieving procedure, the sieve tower was filled with $100 \mathrm{~g}$ of sediment and clamped on to the vibrating table for $10 \mathrm{~min}$ with an amplitude of $1.5 \mathrm{~mm}$ and a vibrating interval of $5 \mathrm{~s}$. Afterwards, the different particle sizes were collected separately. Details on the sorption experiments and its chemical analysis can be found in Chapter 4.2. 

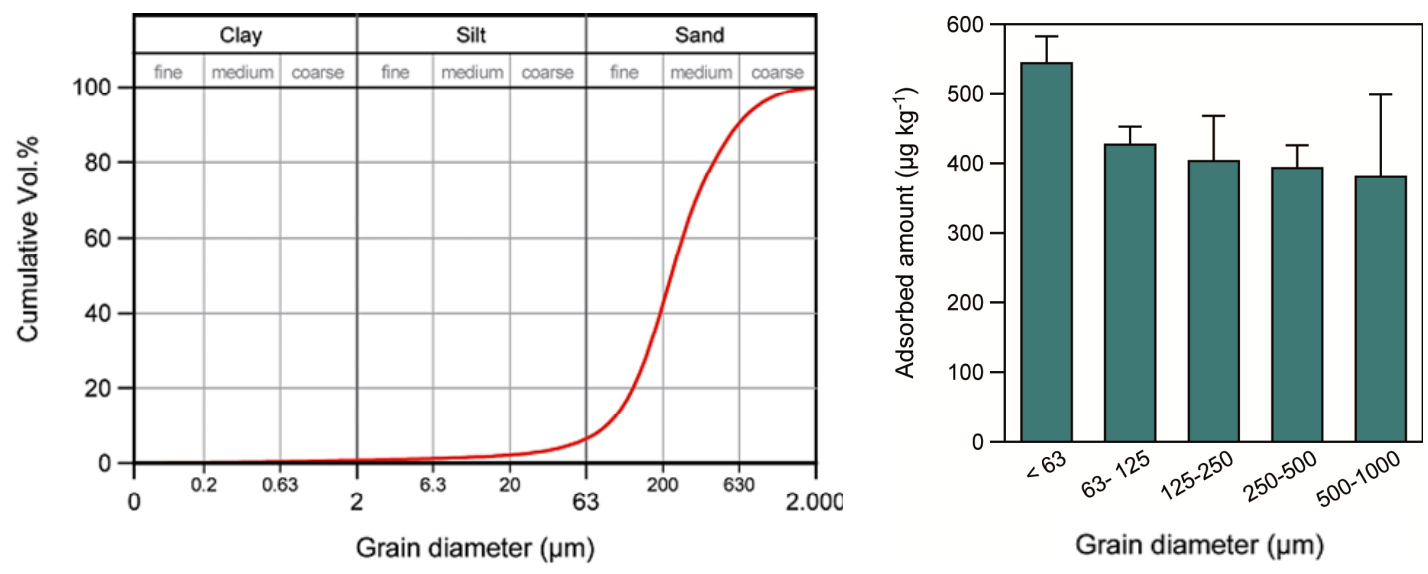

Fig. C1 left: Mean cumulative particle size distribution of the sediment; right: Distribution of sorbed metoprolol on the different particle size fractions at neutral $\mathrm{pH}$ and a temperature of $20 \pm 1^{\circ} \mathrm{C}$. Results are presented in terms of averages of data from the duplicate batches. The error bars reported in the figure have been calculated by considering the difference between batch results.

\section{C2 Statistical analysis of the isotherms}

For evaluating the Freundlich isotherms fit quality and confidence limits, the equilibrium concentrations $c_{e q}$ and sorbed amount $q_{e q}$ were logarithmized and subsequently evaluated with a simple linear regression model. Assuming Student distributed ( $t$-distribution) residuals and a two-sided significance level of $a=0.05$, the 95\% confidence intervals can be calculated with:

$n= \pm t_{n-2 ; 1-\alpha / 2} \frac{\hat{\sigma}}{s_{x} \sqrt{n-1}} \quad$ with $\quad \hat{\sigma}^{2}=\frac{1}{n-2} \sum_{i=1}^{n}\left(\lg q_{e q, i}-\lg K_{F r}-n_{F r} \cdot \lg c_{e q_{i}}\right)$

where $n$ is the number of data points, $t_{n-2 ; 1-\alpha / 2}$ is the $t$-quantile, $s_{x}$ is the standard deviation of $\lg c_{e q}, \hat{\sigma}^{2}$ is the variance of the residuals as estimator for the regression error, $K_{F r}$ is the Freundlich coefficient and $n_{F r}$ is the Freundlich exponent (slope of regression line). The fitted isotherms including the corresponding confidence intervals are shown in Figures C2-C8.

Further, in Table 4.2 the sum of least-square errors (SSE) is given as measure for the fit quality:

SSE $=\sum_{i=1}^{n}\left(\lg q_{i, o b s}-\lg q_{i, f i t}\right)^{2}$ 
Appendix C

$q_{i, o b s}$ is the sorbed amount observed in the experiments and $q_{i, f i t}$ is the simulated sorbed amount for all $c_{e q}$.

C2.1 Reference Isotherm without competition

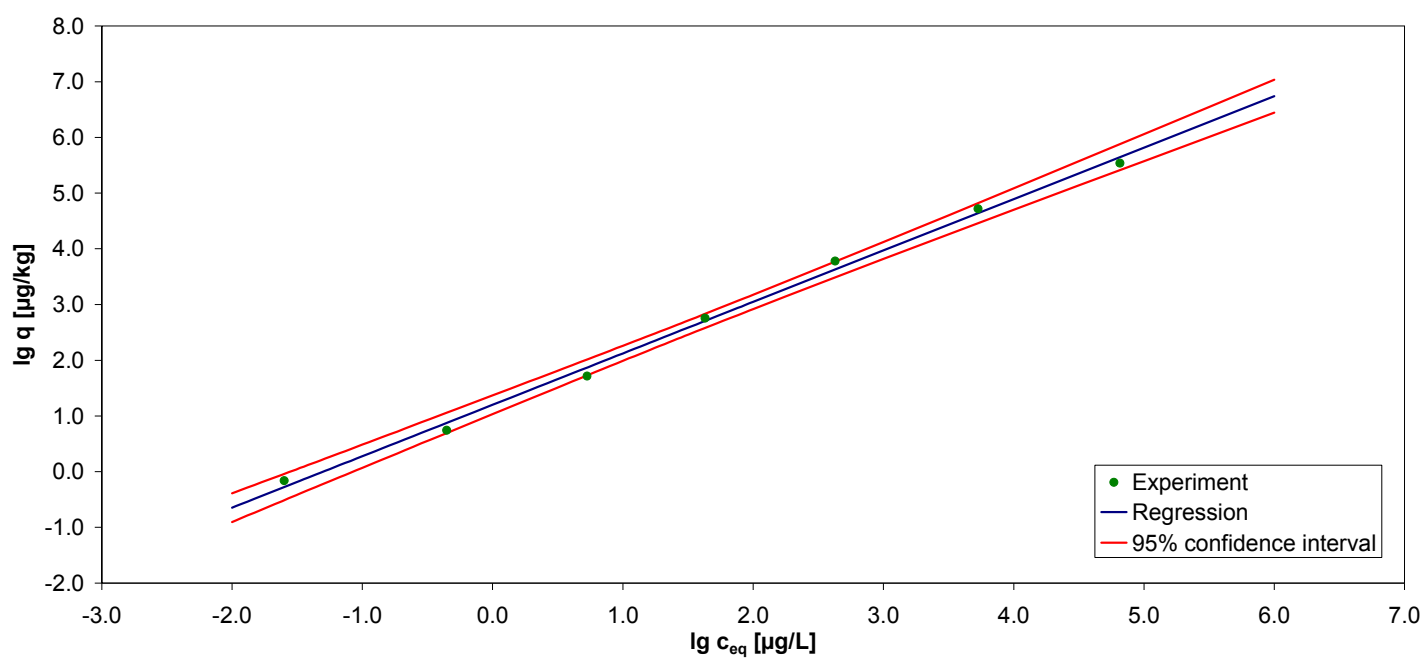

Fig. C2 Reference isotherm for metoprolol $\left(R^{2}=0.9962\right)$. 
C2.2 Isotherms for competition with $\mathrm{Na}^{+}$

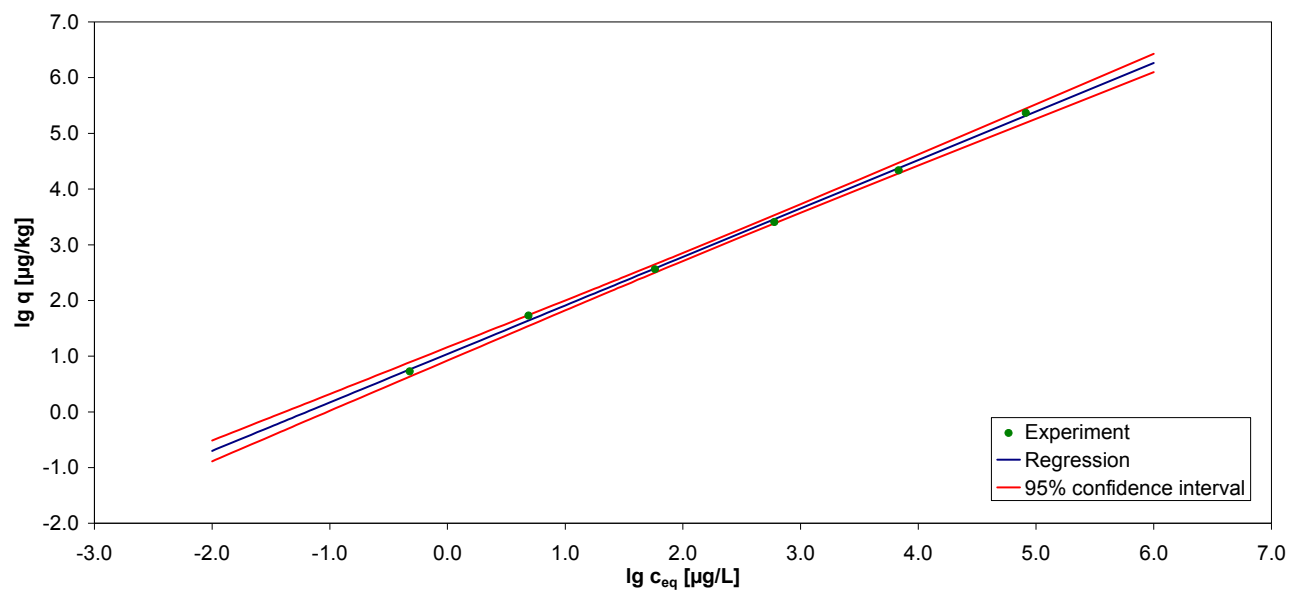

Fig. C3 Isotherm of metoprolol at $0.37 \mathrm{mmol} \mathrm{L}^{-1} \mathrm{Na}^{+}\left(R^{2}=0.9989\right)$.

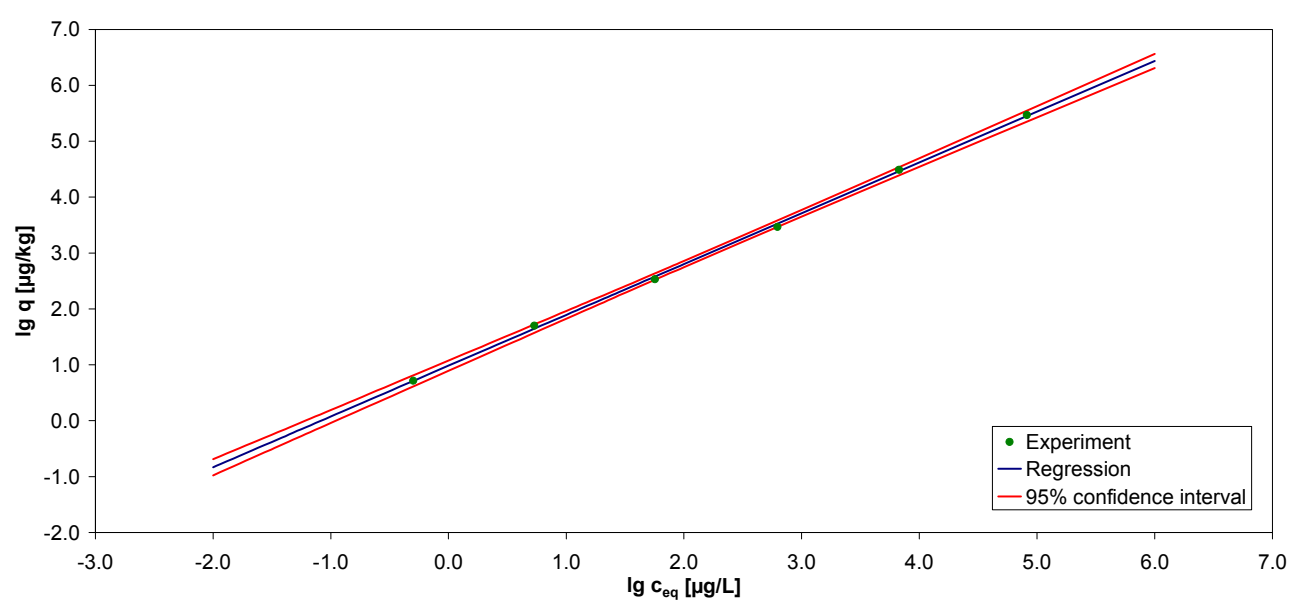

Fig. C4 Isotherm of metoprolol at $3.7 \mathrm{mmol} \mathrm{L}^{-1} \mathrm{Na}^{+}\left(R^{2}=0.9994\right)$.

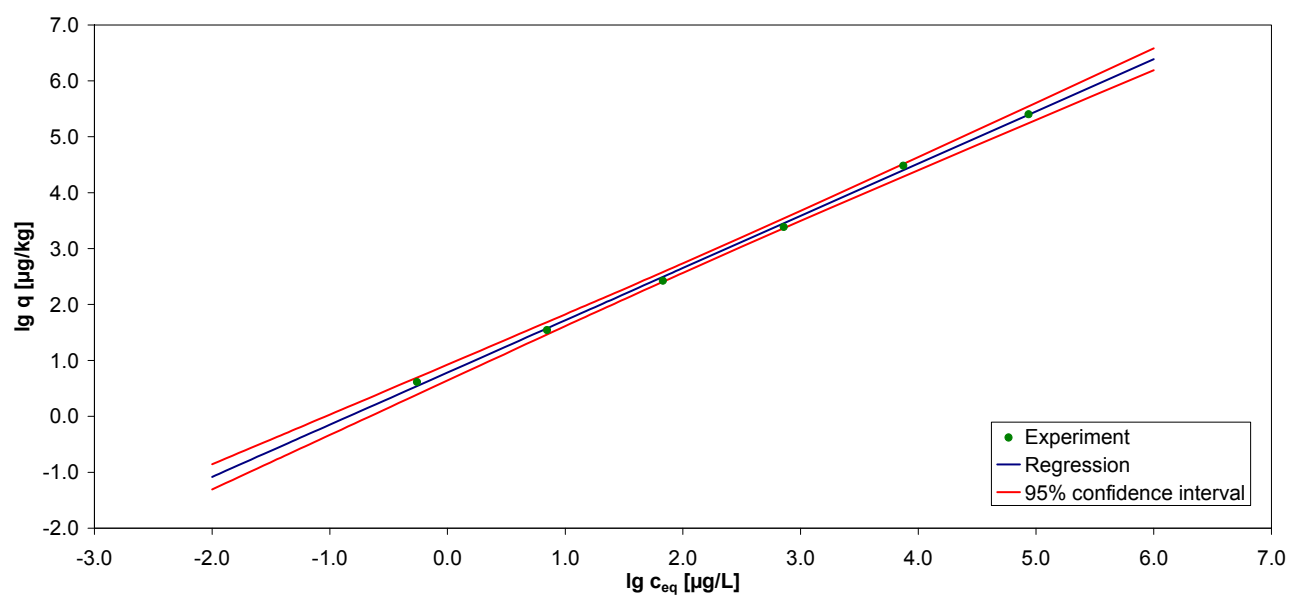

Fig. C5 Isotherm of metoprolol at $37.0 \mathrm{mmol} \mathrm{L}^{-1} \mathrm{Na}^{+}\left(R^{2}=0.9986\right)$. 


\section{C2.3 Isotherms for competition with $\mathrm{Ca}^{2+}$}

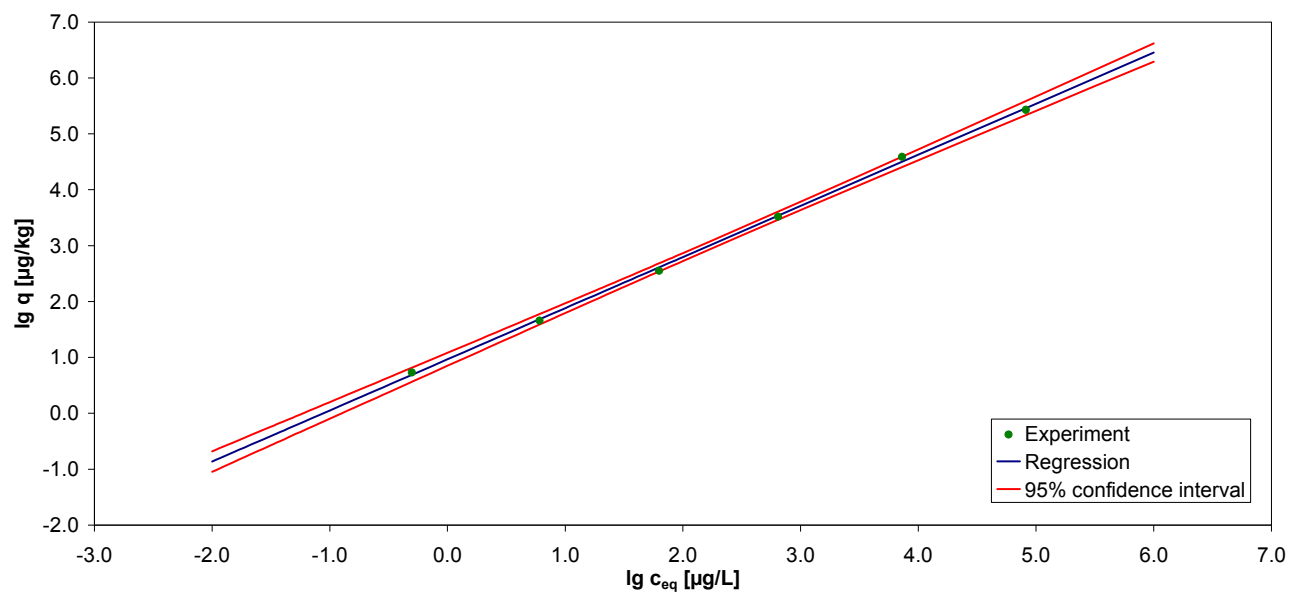

Fig. C6 Isotherm of metoprolol at $0.37 \mathrm{mmol} \mathrm{L}^{-1} \mathrm{Ca}^{2+}\left(\mathrm{R}^{2}=0.9990\right)$.

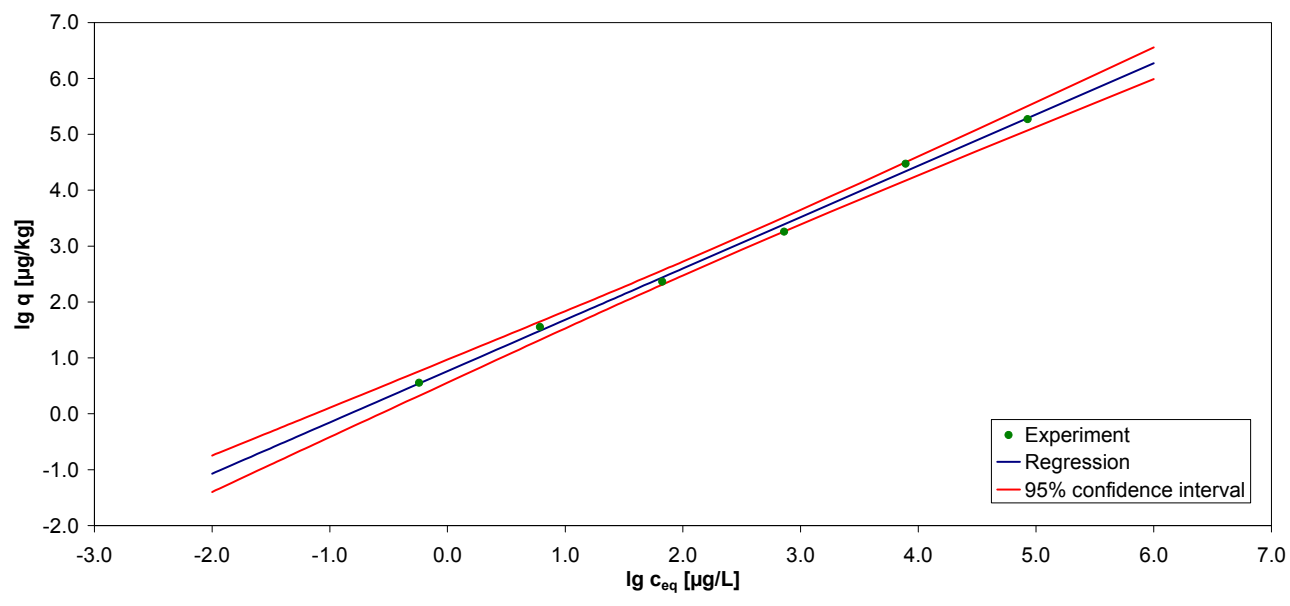

Fig. C7 Isotherm of metoprolol at $3.7 \mathrm{mmol} \mathrm{L}^{-1} \mathrm{Ca}^{2+}\left(\mathrm{R}^{2}=0.9970\right)$.

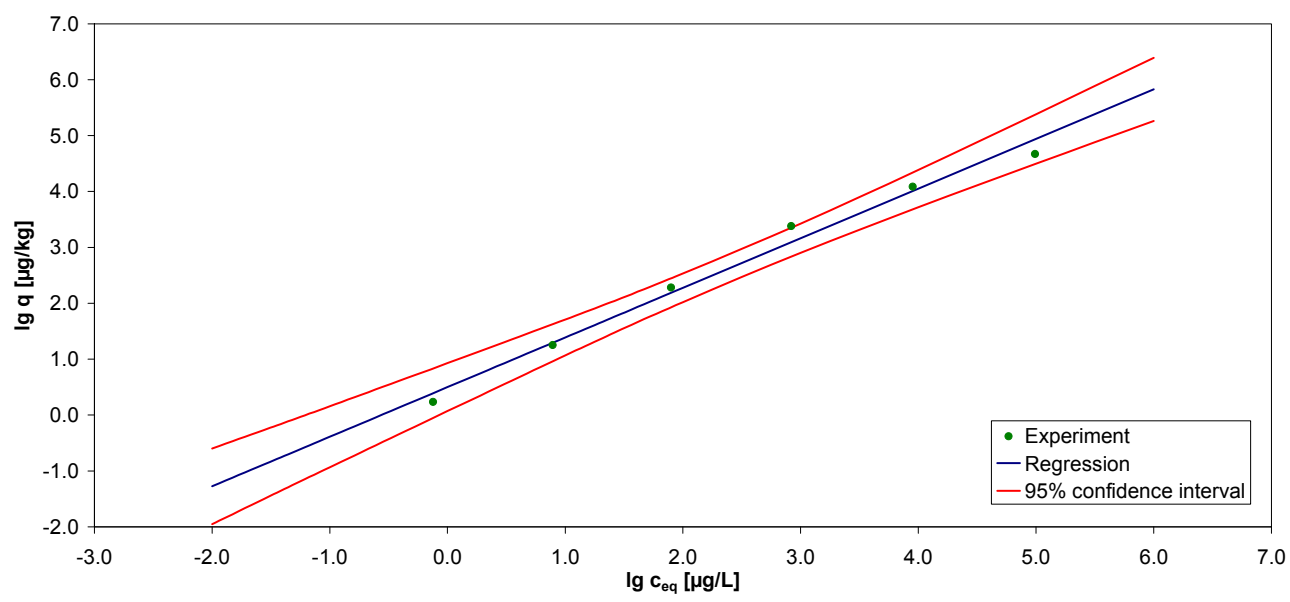

Fig. C8 Isotherm of metoprolol at $37 \mathrm{mmol} \mathrm{L}^{-1} \mathrm{Ca}^{2+}\left(R^{2}=0.9869\right)$. 


\section{Appendix D}

List of all journal articles, conference abstracts, and miscellaneous publications authored or co-authored by me and related to the presented work (latest update: May 2013).

\section{Journals (peer-reviewed)}

Schaffer, M., Maier, F., Licha, T., Sauter, M., 2013. A new generation of tracers for the characterization of interfacial areas during supercritical carbon dioxide injections into deep saline aquifers: Kinetic interface-sensitive tracers (KIS tracer). International Journal of Greenhouse Gas Control 14, 200-208.

Niedbala, A., Schaffer, M., Licha, T., Nödler, K., Börnick, H., Ruppert, H., Worch, E., 2013. Influence of competing inorganic cations on the ion exchange equilibrium of the monovalent organic cation metoprolol on natural sediment. Chemosphere 90 (6), 1945-1951.

Schaffer, M., Börnick, H., Nödler, K., Licha, T., Worch, E., 2012. Role of cation exchange processes on the sorption influenced transport of cationic $\beta$-blockers in aquifer sediments. Water Research 46 (17), 5472-5482.

Schaffer, M., Boxberger, N., Börnick, H., Licha, T., Worch, E., 2012. Sorption influenced transport of ionizable pharmaceuticals onto a natural sandy aquifer sediment at different $\mathrm{pH}$. Chemosphere 87 (5), 513-520.

Schaffer, M., Boxberger, N., Börnick, H., Licha, T., Worch, E., 2010. Säulenversuche zur Simulation des $\mathrm{pH}$-abhängigen Stofftransportes ausgewählter pharmazeutischer Wirkstoffe im Grundwasserleiter. Vom Wasser 108 (4), 111-130. 


\section{Conference contributions}

Tatomir, A., Maier, F., Schaffer, M., Licha, T., Sauter, M., 2013. Modelling of kinetic interface sensitive tracers for two-phase systems. In: Proceedings of the $3^{\text {rd }}$ Sino-German Conference "Underground Storage of $\mathrm{CO}_{2}$ and Energy", Goslar, Germany, pp. 65-74 (ISBN 978-3-642-37848-5).

Börnick, H., Lucks, C., Schaffer, M., Worch, E., Licha, T., 2012. Experimentelle Untersuchung und Modellierung des Stofftransportes von zwei UV-Filtersubstanzen unter Nichtgleichgewichtsbedingungen. In: Tagungsband Gemeinsame Jahrestagung der SETAC GLB und der Fachgruppe Umweltchemie und Ökotoxikologie der GDCh 2012, Leipzig, Germany, p. 156.

Schaffer, M., Niedbala, A., Nödler, K., Licha, T., Börnick, H., Fona, Z., Worch, E., 2012. Untersuchungen zum Kationenaustauschverhalten des basischen $\beta$-Blockers Metoprolol an natürlichen Sorbentien. Schriftenreihe der Deutschen Gesellschaft für Geowissenschaften Heft 78, Tagung der Fachsektion Hydrogeologie in der DGG (FH-DGG), Dresden, Germany, p. 187 (ISSN 1860-1782).

Schaffer, M., Maier, F., Licha, T., Sauter, M., 2012. Entwicklung kinetischer Tracer zur Quantifizierung von Grenzflächen bei Injektionen von überkritischem $\mathrm{CO}_{2}$ in tiefe salinare Aquifere. Schriftenreihe der Deutschen Gesellschaft für Geowissenschaften Heft 78, Tagung der Fachsektion Hydrogeologie in der DGG (FH-DGG), Dresden, Germany, p. 166 (ISSN 1860-1782).

Schaffer, M., Niedbala, A., Nödler, K., Licha, T., Börnick, H., Worch, E., 2012. Sorptionsverhalten organischer Kationen an natürlichem Sediment am Beispiel des Beta-Blockers Metoprolol. In: Tagungsband Jahrestagung der Wasserchemischen Gesellschaft 2012, Neu-Ulm, Germany, pp. 410-414 (ISBN 978-3-936028-71-3).

Schaffer, M., Maier, F., Licha, T., Sauter, M., 2012. Entwicklung kinetischer Grenzflächentracer für Injektionen von überkritischem $\mathrm{CO}_{2}$ in tiefe salinare Grundwasserleiter. In: Tagungsband Jahrestagung der Wasserchemischen Gesellschaft 2012, Neu-Ulm, Germany, pp. 387-391 (ISBN 978-3-936028-71-3).

Ghergut, I., Behrens, H., Licha, T., Maier, F., Nottebohm, M., Schaffer, M., Sauter, M., 2012. Single-well and inter-well dual-tracer test design for quantifying phase volumes and interface areas in subsurface flow and transport systems. Geophysical Research Abstracts 14, EGU2012-13549, EGU General Assembly 2012, Vienna, Austria.

Schaffer, M., Maier, F., Licha, T., Sauter, M., 2012. Development of kinetic interface sensitive tracers (KIS-Tracer) for supercritical carbon dioxide injections into deep saline aquifers. Geophysical Research Abstracts 14, EGU2012-2048. EGU General Assembly 2012, Vienna, Austria.

Ghergut, I., Behrens, H., Licha, T., Maier, F., Nottebohm, M., Schaffer, M., Ptak, T., Sauter, M., 2012. Single-well and inter-well dual-tracer test design for quantifying phase volumes and interface areas. In: Proceedings of the $37^{\text {th }}$ Stanford Geothermal Workshop, Stanford, USA, SGP-TR-194.

Börnick, H., Schaffer, M., Worch, E., Grischek, T., 2011. Characterization of the attenuation behaviour of organic micropollutants in water/sediment systems using column experiments. In: Proceedings GEOINDO 2011, Khon Kaen, Thailand, pp. 344-349 (ISBN 978-616-223-143-8).

Ghergut, I., Bensabat, J., Niemi, A., Licha, T., Nottebohm, M., Schaffer, M., Sauter, M., 2011. Single-well and inter-well tracer test design for CCS pilot site assessment. In: Proceedings of the $6^{\text {th }}$ Trondheim CCS Conference, Trondheim, Norway. 
Schaffer, M., Börnick, H., Licha, T., Nödler, K., Worch, E., Sauter, M., 2011. Säulenversuche zum Stofftransport des basischen Betablockers Atenolol unter gesättigten, kompetitiven Bedingungen. In: Tagungsband Jahrestagung der Wasserchemischen Gesellschaft 2011, Norderney, Germany, pp. 294-298 (ISBN 978-3-936028-66-9).

Schaffer, M., Börnick, H., Licha, T., Nödler, K., Worch, E., 2011. Column experiments to simulate the transport of the basic beta-blocker atenolol in sandy aquifers under competitive conditions. Geophysical Research Abstracts 13, EGU2011-3018, EGU General Assembly 2011, Vienna, Austria.

Ghergut, I., Bensabat, J., Behrens, H., Licha, T., Maier, F., Schaffer, M., Sauter, M., 2011. Single-well and inter-well tracer test design for characterizing the Heletz site (Israel) with a view at CCS. Geophysical Research Abstracts 13, EGU2011-9629, EGU General Assembly 2011, Vienna, Austria.

Schaffer M., Börnick H., Licha, T., Worch E. (2010): Untersuchung zum Stofftransport des basischen Betablockers Atenolol in gesättigten Aquiferen unterschiedlicher Kationenaustauschkapazität. Umweltwissenschaften und Schadstoff-Forschung 22 (4), Gemeinsame Jahrestagung der SETAC GLB und der Fachgruppe Umweltchemie und Ökotoxikologie der GDCh 2010, Dessau-Roßlau, Germany, p. 409.

Schaffer, M., Börnick, H., Boxberger, N., Licha, T., Worch, E., 2010. Investigations of the pH-dependent transport of pharmaceuticals in saturated sandy aquifers using column experiments. In: Book of Abstracts of the $3^{\text {rd }}$ EuCheMS Chemistry Congress, Nuremberg, Germany, Ilb.013. 



\section{Mario Schaffer}

\section{Personal data}

Date of birth

$14^{\text {th }}$ June 1986

Place of birth

Dresden

Nationality

German

\section{EDUCATION}

04/2011-04/2013

\section{Georg-August-Universität Göttingen}

Geoscience Centre

Department Applied Geology

PhD. Student

$10 / 2005-03 / 2010$

\section{Technische Universität Dresden}

Diploma in Hydrology (degree: Dipl.-Hydrol.),

passed with distinction (grade: 1.3) and awarded with the Karl-Franz-Busch-Medal 2010

\section{WORK EXPERIENCE}

Since $10 / 2010$

Georg-August-Universität Göttingen

Geoscience Centre

Department Applied Geology

Research associate

$08 / 2010-09 / 2010$

Georg-August-Universität Göttingen

Geoscience Centre

Department Applied Geology

Scientific assistant

$05 / 2010-07 / 2010$

\section{Technische Universität Dresden}

Institute of Water Chemistry

Scientific assistant 